\title{
The rat perirhinal cortex: A review of anatomy, physiology, plasticity, and function
}

\author{
John Kealy, Sean Commins * \\ Department of Psychology, National University of Ireland Maynooth, Maynooth, Co. Kildare, Ireland
}

\section{A R T I C L E I N F O}

\section{Article history:}

Received 19 April 2010

Received in revised form 28 January 2011

Accepted 10 March 2011

Available online 21 March 2011

\section{Keywords:}

Perirhinal cortex

Hippocampal formation

Anatomy

Physiology

Electrophysiology

Perception

Recognition memory

Spatial memory

Fear conditioning

\begin{abstract}
A B S T R A C T
The perirhinal cortex is located in a pivotal position to influence the flow of information into and out of the hippocampal formation. In this review, we examine the anatomical, physiological and functional properties of the rat perirhinal cortex. Firstly, we review the properties of the perirhinal cortex itself, we describe how it can be separated into two distinct subregions and consider how it differs from other neighbouring regions in terms of cell type, cellular organisation and its afferent and efferent projections. We review the forms of neurotransmission present in the perirhinal cortex and the morphological, electrophysiological and plastic properties of its neurons. Secondly, we review the perirhinal cortex in the context of its connections with other brain areas; focussing on the projections to cortical, subcortical and hippocampal/parahippocampal regions. Particular attention is paid the anatomical and electrophysiological properties of these projections. Thirdly, we review the main functions of the perirhinal cortex; its roles in perception, recognition memory, spatial and contextual memory and fear conditioning are explored. Finally, we discuss the idea of anatomical, electrophysiological and functional segregation within the perirhinal cortex itself and as part of a hippocampal-parahippocampal network and suggest that understanding this segregation is of critical importance in understanding the role and contributions made by the perirhinal cortex in general.
\end{abstract}

() 2011 Elsevier Ltd. All rights reserved.

\section{Contents}

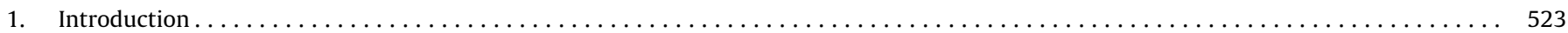

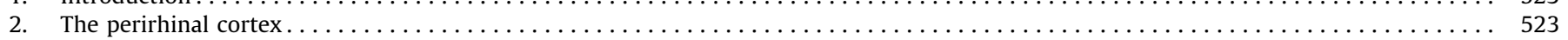

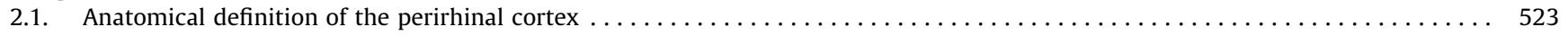

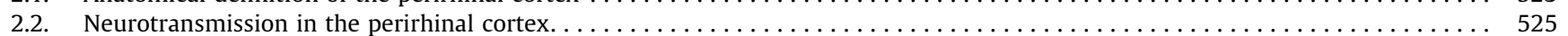

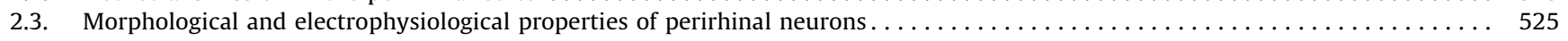

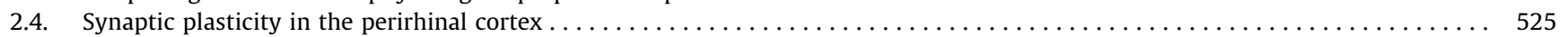

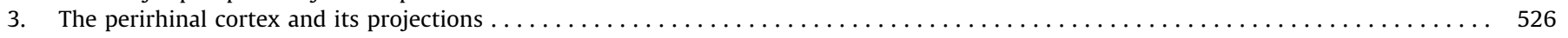

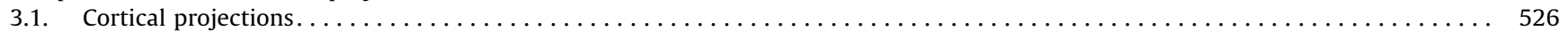

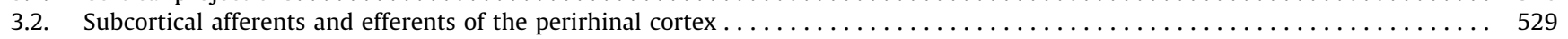

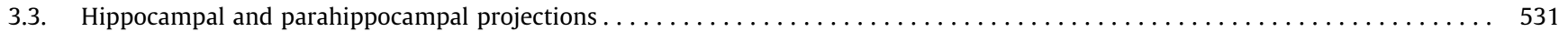

3.4. Anatomical and electrophysiological evidence for segregation within the hippocampal-parahippocampal network:

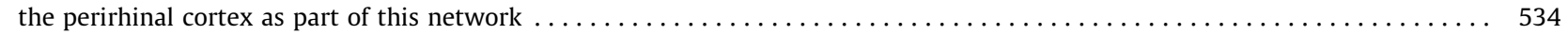

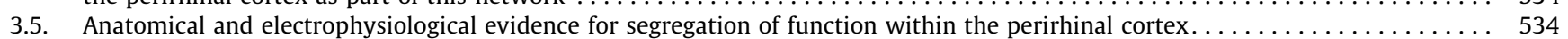

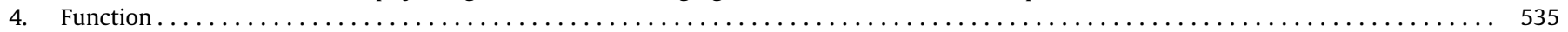

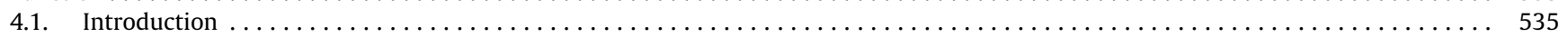

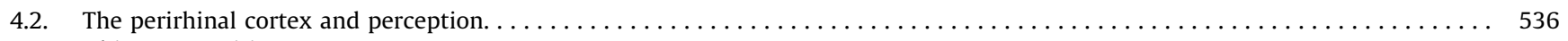

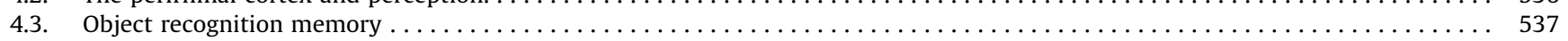

\begin{abstract}
Abbreviations: AMPA, $\alpha$-amino-3-hydroxyl-5-methyl-4-isoxazole-propionate; BDNF, brain-derived neurotrophic factor; CA, Cornu Ammonis fields of hippocampus; CREB, cAMP response element-binding; D, dopamine receptor; fEPSP, field excitatory postsynaptic potential; GABA, $\gamma$-aminobutyric acid; HFS, high frequency stimulation; 5-HT, serotonin receptor; LFS, low frequency stimulation; LTD, long-term depression; LTP, long-term potentiation; mGlu, metabotrophic glutamate receptor; MWM, Morris water maze; NGF, nerve growth factor; NMDA, N-methyl-D-aspartic acid; NR2, subunit of the NMDA receptor; NT, neurotrophin; PPD, paired-pulse depression; PPF, paired-pulse facilitation; Trk, tropomyosin-receptor-kinase.
\end{abstract}

* Corresponding author. Tel.: +3531708 6182; fax: +35317084767.

E-mail address: Sean.Commins@nuim.ie (S. Commins). 
4.4. The role of the perirhinal cortex in fear conditioning. $\ldots \ldots \ldots \ldots$

4.5. The role of the perirhinal cortex in context and spatial memory. $\ldots \ldots \ldots \ldots$

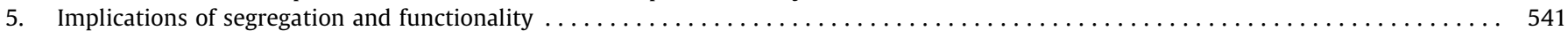

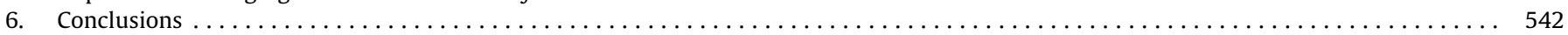

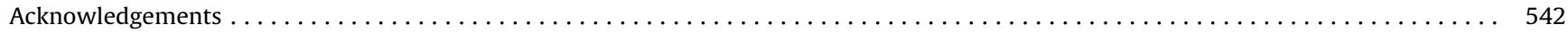

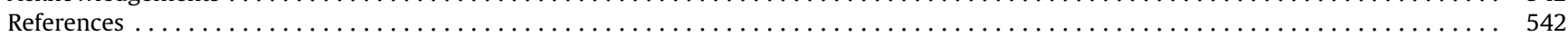

\section{Introduction}

The perirhinal cortex is considered along with the entorhinal and postrhinal cortices as an integral part of the parahippocampal formation. It contributes both direct and indirect (via the entorhinal cortex) projections to the hippocampus as well as being one of its main output structures. The perirhinal cortex is therefore pivotal in the processing of information into and out of the hippocampal region. Although, there have been a number of reviews that have specifically examined the anatomy (e.g. Burwell, 2001; van Strien et al., 2010) and functional roles of the perirhinal cortex (Dere et al., 2007; Winters et al., 2008; Warburton and Brown, 2010), to date, there has been no review that brings anatomy, physiology, synaptic plasticity and function of the perirhinal cortex together. Here we attempt to bring these different strands together and also examine how the perirhinal cortex fits within the general hippocampal-parahippocampal circuitry with particular emphasis on the electrophysiological properties of these connections.

\section{The perirhinal cortex}

\subsection{Anatomical definition of the perirhinal cortex}

In the rat brain, the perirhinal cortex is located along the rhinal sulcus and it is composed of Brodmann's areas 35 and 36 (Brodmann, 1909), although later studies defined the perirhinal cortex as area 35 only (Krieg, 1946a). Area 36 occupies the dorsal bank of the rhinal sulcus and area 35 occupies the ventral bank, extending slightly more rostrally than area 36 (Burwell, 2001). It is bordered rostrally by the posterior agranular insular cortex (bordering with areas 35 and 36) and the visceral area (area 36 only), caudally by the postrhinal cortex, dorsally by the ventral temporal association cortex and ventrally by the lateral entorhinal cortex (Fig. 1a; Burwell et al., 1995; Burwell, 2001; Paxinos and Watson, 2005).

The borders between the perirhinal cortex and its neighbouring areas can be determined by cytoarchitectonic means, in particular the characteristic lack of a distinct layer IV in the perirhinal cortex (Burwell, 2001; Witter, 2002). Area 35 completely lacks layer IV while area 36 does have layer IV but it appears to be less well defined particularly in the medial portions of the cortex compared to other neocortical areas (Burwell et al., 1995). Brodmann's areas 35 and 36 are also cytoarchitectonically different in that layer I of area 35 tends to be thicker than that of area 36, the cells in area 35 are organised radially, the presence of large, heart-shaped pyramidal cells in layer V of area 35 and finally layers II and III are distinctly separated in area 36 and not in area 35 (Krieg, 1946b; Burwell and Amaral, 1998a,b; Burwell, 2001). Burwell (2001) further subdivides areas 35 and 36 into two subregions (ventral and dorsal) and three subregions (dorsal, ventral and posterior) respectively (Fig. 1b). In the ventral subregion of area 35 , there is a more pronounced radial organisation of neurons compared to the dorsal subregion and layers II and III have a more organised appearance. In addition, in the deeper parts of layer II/III of the dorsal subregion there is a lower cell density compared to the ventral subregion. Within area 36 , the dorsal and ventral subregions make up the rostral region (with the ventral subregion sometimes protruding more rostrally than the dorsal subregion) and the posterior subregion is located caudally, bordering the postrhinal cortex. These three subregions are distinct from each other in that cells in layers II-V of the dorsal subregion are organised radially whereas cells in the same layers of the ventral subregion show no particular orientation and layers V and VI are narrower in the dorsal subregion (Burwell and Amaral, 1998b; Burwell, 2001). The posterior subregion differs from the rostral subregions of area 36 due to the presence of round, medium-sized cells throughout layers V and VI and the absence of a bilaminated layer VI (Burwell, 2001). The borders of the perirhinal cortex with the surrounding areas of neocortex can be determined in a similar way to the divisions within the perirhinal cortex. The border with posterior agranular insular cortex is located approximately 2.45$2.80 \mathrm{~mm}$ posterior to the Bregma line and the two areas of cortex differ in that the posterior agranular insular cortex has a trilaminar appearance and the presence of claustral cells but both these features are absent in the perirhinal cortex (Burwell, 2001). The visceral area has a granular layer IV making it distinct from the posterior agranular insular cortex but like the agranular insular cortex, the layers V and VI are distinct from each other. This is in contrast to the perirhinal cortex where the two layers are homogenous and is referred to as layer V (Burwell, 2001).

The border with the ventral temporal association cortex is determinable by observing cell types in layer II; this layer of area 36 of the perirhinal cortex is composed of round, medium-sized cells peppered with smaller pyramidal cells whereas a greater number of cells in the ventral temporal association cortex are pyramidal in shape (Burwell, 2001). In addition, the ventral temporal association cortex sometimes features layers either side of layer $\mathrm{V}$ where cell density is lower but this feature is absent in the perirhinal cortex (Burwell, 2001). Layer VI in area 36 of the perirhinal cortex has a thick bilaminated appearance in contrast to both the ventral temporal association cortex and area 35 of the perirhinal cortex (Burwell, 2001). Finally, based on cortical input to either area, the perirhinal cortex receives markedly greater levels of input from various cortical areas compared to the ventral temporal association area, i.e. the ventral temporal association area receives no input from the piriform but receives more somatosensory and auditory input and lower levels of input from the insular and entorhinal cortices (Burwell and Amaral, 1998b).

The border with the entorhinal cortex is distinct in that the lamina dissecans layer (found in the entorhinal cortex) is absent in the perirhinal cortex (Burwell, 2001; Witter, 2002). The areas can also be defined based on the connections made with subcortical areas, the entorhinal cortex projects to the dentate gyrus (Wyss, 1981) whereas the perirhinal cortex does not (Insausti et al., 1997; Dolorfo and Amaral, 1998; Witter et al., 1999). In addition, the perirhinal cortex receives a much larger input from area CA1 of the hippocampus compared to the entorhinal cortex (Van Groen and Wyss, 1990). On a cellular level, the presence of large, "stellate" cells in layer I of the entorhinal cortex and differences in staining were found between the two areas for parvalbumin, calbindin and zinc (Timm's staining; Insausti et al., 1997; Burwell, 2001; Witter, 2002; Canto et al., 2008). Finally, a more subtle difference can be seen in layer IV of the perirhinal cortex which appears to be better defined in the entorhinal cortex (Witter et al., 2000). 
a

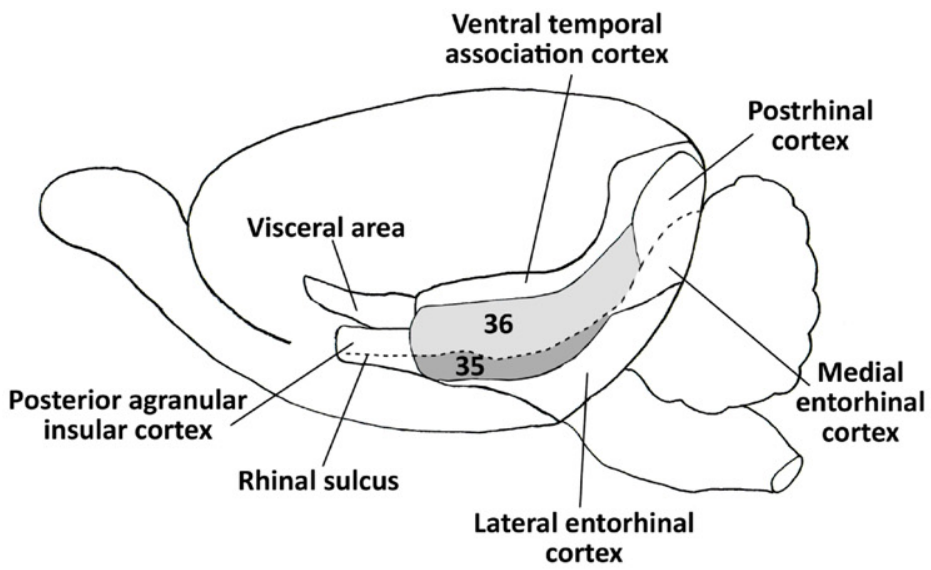

b

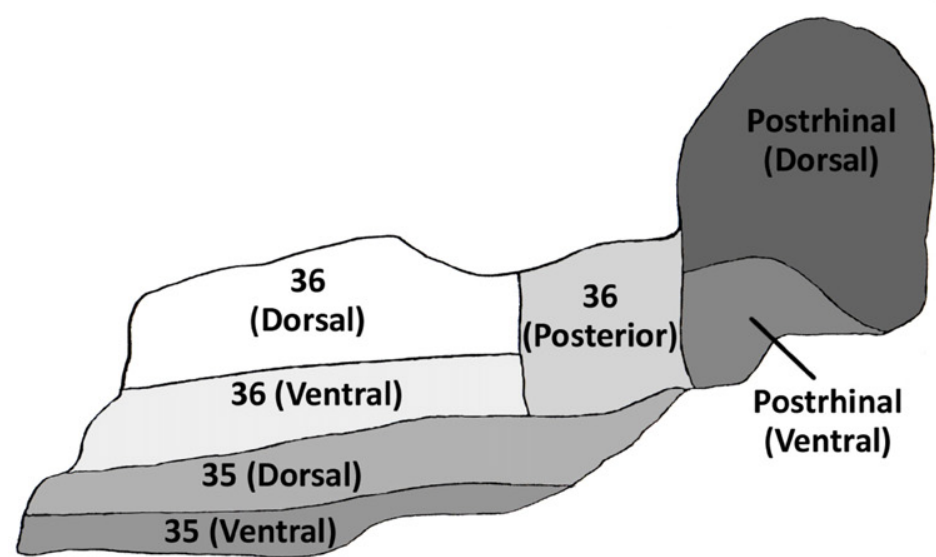

C

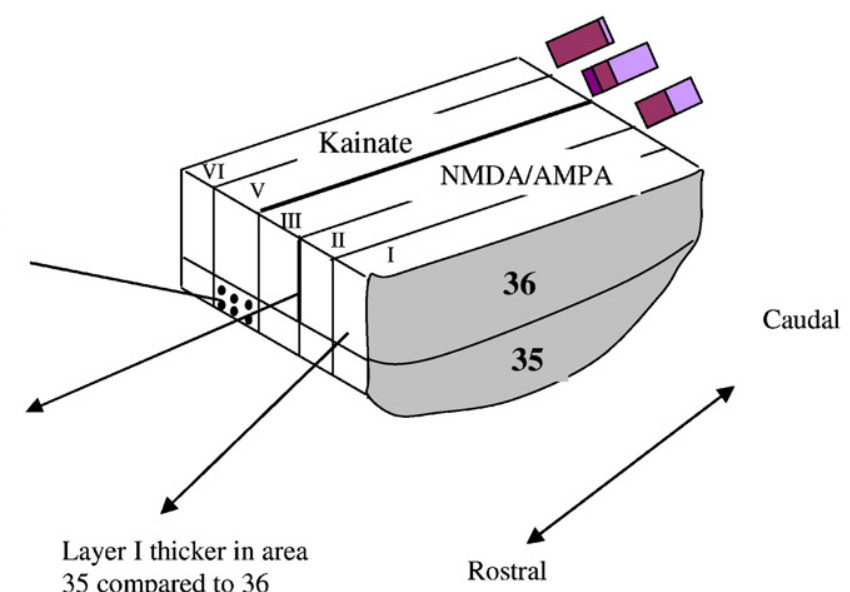

Presence of heart-shaped pyramidal cells

Layers II/III more separated in area 36 compared to 35

35 compared to 36

Regular spiking cells

Late spiking cells

Bursting cells

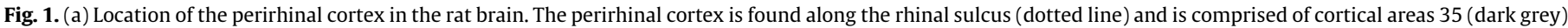

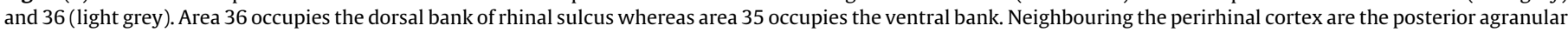

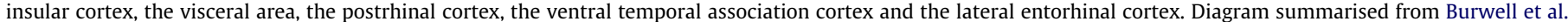

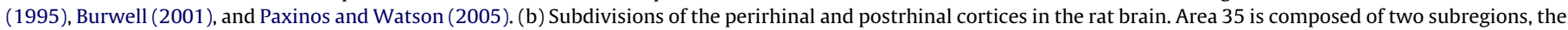

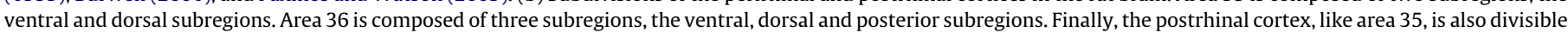

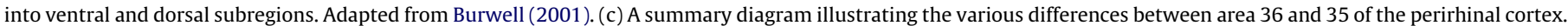

Although similar in terms of cell organisation and amounts of myelin present, the postrhinal and perirhinal cortices can be distinguished by the presence of ectopic layer II cells in the postrhinal cortex and the presence of smaller cells in postrhinal layer II compared to the perirhinal cortex (Burwell, 2001). It has a bilaminate appearance with layers II/III and V/VI forming homogenous bands (Burwell and Amaral, 1998a,b). The two areas can also be distinguished based on their connections with the entorhinal cortex, the perirhinal cortex projects mainly to the lateral entorhinal cortex and the postrhinal cortex projects mainly to the medial entorhinal cortex (Naber et al., 1997). Despite these differences, there is a debate in the literature as to whether to count the postrhinal cortex as a separate area to the perirhinal cortex (Deacon et al., 1983; Burwell et al., 1995) or whether to 
extend the definition of the perirhinal cortex to include the postrhinal cortex (Palomero-Gallagher and Zilles, 2004; Paxinos and Watson, 2005). There are a number of anatomical differences (Burwell et al., 1995; Burwell and Amaral, 1998a,b; Pitkänen et al., 2000; Burwell, 2000, 2001) and functional differences (Norman and Eacott, 2005) existing between the two areas and it has been suggested that the rat postrhinal cortex is homologous to the monkey parahippocampal cortex (Burwell et al., 1995; Burwell, 2000). Therefore, we follow Burwell's classification (2000) and distinguish between the perirhinal and postrhinal cortices as two distinct anatomical regions in the rat brain.

\subsection{Neurotransmission in the perirhinal cortex}

As part of the neocortex, the perirhinal cortex can sustain glutamatergic transmission as expected; it has shown to express metabotropic glutamate receptors (Ohishi et al., 1995; McCaffery et al., 1999), NMDA glutamate receptors (Monaghan and Buller, 1994), AMPA glutamate receptors (Palomero-Gallagher and Zilles, 2004) and kainate glutamate receptors (Nagahara et al., 1993). Ionotropic glutamate receptors (which are the main receptors involved in synaptic plasticity) appear in lower densities in the perirhinal cortex compared to surrounding cortical areas and perirhinal ionotropic glutamate receptors show a layer-specific distribution; NMDA and AMPA glutamate receptors are found in greater densities in layers I-III whereas kainate receptors around found in greater densities in the layers V-VI in the perirhinal cortex (see Fig. 1c, Palomero-Gallagher and Zilles, 2004). Cholinergic transmission can be sustained through muscarinic acetylcholine (Massey et al., 2001) and nicotinic acetylcholine receptors (Palomero-Gallagher and Zilles, 2004). However, although a number of studies have shown the physiological and behavioural importance of perirhinal cholinergic transmission (Massey et al., 2001; Abe and Iwasaki, 2001; Bang and Brown, 2009a) there is little anatomical and histological information on the distribution and density of perirhinal cholinergic receptors available.

The perirhinal cortex can also sustain dopaminergic transmission (Pum et al., 2007); it expresses D1 and D2 dopamine receptors across all layers (Richfield et al., 1989; Goldsmith and Joyce, 1994), D4 receptors (Rivera et al., 2008) and dopamine transporters (Belcher et al., 2005). Based on several tracing studies, there are low levels of GABAergic input to the perirhinal cortex (Christie et al., 1987; Kosaka et al., 1987; Beart et al., 1990; Vaucher et al., 2000) but GABAergic inputs from the temporal and entorhinal cortices have been identified (Garden et al., 2002). Additionally, $\mathrm{GABA}_{\mathrm{B}}$ receptors have been shown to play a role in local perirhinal circuits (Ziakopoulos et al., 2000). Adrenergic transmission can be sustained through $\alpha_{2}$-adrenergic receptors (King et al., 1995) and noradrenaline transporters (Hébert et al., 2001). Finally, the perirhinal cortex receives serotoninergic input (Pum et al., 2007) with a projection from the raphe nucleus terminating in superficial layers of the perirhinal cortex (Hermann et al., 1997; Vertes et al., 1999; Harding et al., 2004). The perirhinal cortex expresses 5-HT $1 \mathrm{~A}$ receptors (Nyakas et al., 1997), 5- $\mathrm{HT}_{2}$ receptors (Altar et al., 1985; Osterlund et al., 1999) and 5-HT transporters (Hébert et al., 2001; Belcher et al., 2005). In addition to the classic neurotransmitters, the perirhinal cortex is also capable of signalling via the neurotrophins and their receptors (Sobreviela et al., 1996). Although there are low levels of nerve growth factor (NGF) and TrkA present in the neocortex (Altar et al., 1991; Merlio et al., 1992), the other neurotrophins and their receptors are more widely expressed throughout the neocortex (Klein et al., 1990; Merlio et al., 1992; Altar et al., 1994). However, the parahippocampal region shows higher levels of neurotrophins compared to rest of the neocortex: NGF (Lin et al., 1996; Conti et al., 2009), brain-derived neurotrophic factor (BDNF, Sato et al., 1996; Vezzani et al., 1999; Engler-Chiurazzi et al., in press), NT-3 (Eagleson et al., 2001) and all three Trk receptors (Bengzon et al., 1993) have been shown to be strongly expressed in the perirhinal cortex. It must be noted that so far, no study has looked at NT-4/5 expression in the perirhinal cortex. Evidence for a physiological role for BDNF in the perirhinal cortex comes from infusion studies where recombinant human BDNF (rhBDNF) is applied to the occipital and entorhinal cortices and subsequently transported retrogradely to the perirhinal cortex (Sobreviela et al., 1996).

\subsection{Morphological and electrophysiological properties of perirhinal neurons}

Morphological analysis of the perirhinal cortex in the adult rat reveals that pyramidal neurons are the most common type of perirhinal neuron and they are morphologically divisible into five subtypes: horizontal, upright, inverted, bifurcating and oblique (with upright pyramidal neurons being the most numerous; Furtak et al., 2007a). Although the most common neuron type, Furtak et al. (2007a) note that the numbers of pyramidal neurons in the perirhinal cortex are comparatively lower than other neocortical areas. Electrophysiological examination of perirhinal cortex has revealed a number of different neuron types based on spiking patterns; a range of neurons falling into the categories of fast spiking, regular spiking, burst spiking and late spiking have been described by Faulkner and Brown (1999). These neurons were all found in layers II/III, V and VI of the perirhinal cortex (Faulkner and Brown, 1999). The various cell layers in the perirhinal cortex show differential distribution of these neurons compared to each other (Fig. 1c); in layers II/III late spiking neurons account for $54 \%$ of the total of pyramidal neurons followed by regular spiking pyramidal neurons (46\%; Beggs et al., 2000). Whereas in layer $\mathrm{V}$ regular spiking pyramidal neurons are the most common of the three types (76\% of total) followed by late spiking (14\%) and burst spiking pyramidal neurons (9\%; Moyer et al., 2002). Lastly, layer VI has been shown to be unique amongst cortical regions in having late spiking neurons account for $86 \%$ with of the total number of pyramidal neurons followed by single spiking (7\%), fast spiking (5\%) and regular spiking pyramidal neurons ( $<1 \%$; McGann et al., 2001). The fast-inactivating voltage-dependent $\mathrm{K}^{+}$current has been identified as a regulator of spiking behaviour in layer II/III pyramidal neurons (Biella et al., 2007). Additionally, the resurgent $\mathrm{Na}^{+}$current in layer II pyramidal neurons has also been identified as a regulator of perirhinal neuronal activity (Castelli et al., 2007). As yet no functional implications for either type of current have been identified in the rat.

The baseline field excitatory postsynaptic potential (fEPSP) in the perirhinal cortex is dependent on the voltage-gated $\mathrm{Ca}^{2+}$ and $\mathrm{Na}^{+}$ion channels (D'Antuono et al., 2001) and AMPA glutamate receptors (Cho et al., 2000) but is less reliant on NMDA or mGlu receptors (Ziakopoulos et al., 1999) or extracellular Ca ${ }^{2+}$ (McCaffery et al., 1999). A long-lasting, positive $G_{A B A}$ component has also been described (Ziakopoulos et al., 2000).

\subsection{Synaptic plasticity in the perirhinal cortex}

The perirhinal cortex can sustain various forms of long-term changes in synaptic plasticity. For example, $100 \mathrm{~Hz}$ high frequency stimulation (HFS) in layers II/III neurons of the perirhinal cortex in vitro produces NMDA receptor-dependent long-term potentiation (LTP) in the same layers (Bilkey, 1996) and, tetanic and theta-burst stimulation at $100 \mathrm{~Hz}$ in layers II/III can also induce NMDA receptor-dependent LTP in layer I neurons (Ziakopoulos et al., 1999). LTP in the perirhinal cortex is associated with an increase in BDNF secretion in the first 5-12 post-stimulation and this LTP can be blocked by inhibiting the BDNF receptor TrkB (Aicardi et al., 
2004). Perirhinal LTP can be blocked by inhibiting CREB as shown by adenoviral transduction of a CREB-inhibitor onto perirhinal slices (Warburton et al., 2005) but it appears to be independent of L-type voltage-dependent $\mathrm{Ca}^{2+}$ channel activation (Seoane et al., 2009). The induction of LTP in the perirhinal cortex has also been demonstrated to be $\mathrm{GABA}_{\mathrm{A}}$-dependent as enhancement of $\mathrm{GABA}_{A}$ receptor function by lorazepam disrupts the induction of LTP in neurons within layers II/III (Wan et al., 2004).

The bulk of research on synaptic plasticity within the perirhinal cortex has focussed on long-term depression (LTD) due to its possible role in recognition memory (see below and Jerusalinsky et al., 1997; Warburton et al., 2003; Wan et al., 2004; Barker et al., 2006a; Griffiths et al., 2008; Seoane et al., 2009). Ziakopoulos et al. (1999) demonstrated that the perirhinal cortex could also undergo depressive synaptic plasticity; short-term depression in the form of paired-pulse depression (PPD) could be induced with a $200 \mathrm{~ms}$ IPI and this PPD was GABA ${ }_{B}$-dependent (Ziakopoulos et al., 2000). Perirhinal LTD was also demonstrated; $1 \mathrm{~Hz}$ and $5 \mathrm{~Hz}$ LFS can induce perirhinal LTD lasting approximately $40 \mathrm{~min}$ and $180 \mathrm{~min}$ respectively and this LTD is associated with transient decreases in BDNF secretion following LFS (Aicardi et al., 2004). Induction of perirhinal LTD has been found to be reliant on L-type voltagedependent $\mathrm{Ca}^{2+}$ channels (Seoane et al., 2009). Like LTP, LTD in the perirhinal cortex seems to be largely glutamatergic in nature with the ionotropic glutamate receptors being of particular importance (Ziakopoulos et al., 1999).

However, even though Ziakopoulos et al. (1999) concluded that both LTP and LTD in the perirhinal cortex were mGlu receptorindependent, it has been shown that a range of mGlu receptor agonists (specific for group I, II and III mGlu receptors) can induce perirhinal LTD in the absence of LFS (McCaffery et al., 1999). These conflicting results were reconciled with the finding that NMDA and mGlu receptors may be both required for LTD induction and that the contribution of NMDA and mGlu receptors to LTD require different electrophysiological conditions induced; group II mGlu receptor-dependent LTD can only be induced at resting membrane potentials whereas NMDA receptor-dependent LTD can be induced even when depolarisation has occurred (Cho et al., 2000; Cho and Bashir, 2002). Furthermore, $\mathrm{Ca}^{2+}$ signalling in mGlu receptordependent LTD relies on neuronal $\mathrm{Ca}^{2+}$ sensor protein interacting with protein $C$ kinase whereas NMDA receptor-dependent LTD relies on calmodulin (Jo et al., 2008). It also appears that interaction between group I and group II mGlu receptors is required for LTD to be induced at resting membrane potentials and this synergy requires protein kinase $\mathrm{A}$ and protein phosphatase $2 \mathrm{~B}$ (Cho et al., 2002). This interaction between group I and group II mGlu receptors is explained by the cAMP-dependent enhancement of mGluR5 (group I mGlu receptor) by mGluR2 (group II mGlu receptor); this enhancement of mGluR5 in turn contributes to the induction of perirhinal LTD (Harris et al., 2004a). NMDA receptordependent LTD involves the internalisation of AMPA receptors (Griffiths et al., 2008) but mGlu receptor-dependent LTD appears to modulate AMPA receptors via a different molecular mechanism to that found with NMDA receptors (Harris et al., 2004b). Kainate receptor-dependent LTD has been described which appears to be independent of NMDA receptor activation and also appears to be regulated by mGluR5 (Park et al., 2006). These findings indicate that glutamatergic LTD in the perirhinal cortex is highly organised and regulated across multiple glutamate receptor systems, perhaps reflecting the complexity of the perirhinal cortex's functional role in the behaving animal.

In addition to LTD that relies on glutamatergic neurotransmission, there appears to be other forms of LTD in the perirhinal cortex. Muscarinic M1 cholinergic receptor-dependent LTD can be induced without electrical stimulation or NMDA receptor activation by the application of carbachol (Massey et al., 2001).
Additionally, Massey et al. (2001) found that perirhinal blockade of intracellular $\mathrm{Ca}^{2+}$ release and protein synthesis could impair this carbachol-induced LTD. Moreover, perirhinal muscarinic receptor antagonism by scopolamine can block LTD while sparing LTP (Warburton et al., 2003). It is worth noting that in the developing rat brain, there is a visual experience-dependent switch from mGlu receptor-dependent to muscarinic receptor-dependent LTD (Jo et al., 2006) which indicates not only that LTD might play a functional role in the perirhinal cortex but also that the forms of LTD expressed in the area are not set in stone and could be further modified with behavioural experience. Yet other forms of LTD have been identified in the literature such as $\mathrm{GABA}_{\mathrm{A}}$ and D2 dopamine receptor-dependent $L T D$; enhancement of $G A B A_{A}$ receptor function using lorazepam disrupts induction of LTD in the perirhinal cortex (Wan et al., 2004) and the D2 dopamine receptor has been implicated in synaptic plasticity abnormalities found in the perirhinal cortex in a mouse model of Huntington's disease (Cummings et al., 2006, 2007). Again, this complex array of processes underlying different forms of LTD may be functionally significant in terms of the perirhinal cortex's role in cognitive processes.

The relationship between LTP and LTD in the perirhinal cortex appears to follow the predictions outlined in the Bienenstock, Cooper and Munro (BCM) model of synaptic plasticity (Bienenstock et al., 1982) as the $\theta_{\mathrm{m}}$ threshold appears to be dependent on intracellular $\mathrm{Ca}^{2+}$ concentrations (Cho et al., 2001). Cho et al. (2001) have also shown that the magnitude of perirhinal synaptic plasticity is also $\mathrm{Ca}^{2+}$-dependent but they also propose that even though synaptic plasticity in the perirhinal cortex obeys the predictions of the BCM model, this LTP and LTD may be two separate co-existing processes instead of one biphasic process. Learning has also been shown to affect the perirhinal cortex's tendency to exhibit LTP or LTD; perirhinal cortex slices taken from rats that had previously been exposed to multiple trials in a visual recognition learning task showed impaired LTD induction but no changes in LTP were observed (Massey et al., 2008). Massey et al. (2008) also demonstrated that scopolamine administration to the perirhinal cortex during learning prevented the learning-induced LTD impairment, indicating that muscarinic receptors are needed for learning to modify synaptic plasticity in the perirhinal cortex. These findings reviewed in this section suggest that although synaptic plasticity in the perirhinal cortex may appear to follow the predictions set out in the BCM model, due to the varying types of LTP and LTD and the complex variations in LTD observed in several experiments, it may be that perirhinal LTP and LTD are separate but related processes which would allow for finer control of physiological functions compared to a biphasic LTP/LTD process.

\section{The perirhinal cortex and its projections}

\subsection{Cortical projections}

Aside from the components of the hippocampal-parahippocampal network (see Section 3.3), there exists a number of projections to the perirhinal cortex from other cortical areas; namely the precentral, cingulate, parietal, frontal, piriform, insular, prelimbic, infralimbic, periamygdaloid, visual association and auditory cortices (Fig. 2a; Saper, 1982; Deacon et al., 1983; Wyss and Van Groen, 1992; Burwell and Amaral, 1998b; Haberly, 2001; Naber et al., 2001a,b; Majak and Pitkänen, 2003; Jones and Witter, 2007). Out of these cortical areas, a number project to both areas 35 and 36 of the perirhinal cortex including the cingulate, parietal, piriform, insular and auditory cortices (Saper, 1982; Deacon et al., 1983; Wyss and Van Groen, 1992; Burwell and Amaral, 1998a,b; Haberly, 2001; Naber et al., 2001a,b). In contrast, the precentral, prelimbic and periamygdaloid cortices project to area 35 only 
a

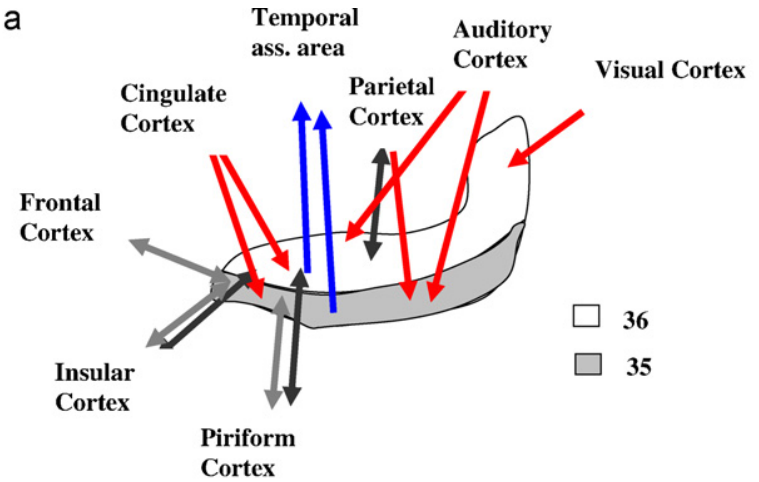

b

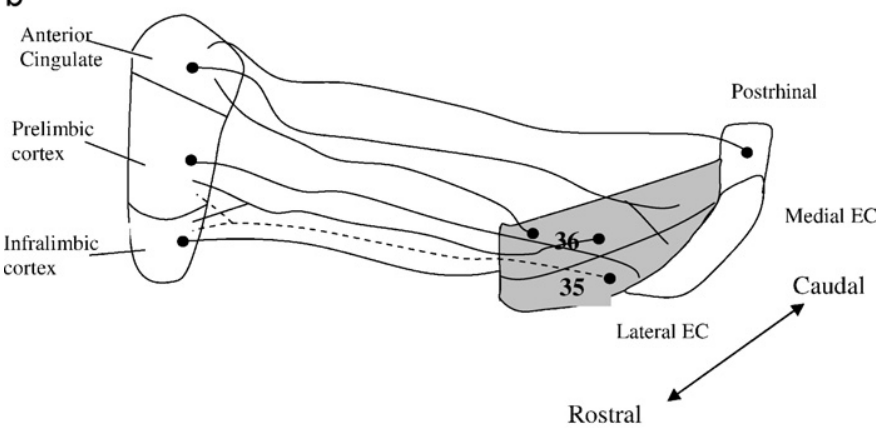

C

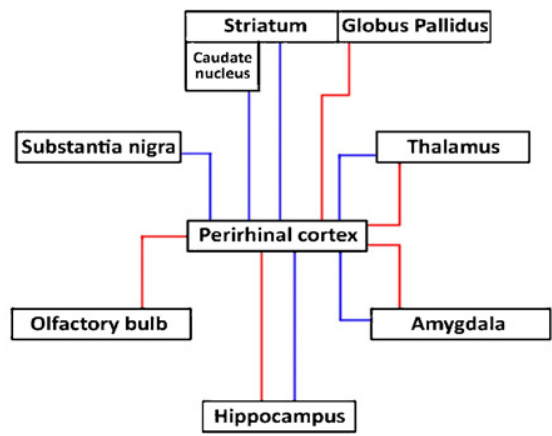

Fig. 2. (a) The main cortical afferent (red) and efferent (blue) projections of the perirhinal cortex (areas 35 and 36). (b) A detailed diagram of the connectivity between the prefrontal and perirhinal cortex. (c) Schematic diagram showing main subcortical afferent (red) and efferent (blue) projections of the perirhinal cortex (areas 35 and 36).

(Deacon et al., 1983; Majak and Pitkänen, 2003) and the visual association cortex projects to area 36 only (Burwell and Amaral, 1998 b). Many of the projections also show topographic organisation which vary depending on the pathway, some show rostralcaudal or ventral-dorsal topographical gradients whereas others project to a particular region of the perirhinal cortex alone (see below for a more detailed description of these topographies).

Projections originating in the perirhinal cortex and terminating in other cortical areas include the anterior cingulate, prelimbic, infralimbic, frontal, piriform, visual and parietal cortices (Saper, 1982; Naber et al., 1997; Burwell and Amaral, 1998a,b; Haberly, 2001; Hoover and Vertes, 2007; Agster and Burwell, 2009). Unlike the afferent projections of the perirhinal cortex, its efferents all involve both areas 35 and 36, albeit with some weighting towards one or the other in some cases (Burwell and Amaral, 1998a; McIntyre et al., 1996; Delatour and Witter, 2002; Agster and Burwell, 2009).

The perirhinal cortex shares important reciprocal connections with the medial prefrontal cortex (Fig. 2b, Deacon et al., 1983;
Sesack et al., 1989). The medial prefrontal cortex is usually subdivided into four regions: the medial precentral, anterior cingulate, prelimbic and infralimbic cortices and together these areas are involved in working memory, attention, control of emotional and planning (Heidbreder and Groenewegen, 2003). All four of these subregions of the medial prefrontal cortex project to the perirhinal cortex (Heidbreder and Groenewegen, 2003) though it is mainly the more rostral structures (prelimbic and infralimbic cortices as well as the rostral regions of the anterior cingulate cortex) that project to the perirhinal cortex (Jones and Witter, 2007). Jones and Witter (2007) also suggest that there is a topographic distinction between the different medial prefrontal regions; the anterior cingulate, prelimbic and infralimbic all project to the perirhinal and lateral entorhinal cortices whereas the other areas project mainly to the postrhinal and medial entorhinal cortices (see Section 4 for the implications of such topographic delineation).

The medial precentral cortex projects to the caudal perirhinal cortex but terminates only in the deep layers of area 35 (Deacon et al., 1983). The cingulate cortex projection originates in the dorsal anterior region in layers II/III and V and projects to the caudal regions of both areas 35 and 36 (Deacon et al., 1983; Burwell and Amaral, 1998b) predominantly in the deep layers of the perirhinal cortex (Jones and Witter, 2007). Similarly, the prelimbic cortex projects caudally but terminates only in area 35 (Deacon et al., 1983) mainly in the deep layers of area 35 but with a small amount of projections terminating in superficial layers (Sesack et al., 1989; Jones and Witter, 2007). Jones and Witter (2007) also report that projections originating in the deep layers of the prelimbic cortex are more numerous than those originating in superficial layers, though both terminate in the deep layers of area 35 . The infralimbic cortex projects to the perirhinal cortex (Hurley et al., 1991; Takagishi and Chiba, 1991) with most of the projections terminating in the superficial layers with a small amount terminating in deep layers (Jones and Witter, 2007).

There are a number of return projections from the perirhinal cortex to the medial prefrontal cortex (Hoover and Vertes, 2007). Specifically, the perirhinal cortex projects to the anterior cingulate, prelimbic and infralimbic cortices (McIntyre et al., 1996; Agster and Burwell, 2009). The projection from the perirhinal cortex to the anterior cingulate cortex originates in layers III/V, V/VI and VI of areas 35 and 36 (McIntyre et al., 1996) and terminates weakly in superficial layers (Agster and Burwell, 2009). The strongest projection from the perirhinal cortex originates in the rostral region of area 36 and terminates in the rostral region of the dorsal anterior cingulate cortex (Agster and Burwell, 2009). The projections from the perirhinal cortex to the prelimbic cortex also originate in both areas 35 and 36 and terminate across all layers but with an emphasis on layers I-III (Delatour and Witter, 2002; Agster and Burwell, 2009). Finally, the projection from the perirhinal cortex to the infralimbic cortex originates in layers III/V and V/VI of areas 35 and 36 (McIntyre et al., 1996) and terminates across all layers, again with an emphasis on layers I-III (Delatour and Witter, 2002; Agster and Burwell, 2009). In both the prelimbic and infralimbic cortices, Agster and Burwell (2009) report heavier labelling following injection of the tracer in area 36 than in area 35, however only the projections from area 36 showed any topographical pattern. In this case a rostral-caudal topography was reported with more rostral areas of area 36 targeting the prelimbic cortex whereas the more caudal areas target the infralimbic cortex (Agster and Burwell, 2009).

Interestingly, the postrhinal cortex does not project to either the prelimbic or the infralimbic cortices but does project to the anterior cingulate cortex (Delatour and Witter, 2002; Agster and Burwell, 2009). Agster and Burwell (2009) also report that the lateral entorhinal cortex projects moderately to both the prelimbic 
and infralimbic cortices while the medial entorhinal cortex forms a weaker set of projections to the prelimbic and infralimbic cortices. Similarly, while both the lateral and medial entorhinal cortices project weakly to the anterior cingulate cortex; it is the lateral entorhinal cortex that projects the strongest to the anterior cingulate cortex (Agster and Burwell, 2009). Delatour and Witter (2002) do not differentiate between the lateral and medial entorhinal cortices but they do report a rostral-caudal topography in the termini of the projections. The presence of reciprocal projections between the parahippocampal region and the medial prefrontal cortex points to a functional relationship between these areas and a number of behavioural studies point towards a role for the medial prefrontal cortex in memory formation (Aggleton and Brown, 2006; Brown et al., 2010). Unfortunately, as far as the authors are aware, no electrophysiological studies have been done on any of the projections between the medial prefrontal and the perirhinal cortices in the rat.

As well as the medial prefrontal cortex, a number of frontal lobe regions also sends and receives numerous lighter projections to and from the perirhinal cortex. There projections present between the perirhinal cortex and the frontal pole and the motor and orbitofrontal cortices (Deacon et al., 1983; Burwell and Amaral, 1998b; Agster and Burwell, 2009). The frontal pole projects to area 35 only and follows a rostral-caudal topography (Deacon et al., 1983). The remaining frontal lobe areas project to both areas 35 and 36, with most projections originating in layer II/III of their respective cortices (Burwell and Amaral, 1998b). Return projections from both areas 35 and 36 to the various motor cortices have been described; the projections from area 36 are stronger than those from area 35 apart from the projection to the primary motor cortex where the connection originating in area 35 is stronger than that of area 36 (Agster and Burwell, 2009). Agster and Burwell (2009) also report that the termini of these perirhinal projections favour layers I and VI over layers II-V and that, while projections from area 35 show no apparent topography, those from area 36 show a rostral-caudal topography. They also describe the projections from the perirhinal cortex to the orbitofrontal cortices; area 36 projecting more heavily compared to area 35 and termini being found in all layers of the orbitofrontal cortices. Again there was no topographical pattern associated with area 35 but projections from more rostral regions of area 36 showed heavier labelling in the orbitofrontal cortices than in caudal regions.

In keeping with the perirhinal cortex's role as an association area, it receives input from a number of sensory or associative areas, namely the parietal, insular, ventral temporal association, piriform, periamygdaloid, visual and auditory cortices (Deacon et al., 1983; Paperna and Malach, 1991; Burwell and Amaral, $1998 b)$. The first three areas of cortex listed are both associative in nature; the parietal cortex acts as a site for associating perceptual stimuli (Save and Poucet, 2009), spatial representation (Save and Poucet, 2000, 2009; Nitz, 2009) and may act as an interface between attention and learning during working memory (Bucci, 2009), the insular cortex has many different sensory and associative functions attributed to it (Rodgers et al., 2008) and the ventral temporal association cortex is involved in integrating separate sensory modalities (Bai et al., 2004). The parietal cortex projection originates in the caudal, granular regions of layers II, V and VI and terminates in all layers of areas 35 and 36 following a rostral-caudal topography (Deacon et al., 1983; Insausti et al., 1997). The projection from the perirhinal to the parietal cortex originates in both areas 35 and 36, with rostral regions of the perirhinal cortex projecting more heavily to layers I-III of the parietal cortex (Agster and Burwell, 2009).

The projection from the insular cortex originates in layers II and III and terminates in both areas 35 and 36 with approximately equal weighting. However, the projection to area 35 follows a rostral-caudal pattern of topography whereas the projection to area 36 follows a ventral-dorsal pattern of topography (Deacon et al., 1983; Burwell and Amaral, 1998b). The return projection from the perirhinal cortex originates in both areas 35 and 36 but both show different termination patterns in the insular cortex; projections from area 35 terminate in layers II-V of the insular cortex whereas projections from area 36 terminate in layers I-III in rostal regions of the insular cortex and in layers V and VI in caudal regions (Agster and Burwell, 2009). Like the perirhinal cortex, the insular cortex also receives input from the medial prefrontal cortex (Guldin and Markowitsch, 1983; Takagishi and Chiba, 1991) which suggests the presence of a direct and indirect input from the medial prefrontal cortex to the perirhinal cortex. As mentioned above, there have been no electrophysiological studies of the projections between the medial prefrontal cortex and the perirhinal cortex; paired-pulse facilitation/depression experiments should reveal whether the medial prefrontal cortex communicates with the perirhinal cortex via a mono- or polysynaptic projection.

The ventral temporal association cortex provides a large input to the perirhinal cortex, projecting mainly to area 36 with a smaller degree of its projections terminating in the caudal region of area 35 (Burwell and Amaral, 1998b). This projection originates in layers II, $\mathrm{V}$ and VI of the ventral temporal association cortex (Burwell and Amaral, 1998b). The entorhinal and postrhinal cortices also receive inputs from the ventral temporal association area (Burwell and Amaral, 1998b) which points to an upstream processing role for the ventral temporal cortex governing parahippocampal functioning.

The projection from the piriform cortex originates in the caudal region of layer III and terminates in the superficial layers of both areas 35 and 36 with area 35 receiving a greater amount of input compared to area 36 (Burwell and Amaral, 1998b). Similarly, the endopiriform nucleus also projects mainly to area 35 but terminating in layers I and VI (Behan and Haberly, 1999). The return projection from the perirhinal cortex to the piriform originates in both areas 35 and 36 with projections from area 35 not showing a strict topographic arrangement but projections from area 36 showing a rostral-caudal pattern of topography (Agster and Burwell, 2009). The amygdalopiriform transitional area also receives input from the perirhinal cortex with the projections mainly originating in layer II of area 35 (Santiago and ShammahLagnado, 2005). The projection from the periamygdaloid cortex originates the caudal region of layer III and terminates in layers II and III of area 35 only (Majak and Pitkänen, 2003) and a return projection has also been reported (Pitkänen et al., 2000).

As both the piriform (Barkai and Saar, 2001; Wilson, 2001) and periamygdaloid (Scalia and Winans, 1975) cortices are involved in the processing and integration of olfactory stimuli, it is conceivable that olfactory information is passed on to the perirhinal cortex via these areas. The weighting given over to olfactory input in the rat perirhinal cortex may not be the same as other animals (such as primates) who do not rely on olfactory information to such a great degree. As both areas project mainly to area 35 , there is an argument to be made for a functional distinction between areas 35 and 36 of the perirhinal cortex.

The visual cortex receives a projection from the rostral region of layer V of the perirhinal cortex (Miller and Vogt, 1984) but there is no substantial projection reported from the primary visual cortex to the perirhinal (Burwell and Amaral, 1998b). However, light labelling in the caudal perirhinal cortex has been reported following injection of the anterograde tracer Phaseolus vulgaris leucoagglutinin into the primary visual cortex (McDonald and Mascagni, 1996) and electrophysiological stimulation of the primary visual cortex has been shown to evoke fEPSPs in the perirhinal cortex (Naber et al., 2000). The perirhinal cortex shows a greater connectivity with the visual association areas compared to 
the primary visual cortex (Paperna and Malach, 1991; McDonald and Mascagni, 1996); the projection from the visual association cortex originates in layers II, V and VI and terminates only in the caudal region of area 36 (Burwell and Amaral, 1998b; Agster and Burwell, 2009).

The projections from auditory areas originate in layers II, $\mathrm{V}$ and VI and terminate in the rostral region of area 36, projecting to a lesser degree to area 35 (Burwell and Amaral, 1998b). There are also an input to the perirhinal cortex from the secondary auditory areas $\mathrm{Te} 2$ and Te3; the ventral regions of Te 2 and $\mathrm{Te} 3$ project to the caudal region of area 36 (Arnault and Roger, 1990; Shi and Cassell, 1997). A return projection to the auditory cortex from the perirhinal cortex has also been described (Paperna and Malach, 1991); perirhinal projections terminating mainly in layers I-III and VI of the auditory association cortices (Agster and Burwell, 2009). Return projections from the perirhinal cortex to the secondary auditory areas have also been reported (Paperna and Malach, 1991); projections from the middle layers of the caudal region of area 36 terminate mainly in the superficial and middle layers of Te2 and in the superficial layers of Te3 (Shi and Cassell, 1999). However, Shi and Cassell's (1999) definition of the perirhinal cortex differs from our definition and some of these projections may actually be postrhinal in origin.

It is worth noting that the postrhinal cortex receives a substantial input from the visual cortex but relatively little input from auditory areas (Burwell and Amaral, 1998b). Additionally, the postrhinal cortex shows a stronger electrophysiological response to stimulation of the visual cortex compared to the perirhinal cortex (Naber et al., 2000). This evidence further supports the argument for the postrhinal cortex being classed as a separate area both anatomically and functionally to the perirhinal cortex (see Section 2.1 for more information on the separation of these two cortical areas).

\subsection{Subcortical afferents and efferents of the perirhinal cortex}

Subcortical projections to the perirhinal cortex originate from the amygdala, thalamus, hypothalamus, basal ganglia, raphe nucleus and olfactory bulb (Fig. 2c; Deacon et al., 1983; Shammah-Lagnado et al., 1996; Van Groen et al., 1999; Vertes et al., 1999; Pikkarainen and Pitkänen, 2001).

The amygdala consists of a number of nuclei, including the nucleus of the lateral olfactory tract, bed nucleus of the olfactory tract, anterior amygdaloid area, accessory basal nucleus, basal nucleus and lateral nucleus (Pitkänen et al., 2000; de Olmos et al., 2004), and the amygdala has been linked to emotion (de Vito and Smith, 1982; Ansah et al., 2010; Ponomarev et al., 2010), memory (Maren, 1999; Savage and Guarino, 2010), sexual functioning (Carrer et al., 1973; Carrer, 1978; Holder and Mong, 2010) and neuroendocrine functioning (Beltramino and Taleisnik, 1978, 1980). From the amygdala, the perirhinal cortex receives projections from the nucleus of the lateral olfactory tract, accessory basal nucleus, basal nucleus and lateral nucleus (Krettek and Price, 1974, 1977; McDonald and Jackson, 1987; Pikkarainen and Pitkänen, 2001; Furtak et al., 2007b) with area 35 receiving the heaviest projections from the amygdala compared to area 36 and the accessory basal and lateral nuclei being the most prominent origins of these projections (Pitkänen et al., 2000). Approximately half of all subcortical afferents to area 36 originate in the amygdala, terminating in the rostral region of area 36 (Furtak et al., 2007b). Furtak et al. (2007b) also report that area 35 receives approximately half of its subcortical inputs from the amygdala, terminating in the caudal region of area 35 . The accessory basal, basal and lateral nuclei project heavily to area 35 and form a weaker projection to area 36 (McDonald and Jackson, 1987; Pikkarainen and Pitkänen, 2001). Although Krettek and Price (1977) only report a projection to area 36 and to the border between areas 35 and 36 from the lateral nucleus, the heaviest projection comes from the lateral nucleus (McDonald and Jackson, 1987; Pikkarainen and Pitkänen, 2001). The posterior basomedial nucleus has been shown to project to the perirhinal cortex, projections terminating mainly in layers II, III and V (Petrovich et al., 1996). McDonald and Jackson (1987) demonstrate that the projections from the amygdala follow a rostral-caudal topography. It must be noted that not all components of the amygdala project to the perirhinal cortex, the posterior cortical nucleus of the amygdala has not been shown to project to the perirhinal cortex (Kemppainen et al., 2002). Furthermore, it is interesting that the posterior basomedial nucleus mainly projects to a number of areas which show a strong anatomical interaction with the perirhinal cortex including the hippocampus and the medial prefrontal cortex (Petrovich et al., 1996).

While there has been little electrophysiological work looking at synaptic plasticity in these projections, there have been a number of electrophysiological studies looking at epileptiform activity in the perirhinal cortex, especially utilising the kindling model of temporal lobe epilepsy (Goddard, 1967; Giblin and Blumenfeld, 2010). Slices of perirhinal cortex from amygdala-kindled rats showed abnormal generation and synchronisation of fEPSPs following tetanus stimulation compared to slices taken from control rats (Matsumoto et al., 1996). Moreover, while electrophysiological stimulation of either the lateral nucleus or the superficial perirhinal cortex in vitro does not propagate to the entorhinal cortex, simultaneous stimulation of the lateral nucleus and the superficial perirhinal cortex (which they use to approximate sensory input to the perirhinal cortex) results in strong depolarisation in the deep layers of area 35 and this electrophysiological response was propagated to the entorhinal cortex and dentate gyrus (Kajiwara et al., 2003). Based on this evidence, Kajiwara et al. (2003) posit that the perirhinal cortex acts as an association area for emotional and sensory information before these types of information enter the hippocampus. This hypothesis is supported by electrophysiological evidence in vitro which shows that the perirhinal cortex does act as a gateway between the amygdala and the hippocampal-parahippocampal network (Koganezawa et al., 2008). Koganezawa et al. (2008) also show using slices cut along a different axis to Kajiwara et al. (2003) that stimulation of the lateral nucleus or of area 35 alone is enough to propagate information to the entorhinal cortex and dentate gyrus but that simultaneous stimulation of the lateral nucleus and area 36 was needed to elicit a response in the entorhinal cortex or the dentate gyrus. Further electrophysiological analysis of these projections is required to fully flesh out the hypothesis of the perirhinal cortex as an associative area for sensory and emotional information although we review the functional evidence for this hypothesis in Section 4.4.

There have been strong return projections reported from the perirhinal cortex to the amygdala (Ottersen, 1982; Pitkänen et al., 2000); the perirhinal cortex projects to the lateral, basolateral and basomedial nuclei in the amygdala; these projections originating predominantly in the layers $\mathrm{V}$ and VI of the perirhinal cortex (McIntyre et al., 1996) though projections to the basolateral amygdaloid nucleus are reported to originate from layer II of the perirhinal cortex (Shi and Cassell, 1999). The heaviest projection from the perirhinal cortex is the one which targets the lateral nucleus (Pitkänen et al., 2000). The projections from area 36 project more heavily to the amygdala than those of area 35 (Shi and Cassell, 1999). Projections from the middle rostral-caudal region of area 36 terminate in the various nuclei of the amygdala (Furtak et al., 2007b). Furtak et al. (2007b) report that the return projection to the amygdala from area 35 originates in the rostral region of area 35 and mainly targets the basomedial nucleus. Shi and Cassell 
(1999) report no direct connections to the central and medial amygdaloid nuclei. There is growing electrophysiological evidence to suggest a role for the perirhinal cortex in transferring information to the amygdala; stimulation of either area 35 or 36 can elicit fEPSPs in the basal and lateral nuclei of the amygdala (Yaniv and Richter-Levin, 2000; Yaniv et al., 2001). Evidence from paired-pulse facilitation experiments show that the projection from area 35 to the basal nucleus is monosynaptic (Yaniv and Richter-Levin, 2000). Yaniv et al. (2001) also report that the projections from areas 35 to the basal nucleus can sustain LTP in vivo following theta-burst stimulation but they could not induce LTP in the projection from area 35 to the lateral nucleus or in the area 36 projections to either the basal or the lateral nuclei.

The thalamus is a diencephalic structure involved in the relay and modulation of information to and from the cortex (Groenewegen and Witter, 2004). The thalamus can be divided into the dorsal and ventral thalamus and these divisions can be subdivided further into a number of nuclei (Groenewegen and Witter, 2004). A number of these thalamic nuclei have been shown to project to the perirhinal cortex. From the midline thalamus, both the nucleus reuniens and rhomboid nucleus project to the perirhinal cortex (Vertes et al., 2006). The projection from the dorsal nucleus reuniens terminates mainly in layer I with some labelling found in layers IV-VI of both areas 35 and 36 (Wouterlood et al., 1990) and the projection from the rhomboid nucleus terminates mainly in layers $\mathrm{I}$ and $\mathrm{V}$ of the perirhinal cortex (Vertes et al., 2006). It has since been demonstrated that projections to the superficial perirhinal cortex from the nucleus reuniens originate mainly in the perireuniens nucleus (DollemanVan Der Weel and Witter, 1996). The anteromedial nucleus also projects to the perirhinal cortex, terminating in mainly layer $\mathrm{V}$ of the caudal perirhinal cortex (Van Groen et al., 1999) but with some lighter labelling also observed in layer I (Shibata, 1993). Shibata (1993) also describes a projection from the interanteromedial nucleus to layer $V$ of the perirhinal cortex and from the anteroventral nucleus to layers V and VI of the perirhinal cortex. The posterior intralaminar nucleus and the dorsal medial geniculate nucleus both project to the perirhinal cortex with the posterior intralaminar nucleus projection being the heaviest of the pair, projecting mainly to the superficial layers of the perirhinal cortex (Namura et al., 1997; Linke, 1999; Doron and LeDoux, 2000). Namura et al. (1997) also report projections from the suprageniculate and subparafascicular nuclei. Unfortunately there have been no electrophysiological studies performed on the projections from the thalamus to the perirhinal cortex.

Although the projections from the thalamus to the perirhinal cortex have been well characterised in anatomical terms, there has been less attention paid to the return projection though the number of such studies is mounting. The projection from the perirhinal cortex to the thalamus mainly originates in layers $V$ and $\mathrm{VI}$ and terminates in the reuniens, posterior and ventral posteromedial nuclei (Cornwall and Phillipson, 1988; McIntyre et al., 1996). Projections from the deep layers of the perirhinal cortex to the rostral, caudomedial and rostrolateral regions of the nucleus reuniens have also been described (McKenna and Vertes, 2004). McKenna and Vertes (2004) also describe a light projection to rhomboid nucleus from the deep layers of the perirhinal cortex. As with the projections from the thalamus to the perirhinal cortex, there have been no electrophysiological studies done either on synaptic plasticity or epileptiform activity. Now that there is a growing body of anatomical data, the need for electrophysiological characterisation of these projections is becoming more apparent.

The hypothalamus is a subcortical structure which governs endocrine, autonomic and somatomotor function (Simerly, 2004). As its role requires extensive integration of many disparate functions, the structure of the hypothalamus matches its range of tasks and it can be broadly delineated into three main sections: the periventricular, medial and lateral areas (Simerly, 2004). These can in turn be subdivided numerous times into various nuclei and some of these nuclei form connections with the perirhinal cortex. Several subfields of the ventromedial nucleus and the tuberal nucleus project to the perirhinal cortex, in all cases there is light labelling observed in layers III-VI of the perirhinal cortex following injection of $P$. vulgaris leucoagglutinin into the respective hypothalamic nuclei (Canteras et al., 1994). There is a light projection from the caudal posterior nucleus to the deep layers of the perirhinal cortex and a heavier projection from the rostral posterior nucleus which terminates mainly in layers I and II of the perirhinal cortex (Vertes et al., 1995). There is little description in the literature of area 35 versus area 36 in terms of hypothalamic projections and there has been no electrophysiological analysis of any of these hypothalamic projections to the perirhinal cortex.

The basal ganglia are a group of subcortical structures including the striatum (including the nucleus accumbens), caudate, putamen, globus pallidus and substantia nigra (Gerfen, 2004). The basal ganglia act as a gateway between the cortex and various subcortical regions involved in the generation of behaviours (e.g. movement and autonomic function; Gerfen, 2004). Few projections from the basal ganglia to the perirhinal cortex have been described but there has been a projection from the globus pallidus reported which has been found to terminate across all layers in the perirhinal cortex (Shammah-Lagnado et al., 1996). Return projections to the basal ganglia from the perirhinal cortex have also been described (McGeorge and Faull, 1989); projections to the striatum originate in layers III and V of the perirhinal cortex and projections to the caudate and substantia nigra originate in layer V of the perirhinal cortex (McIntyre et al., 1996). Projections to the striatum mainly terminate in the nucleus accumbens (Christie et al., 1987), terminating mainly in the core of the lateral nucleus accumbens (Phillipson and Griffiths, 1985; Brog et al., 1993). As with most of the subcortical projections of the perirhinal cortex, no electrophysiological studies have been performed on these basal ganglia projections.

The raphe nuclei are a group of neuronal clusters responsible for serotoninergic signalling within the brain and are involved in mood (Gardier et al., 1996) and circadian rhythms (Monti, 2010). The perirhinal cortex maintains multiple connections throughout the raphe nuclei (Vertes, 1991; Hermann et al., 1997; Vertes et al., 1999). The dorsal raphe nucleus (Vertes, 1991) and the median raphe nucleus (Deacon et al., 1983; Vertes et al., 1999) both project to the perirhinal cortex. In the case of the dorsal raphe nucleus, the majority of projections to the perirhinal cortex originate in the rostral region of the dorsal raphe nucleus (Vertes, 1991). In the case of the median raphe nucleus, the projections terminate across all layers of the caudal perirhinal cortex with the heaviest labelling observed in superficial layers (Deacon et al., 1983; Vertes et al., 1999). Return projections from the perirhinal cortex terminate in the rostral raphe magnus and raphe pallidus (Hermann et al., 1997). However, Hermann et al. (1997) do not differentiate between areas 35 and 36 and do not report what layers or regions the perirhinal projections originate in. The role of the raphe nucleus as regards the perirhinal cortex and vice versa is not clear as no functional or electrophysiological studies focussing on their relationship have yet been performed.

The main olfactory bulb is a structure which receives input directly from olfactory receptor neurons in the nose and relays the olfactory information on to other brain areas (Shipley et al., 2004). The perirhinal input from the olfactory bulb terminates across multiple layers of the perirhinal cortex but no return projection from the perirhinal cortex has been reported (Santiago and Shammah-Lagnado, 2004). As reported in Section 3.2, the perirhinal cortex does form reciprocal projections with a number of cortical areas associated with olfactory processing such as the 
piriform and periamygdaloid cortices (Burwell and Amaral, 1998b; Behan and Haberly, 1999; Majak and Pitkänen, 2003; Agster and Burwell, 2009). As such it is probable that the perirhinal cortex does not communicate directly with the olfactory bulb but instead processes "raw" olfactory bulb input simultaneously with input from olfactory association areas. However, without relevant functional and electrophysiological data this hypothesis remains untested.

Finally, there are a number of other subcortical nuclei which are connected with the perirhinal cortex but little research has been performed on these projections beyond the initial studies which originally reported the projections. Miscellaneous subcortical afferents of the perirhinal cortex include the nucleus incertus (Olucha-Bordonau et al., 2003) and the substantia innominata (Grove, 1988b). Miscellaneous subcortical efferents of the perirhinal cortex include the suprachiasmatic nucleus (Krout et al., 2002) and the substantia innominata (Grove, 1988a).

\subsection{Hippocampal and parahippocampal projections}

The intrinsic projections of the perirhinal cortex follow a dorsal-ventral gradient within area 36 and between areas 35 and 36 (Burwell, 2000). Area 36 projects laterally into area 35 with the majority of connections originating in the ventral region of area 36 in layers II, V and VI and terminating in layers I and V of area 35 (Burwell and Amaral, 1998a). Burwell and Amaral (1998a) also show that area 35 of the perirhinal cortex projects into area 36 (to a lesser degree than the 36 into 35 projections) and forms a feedback pathway with most projections originating in layers II and III and terminating in all layers.

The perirhinal cortex is well connected with the other hippocampal and parahippocampal fields; it forms reciprocal projections with the area CA1, subiculum, entorhinal cortex and postrhinal cortex (Fig. 3a; Swanson and Cowan, 1977; Wyss, 1981;

a

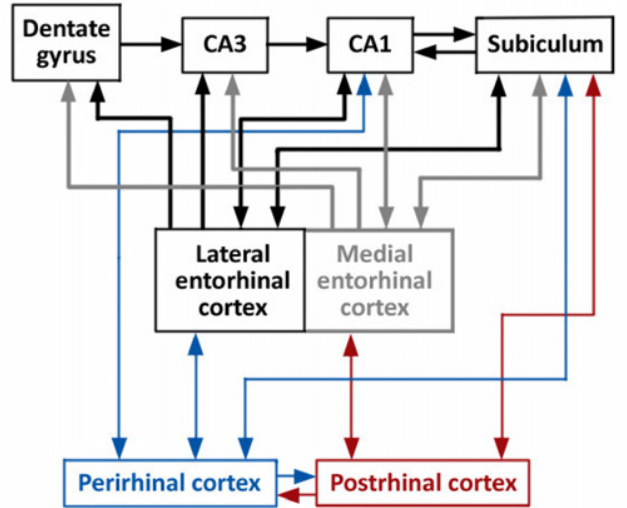

b

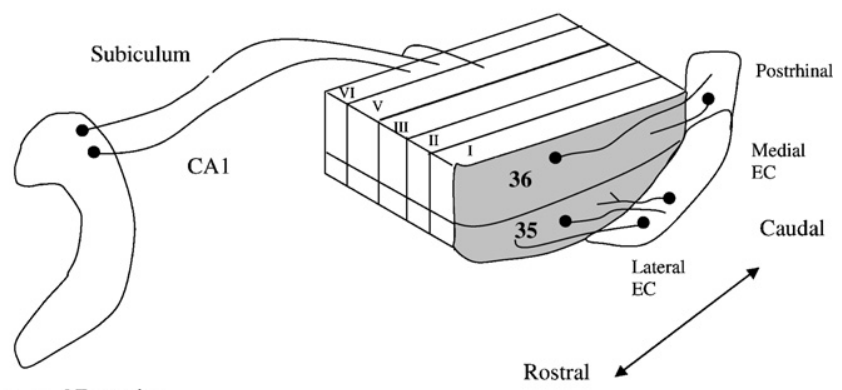

Hippocampal Formation

Fig. 3. (a) Schematic diagram showing the main projections within the hippocampal-parahippocampal circuit. (b) A more detailed diagram illustrating the projections to and from various sub regions of the perirhinal cortex.
Kosel et al., 1982, 1983; Deacon et al., 1983; Köhler, 1988; Van Groen and Wyss, 1990; Insausti et al., 1997; Burwell and Amaral, 1998a,b; Shi and Cassell, 1999; Kloosterman et al., 2003b). Based on anatomical (Witter et al., 2000b; Witter, 2002), electrophysiological (Young et al., 1997; Ivanco and Racine, 2000; Naber et al., 1997, 1999, 2001a,b) and functional evidence (Bussey et al., 2000; Wan et al., 2001; Burwell et al., 2004a,b; Jenkins et al., 2004; Amin et al., 2006; Albasser et al., 2010; Romero-Granados et al., 2010), the hippocampal-parahippocampal region of the brain has been implicated in several aspects of learning and memory. The role of the perirhinal cortex in this hippocampal-parahippocampal network has been traditionally seen as a gateway for sensory information into the hippocampus via the entorhinal cortex (Witter et al., 2000a,b) but, as discussed below, the current evidence does not fully support this model but points to a more complex relationship between the hippocampal-parahippocampal regions.

The hippocampal input to the perirhinal cortex originates principally in the septal region of the area CA1 and in the dorsal region of the subiculum and both projections terminate in the deep layers of the perirhinal cortex (Swanson and Cowan, 1977; Deacon et al., 1983; Van Groen and Wyss, 1990, see Fig. 3b). Projections from the septal proximal subiculum terminate ipsilaterally in layers V and VI of the perirhinal cortex (Kloosterman et al., 2003b). Kloosterman et al. (2003b) noted that there were some projections that terminated more superficially (layers I, II and III) and in addition, some of the subicular efferents projected contralaterally. Swanson and Cowan (1977) indicate that the CA1 projection may go through the subiculum and continue on to the perirhinal cortex by either passing straight through the subiculum or by terminating there and the direct connection to the perirhinal cortex actually originating in subicular neurons. However, retrograde tracing using horse radish peroxidase results in labelling of both the area CA1 and the subiculum (Deacon et al., 1983) which suggests that a direct connection from the area CA1 to the perirhinal cortex exists. In a later study using both anterograde and retrograde tracing, a projection originating the septal region of area CA1 was found to terminate in layer VI of the caudal perirhinal cortex (Van Groen and Wyss, 1990).

There is a growing amount of electrophysiological research to support the functional significance of the projections going from the hippocampus to the perirhinal cortex. As well as generating fEPSPs in the perirhinal cortex, stimulation of the monosynaptic return projection from the hippocampus to the perirhinal cortex can induce changes in long-term synaptic plasticity (Cousens and Otto, 1998; Kealy and Commins, 2009, 2010). Stimulation of area CA1 using $300 \mathrm{~Hz}$ HFS in the freely moving rat (Ivanco and Racine, 2000) and, $100 \mathrm{~Hz}$ theta-burst stimulation (Cousens and Otto, 1998 ) and $250 \mathrm{~Hz}$ (Kealy and Commins, 2009, 2010) in the anaesthetised rat can induce LTP in the perirhinal cortex. However, Ivanco and Racine (2000) observed that synaptic changes in the perirhinal cortex following HFS of CA1 took several sessions to induce, indicating that this projection may be resistant to activitydependent changes in synaptic plasticity but the findings of Cousens and Otto (1998) appear to contradict this view as the LTP observed during their experiment was robust and easily induced with their stimulation protocol. In general, however, the findings that the CA1 to perirhinal cortex projection can sustain both shortand long-term changes in activity-dependent synaptic plasticity indicate that this projection may therefore play a role in the storage or consolidation of perirhinal-dependent memories (Hasselmo and McClelland, 1999).

Here we present findings from research in the anaesthetised rat from our own lab (Kealy and Commins, 2009, 2010) which fills in some of the details as regards the electrophysiological properties of the projection arising in area CA1 of the hippocampus and 
terminating in the perirhinal cortex (see Fig. 4a for location of stimulating and recording electrode sites in area CA1 and perirhinal cortex respectively). By pooling data from a number of experiments already published (Kealy and Commins, 2009, 2010), we confirm that the projection from area CA1 to the perirhinal cortex is also capable of sustaining both short-term plastic effects in the form of paired-pulse facilitation (Fig. 4b) with

a

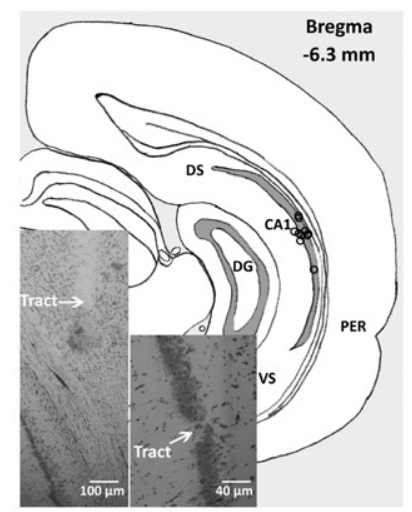

facilitation peaking at the $40 \mathrm{~ms}$ interval before tapering out at longer intervals with a significant depression observed at the $480 \mathrm{~ms}$ interval, and long term potentiation (Fig. 4c).

As well as a group of direct projections from the hippocampus to the perirhinal cortex, there is also a direct projection from the perirhinal cortex to a number of hippocampal fields (Liu and Bilkey, 1998b). The efferent projections from the perirhinal cortex

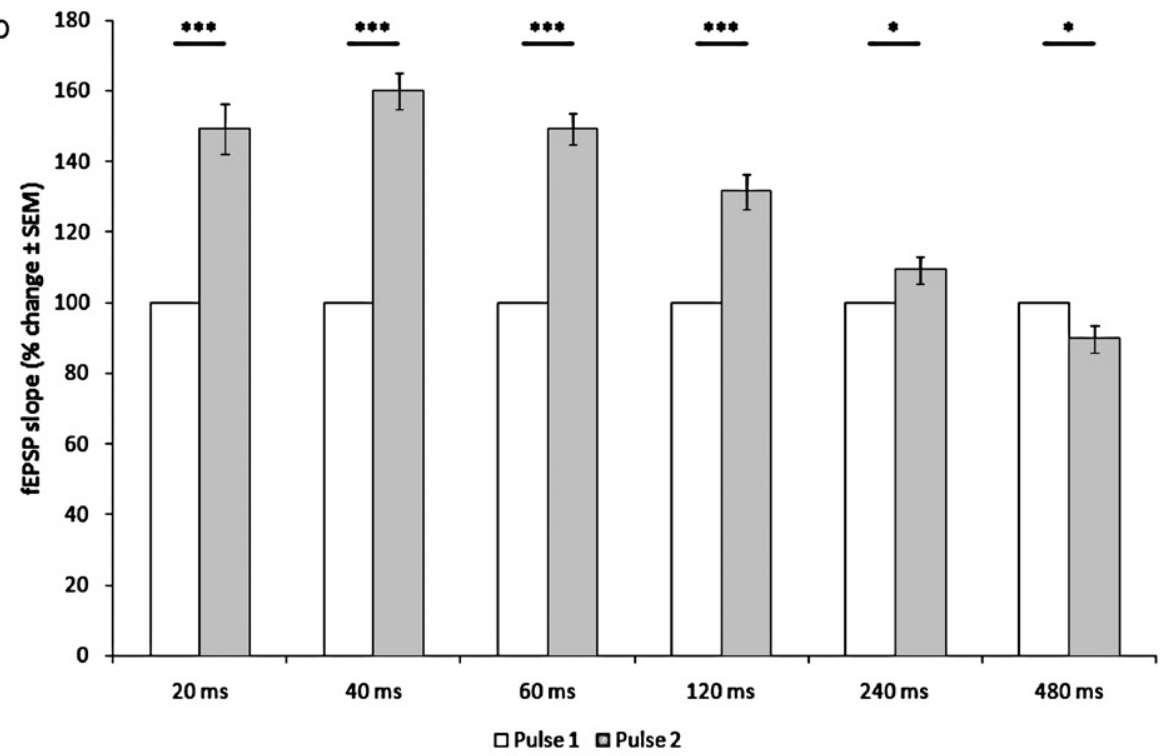

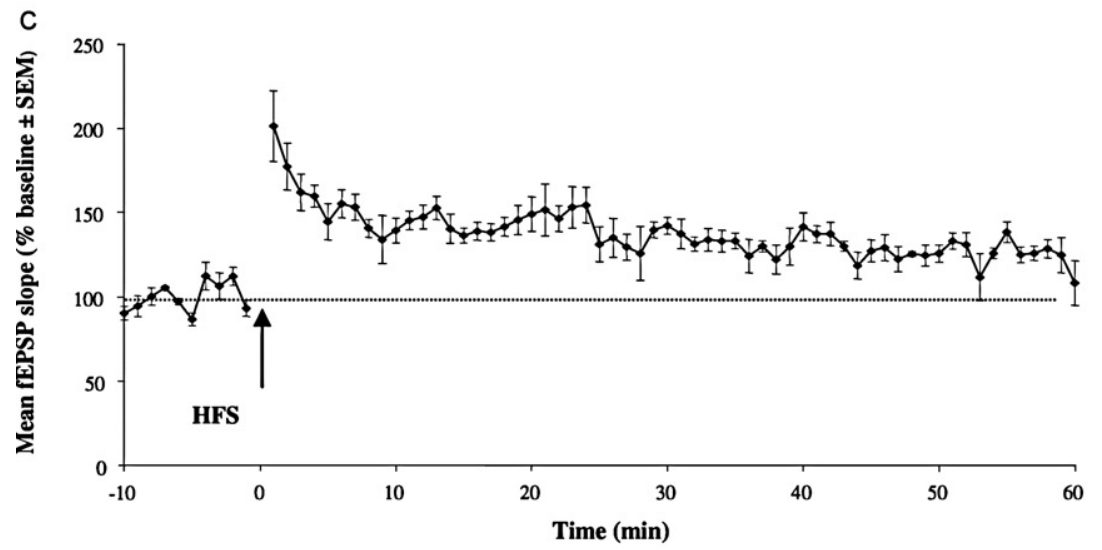

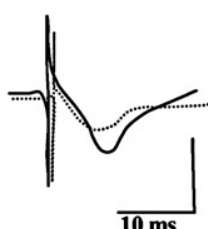

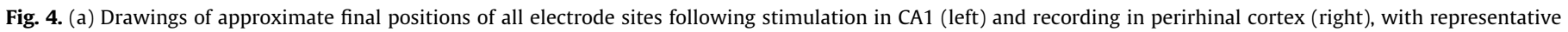

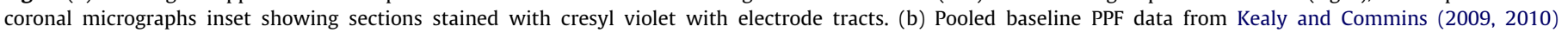

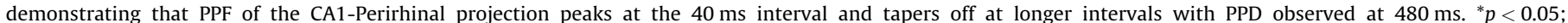

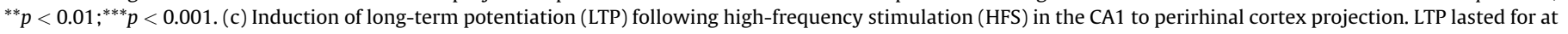

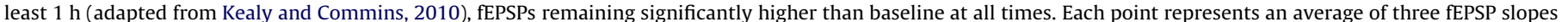

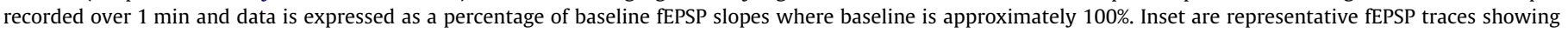
typical fEPSPs at baseline, 0-10 $\mathrm{min}, 20-30 \mathrm{~min}$ and 50-60 min. 
to the hippocampal formation terminate in area CA1, subiculum and prosubiculum but not in the dentate gyrus, CA2, CA3 and CA4 (Kosel et al., 1983; McIntyre et al., 1996; Naber et al., 1999; Shi and Cassell, 1999; Witter et al., 1999). A direct connection from area 35 to the molecular layer of the middle dorsoventral subiculum and adjacent parts of the prosubiculum and area CA1 has been described (Kosel et al., 1983; Shi and Cassell, 1999). A later study found that the perirhinal cortex projected to the border area of CA1 and the subiculum but spared other regions of the hippocampus (Naber et al., 1999). There is a caveat as regards the perirhinal cortex projection to the hippocampus as depending on which anatomical definition of the perirhinal cortex is taken, what might be considered area 35 of the perirhinal cortex by one group may be considered to be the dorsal lateral entorhinal cortex by others (a region that is well-connected with the hippocampus; Kajiwara et al., 2008).

As with the projections from the hippocampus to the perirhinal cortex, there are a number of studies which show that the perirhinal efferents are capable of sending electrophysiological information to the hippocampus. Stimulation of the perirhinal cortex can also result in the generation of fEPSPs in the CA1/ subiculum (Naber et al., 1999) although others have reported that stimulation of the perirhinal cortex does not elicit excitatory electrophysiological activity in the area CA1 (Canning and Leung, 1997). However, the monosynaptic projection from the perirhinal cortex to the area CA1 has also been shown to be capable of sustaining LTP (Liu and Bilkey, 1996b) and this LTP is NMDA receptor-dependent (Liu and Bilkey, 1996a) which strengthens the case considerably for this projection being capable of sending information directly to the hippocampus from the perirhinal cortex. Despite there being no monosynaptic input from the perirhinal cortex to the dentate gyrus (Kosel et al., 1983; McIntyre et al., 1996), an indirect, polysynaptic projection from the perirhinal cortex to the dentate gyrus has been shown to be capable of sustaining LTP in the freely moving rat (Ivanco and Racine, 2000). In addition to the direct projection to the hippocampus, the perirhinal cortex can also exert an indirect electrophysiological influence in area CA1 through the entorhinal cortex (Naber et al., 1999); stimulation of the perirhinal cortex leads to an enhancement of entorhinal-induced fEPSPs in the area CA1 (Liu and Bilkey, 1996b).

As mentioned above, the perirhinal cortex forms part of the parahippocampal region along with the entorhinal and postrhinal cortices. Anatomical evidence suggests that these parahippocampal areas and the hippocampus form the hippocampal-parahippocampal network (Fig. 3a); the hippocampus is reciprocally connected to all the regions of the parahippocampal neocortex to form a network of parallel pathways that are proposed to work in concert during learning and memory formation (Witter et al., 2000a,b; Witter, 2002). We have reported above that the projections between the perirhinal cortex and hippocampus can sustain changes in synaptic plasticity which points to a functional role for these projections.

The most prominent of all afferent cortical projections to the perirhinal cortex is the one originating in the entorhinal cortex (Wyss, 1981; Kosel et al., 1982; Köhler, 1988; Insausti et al., 1997; Burwell and Amaral, 1998a; Canto et al., 2008). Lateral entorhinal projections project more to area 35 than 36 with rostral lateral entorhinal projections terminating in rostral regions of the perirhinal cortex and caudal lateral entorhinal projections terminating across the perirhinal cortex (Burwell and Amaral, 1998a). The lateral entorhinal cortex projection to the perirhinal cortex originates in all layers of the lateral entorhinal cortex but laminar distribution changes depending on location within the entorhinal cortex (Insausti et al., 1997) which supports later findings that suggest the projection originates in layers III and V of the lateral entorhinal cortex (Burwell and Amaral, 1998a). In any case, the lateral entorhinal cortex projects more heavily to area 35 than area 36 (Insausti et al., 1997; Burwell and Amaral, 1998a). These projections terminated across all layers of area 35 (albeit with heavier staining present in layers I and V comparatively) and a similar story is seen for area 36 (Burwell and Amaral, 1998a). There is only a minimal projection to area 35 from layer $\mathrm{V}$ of the medial entorhinal cortex (Burwell and Amaral, 1998a). Stimulation of the entorhinal cortex elicits an electrophysiological response in the perirhinal cortex and this projection from the entorhinal to the perirhinal cortex can sustain short-term synaptic plasticity in the form of PPD (Garden et al., 2002). The capability of this projection to sustain changes in synaptic plasticity reinforces the idea of a functional parahippocampal network in the rat brain.

The efferent projection from the perirhinal cortex to the entorhinal cortex follows a similar topographic weighting; projections from area 35 to the entorhinal cortex are heavier than those from area 36 (Burwell and Amaral, 1998a). Additionally, the majority of projections from the perirhinal cortex to the entorhinal cortex terminate in the lateral entorhinal cortex (Naber et al., 1997; Santiago and Shammah-Lagnado, 2005). Cells from the rostral perirhinal cortex innervate rostral regions of the lateral entorhinal cortex and likewise those from the caudal perirhinal cortex go to caudal areas of the entorhinal cortex (Burwell and Amaral, 1998a). Area 36 efferents to the entorhinal cortex originate in layers II, V and VI and with more superficial cells projecting to lateral regions of the lateral entorhinal cortex and deeper cells projecting to more intermediate regions (Burwell and Amaral, 1998a). In area 35, more projections originate from superficial layers, i.e. II/III, with a smaller proportion originating from layers $\mathrm{V}$ and VI (Burwell and Amaral, 1998a). No matter which area of the perirhinal cortex that a projection originates from, the majority of projections terminate in layers II and III of the entorhinal cortex (Burwell and Amaral, 1998b). Electrophysiological confirmation of this projection has been reported; stimulation of the perirhinal cortex can generate fEPSPs in the entorhinal cortex and this projection is capable of sustaining LTP (Ivanco and Racine, 2000).

Electrophysiological evidence shows that the perirhinal cortex can send information to the hippocampus via an indirect pathway through the entorhinal cortex (Canning and Leung, 1997; Naber et al., 1999) but studies in cats (Pelletier et al., 2004) and in guinea pigs (Biella et al., 2003, 2010) have shown that the perirhinal cortex may not simply just relay information from upstream areas to the entorhinal cortex as has been suggested based on anatomical data. All of these studies have focussed on the flow of information through a number of cortical areas but there is a need for more concentrated research on the electrophysiological properties of the reciprocal projections between the entorhinal and perirhinal cortices. Little is known about the effects of stimulation in either cortical area on plasticity in the other, nor of the molecular mechanisms that may govern communication between them.

The next major cortical area associated with the perirhinal cortex is the postrhinal cortex, an area of the brain involved in contextual processing (Eacott and Gaffan, 2005) and spatial representation (Burwell and Hafeman, 2003). Projections from the postrhinal cortex originate rostral areas in layers II and V and terminate in both areas 35 and 36 but favouring the caudal region of area 36 (Burwell and Amaral, 1998a,b) forming a lateral pathway across all cortical layers in the perirhinal cortex (Deacon et al., 1983; Burwell and Amaral, 1998a). The return projections from area 36 to the postrhinal cortex are heavier than those from area 35 (Burwell and Amaral, 1998a). Burwell and Amaral (1998a,b) show that both areas of the perirhinal cortex form a feedback pathway with the postrhinal cortex; projections originate from layers II, V and VI of the perirhinal cortex and terminate mainly in layers I/II and VI of the rostral part of the postrhinal cortex with projections 
from the rostral region of area 36 terminating in the caudal postrhinal cortex.

As with the entorhinal cortex, there is a dearth of electrophysiological studies looking at the electrophysiological properties between the perirhinal and postrhinal cortices. A single study in guinea pigs (Biella et al., 2010) has shown some electrophysiological interaction between the perirhinal and postrhinal cortices but does not uncover what sort of electrophysiological relationship there is between these two neighbouring regions of cortex. There is a need for more in depth electrophysiological studies looking at the connections between the parahippocampal cortices in the rat in order to fully appreciate their roles during behaviour.

Taking all this information together, there is a strong case for the existence of a hippocampal-parahippocampal network. The cortices that make up the parahippocampal region all form reciprocal connections with each other. As shown above, the perirhinal cortex forms reciprocal connections with the entorhinal (Wyss, 1981; Kosel et al., 1982; Köhler, 1988; Insausti et al., 1997; Naber et al., 1997; Burwell and Amaral, 1998a) and postrhinal cortices (Burwell and Amaral, 1998b; Burwell, 2000). The entorhinal and postrhinal cortices also project to and from each other to complete the cortical aspect of the hippocampalparahippocampal network (Burwell and Amaral, 1998a,b). These three neocortical areas have been shown to be capable of transferring electrophysiological information with each other (Ivanco and Racine, 2000; de Curtis and Biella, 2002; Garden et al., 2002) which is a necessary requirement of any neuronal network.

In addition to being connected to each other, these cortical areas also show large amounts of interconnectivity with the hippocampus. As well as the hippocampus forming reciprocal connections with the perirhinal cortex (Swanson and Cowan, 1977; Deacon et al., 1983; Kosel et al., 1983; Van Groen and Wyss, 1990; McIntyre et al., 1996; Kloosterman et al., 2003b), it also shows strong interconnectivity with the entorhinal (Steward, 1976; Steward and Scoville, 1976; Swanson and Cowan, 1977; Swanson et al., 1981; Wyss, 1981; Tamamaki and Nojyo, 1993, 1995; Ohara et al., 2009) and postrhinal cortices (Kloosterman et al., 2003b). Many of these projections have been shown to be capable of eliciting an electrophysiological response in their respective tissues. Electrical stimulation of the entorhinal (Naber et al., 1999) and postrhinal cortices (Naber et al., 2001b) results in the generation of fEPSPs in area CA1 and the subiculum. Furthermore, the projection from the entorhinal cortex to area CA1 can sustain NMDA receptor-dependent LTP following $100 \mathrm{~Hz}$ HFS (Remondes and Schuman, 2003). Additionally, the return projection from the hippocampus to the entorhinal cortex can also carry electrophysiological information (Ivanco and Racine, 2000; Kloosterman et al., 2003a, 2004). Moreover, the CA1 to entorhinal (Craig and Commins, 2005) and subiculum to entorhinal projections (Craig and Commins, 2006) are both capable of sustaining short- and long-term changes in synaptic plasticity. Both projections can sustain LTP or LTD depending on previous electrophysiological activity as both show a frequency-dependent metaplasticity (Craig and Commins, 2007).

3.4. Anatomical and electrophysiological evidence for segregation within the hippocampal-parahippocampal network: the perirhinal cortex as part of this network

Based on anatomy (Swanson and Cowan, 1977; Wyss, 1981; Kosel et al., 1982, 1983; Deacon et al., 1983; McIntyre et al., 1996; Naber et al., 1997, 1999, 2000, 2001a,b; Burwell and Amaral, 1998a; Kloosterman et al., 2003b) and physiology (Canning et al., 2000; Ivanco and Racine, 2000; de Curtis and Biella, 2002; Garden et al., 2002; Kloosterman et al., 2003a, 2004; Craig and Commins,
2005, 2006, 2007; Kealy and Commins, 2009, 2010), the hippocampal-parahippocampal network has been proposed as a relay of parallel pathways between the hippocampus and the constituents of the parahippocampal region that may play a role in learning and memory (Witter et al., 2000a,b; Witter, 2002). Our lab has shown previously that the projections originating in the distal CA1 and proximal subiculum which terminating in the lateral entorhinal cortex show a greater tendency to sustain 'electrophysiologically excitatory' synaptic plasticity (demonstrating a greater tendency to show potentiation, even at low frequency stimulation levels) whereas those originating in the proximal CA1 and terminating in the medial entorhinal cortex show a greater tendency to sustain 'electrophysiologically inhibitory' synaptic plasticity (readily demonstrating LTD, see Craig and Commins, 2007). Looking at perirhinal-entorhinal interconnectivity; the lateral entorhinal cortex has multiple reciprocal projections with the perirhinal cortex whereas the medial entorhinal cortex is connected reciprocally with the postrhinal cortex (Insausti et al., 1997; Burwell and Amaral, 1998a). Taking into account these anatomical findings, there seems to be differences also in electrophysiological activity between two main circuits connecting in the hippocampal-parahippocampal network, with the circuit centred around the lateral entorhinal cortex (which includes the perirhinal cortex) being 'electrophysiologically excitatory' in nature and the circuit centred around the medial entorhinal cortex (including the postrhinal cortex) being electrophysiologically inhibitory in nature. From this model, one would predict that the CA1 to perirhinal cortex projection should be 'electrophysiologically excitatory' in nature as it forms part of the CA1/subiculum to lateral entorhinal cortex circuit (Figs. 3a and 5). Based on our recent investigation into frequency-dependent changes in synaptic plasticity in the CA1 to perirhinal cortex projection (Kealy and Commins, 2010), our findings fit with the proposed model of electrophysiological as well as anatomical segregation along the hippocampal-parahippocampal pathways (Fig. 5). HFS induced LTP as predicted and LFS did not induce LTD. We did, however, observe low levels of potentiation (rather than depression) following $1 \mathrm{~Hz}$ and $5 \mathrm{~Hz}$ LFS protocols which would be expected of an 'electrophysiologically excitatory' pathway.

From this and previous work (Burwell, 2000; Witter et al., 2000; Craig and Commins, 2007), clear predictions can be made in terms of the remaining projections and future work should focus on determining the electrophysiologically excitatory and inhibitory capabilities of the other projections in the hippocampal-parahippocampal network. We suggest, for example, that the projections from the proximal subiculum and lateral entorhinal to the perirhinal cortex will both be electrophysiologically excitatory in nature. We also predict that the projections from the proximal CA1, distal subiculum and medial entorhinal cortex will be electrophysiologically inhibitory in nature. Further electrophysiological examination of the distal CA1 to the perirhinal cortex may reveal that LTD can be induced following changes in metaplasticity as metaplastic effects have been described in other projections within the hippocampal-parahippocampal network (Craig and Commins, 2007).

\subsection{Anatomical and electrophysiological evidence for segregation of} function within the perirhinal cortex

Further, it is becoming clear from the various anatomical experiments described in the previous sections that there must also be some specialisation of function within the perirhinal cortex. Two main forms of anatomical segregation appear repeatedly in the literature: segregation by cortical area (i.e. area 35 versus area 36) and the existence of a rostral-caudal topography amongst many perirhinal projections. For example, visual inputs to the 


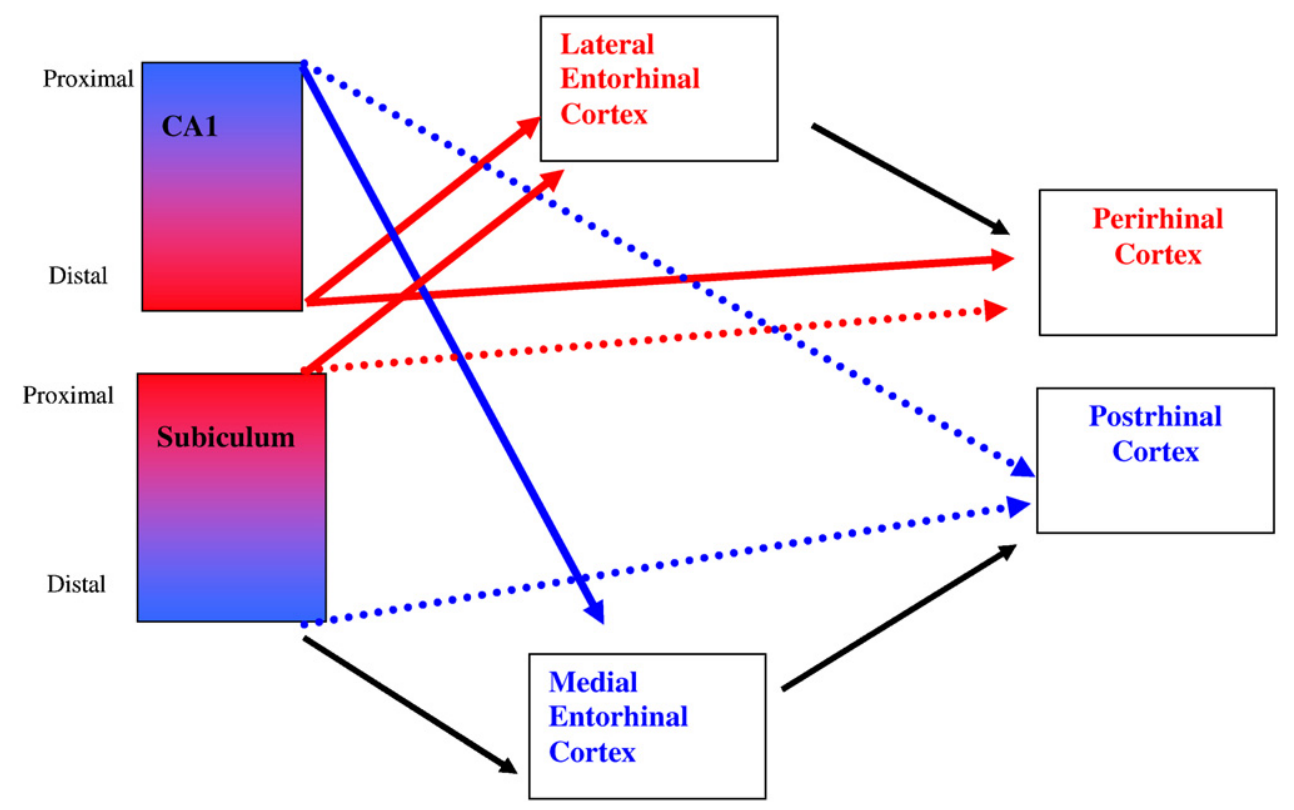

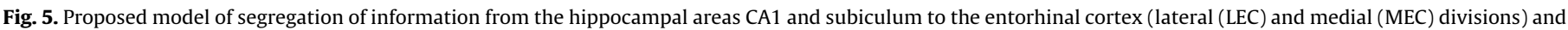

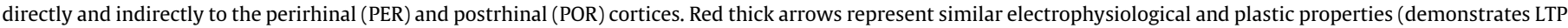

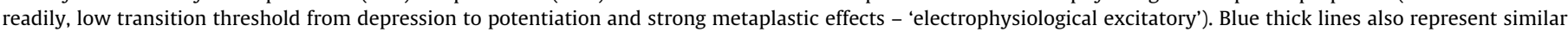

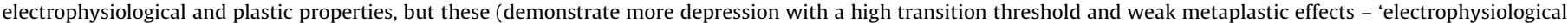

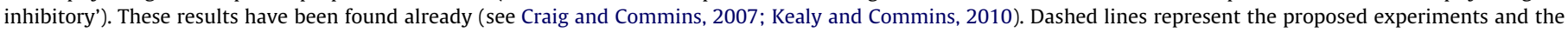

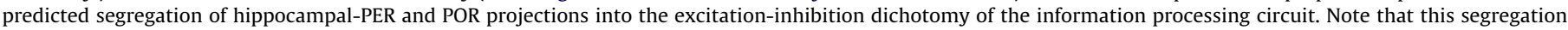
maps directly onto the anatomical separation (Witter et al., 2000).

perirhinal are denser to area 36 compared to 35 . Whereas projections to both prelimbic and infralimbic cortices are denser from area 36 compared to area 35. In addition, perirhinal projections to the anterior cingulate cortex arises mainly in the rostral region of area 36, however the return projections from the anterior cingulate terminate in the caudal aspect of both areas 36 and 35 . Interestingly, given the close connectivity between the lateral entorhinal cortex and the perirhinal cortex (described in the previous section) these connections seem to involve mainly the rostral extent of the lateral entorhinal cortex and the rostral region of area 35. Whereas, projections between the postrhinal and perirhinal cortices mainly the caudal extent of area 36 .

To complicate issues, perirhinal afferents and efferents, depending on each case, also show segregation in the layers of the perirhinal cortex in which they originate or terminate in. For example, a number of subcortical afferents to the perirhinal cortex terminate in superficial layers but the return projections from the perirhinal cortex tend to originate in deep layers. Equally, sensory and amygdalar input to the perirhinal cortex terminate in superficial layers but the associational properties of the perirhinal cortex appear to require deep layer neurons (Kajiwara et al., 2003; Koganezawa et al., 2008). As described in Sections 2.2 and 2.3, there are different distributions of neuron types in the various layers of the perirhinal cortex and where the various projections to and from the perirhinal cortex begin or terminate may be dependent on what cell types (and therefore what layers) are involved. An interesting observation by Paperna and Malach (1991) was the intermingling of perirhinal efferents to the visual and auditory cortices. They suggest that this intermingling may allow for cross talk between the different sensory modalities, reinforcing the idea of the perirhinal cortex being an association area. This view is supported by anatomical evidence from Shi and Cassell (1997) which shows that multimodal inputs converge in the same areas of the perirhinal cortex.

Finally, tracing experiments have suggested that the perirhinal cortex is a "border area" where dorsal-ventral projections from neighbouring cortical areas are segregated (Deacon et al., 1983; Burwell and Amaral, 1998a). $\mathrm{H}^{3}$-labelled amino acid autoradiographic and horse radish peroxidase tracing experiments show that projections from ventral areas do not traverse the perirhinal cortex dorsally and similarly projections from dorsal areas do not traverse ventrally (Deacon et al., 1983). Similarly, the situation described above with perirhinal-postrhinal connections focussing mainly in area 36 and perirhinal-entorhinal connections focussing mainly in area 35 (Burwell and Amaral, 1998a) thus supporting the idea of there being a segregation role for the perirhinal cortex along the dorsal-ventral axis.

\section{Function}

\subsection{Introduction}

The main behavioural role identified for the perirhinal cortex is recognition memory (Mumby and Pinel, 1994; Suzuki, 1996; Liu and Bilkey, 2001; Mumby et al., 2002b, 2007; Winters and Bussey, 2005a; Hannesson et al., 2005; Albasser et al., 2009; Brown et al., 2010) but roles for the perirhinal cortex in fear conditioning (Suzuki, 1996) and in spatial memory-related tasks (Wiig and Bilkey, 1994; Glenn et al., 2003; Abe et al., 2009) will also be discussed. Additionally, we will review the developing evidence for the perirhinal cortex in perceptual processing that is typically not addressed in the wider learning and memory literature (Bussey et al., 2003, 2005).

Previous functional reviews of the perirhinal cortex tend to focus primarily on its role in recognition memory, especially in relation to other areas of the medial temporal lobe. Here we offer a more general overview of the perirhinal cortex and attempt to integrate the functional data with the anatomical and physiological data previously reviewed. As such, our focus will be on lesion studies, immediate early gene expression studies and electrophysiological recordings in the perirhinal cortex in the behaving animal. Each of these methodological approaches has their own advan- 
tages and disadvantages but looking at them in parallel with the anatomical and physiological data previously described, we hope to evaluate, where possible, the hypothesis that there are functional differences between the different regions of the perirhinal cortex. In addition, where information is available, we will highlight that suggestion that the anatomical segregation of the connectivity between the perirhinal cortex and other regions may also have a bearing on the different functional roles of the perirhinal cortex.

\subsection{The perirhinal cortex and perception}

At the root of many of the perirhinal cortex's functions is its role in discriminating between stimuli. However, a distinction must be made between the perirhinal cortex's role in discriminating between stimuli in general (e.g. one light from another) and being able to discriminate between familiar and novel stimuli (e.g. an object encountered during a previous trial and a new object that the animal has never encountered before). Some early studies have shown that discrimination between stimuli can occur independently of the perirhinal cortex: combined lesion of the rhinal region and area TE did not significantly impair rats on a visual discrimination task (Aggleton et al., 1997) and ablation of the rhinal region does not impair rats in the acquisition of an object discrimination task (Mumby and Pinel, 1994). Both these studies suggest that stimulus discrimination may not be one of the perirhinal cortex's primary functions even if it requires an ability to discriminate stimuli in order to perform its role as a novelty detector. Some subsequent studies showed that the perirhinal cortex may be involved more in a mnemonic rather than a sensory capacity (Albasser et al., 2009), i.e. once a delay is introduced, performance becomes largely perirhinal cortex-dependent (Wiig and Bilkey, 1995). Animals with perirhinal cortex lesions showed impairments in acquisition and retention in a visual discrimination task but performed similarly to controls on the first day of the experiment, showing no apparent impairment in visual discrimination but did show impairments in recognition memory (Myhrer and Wangen, 1996; Myhrer, 2000). These findings indicate that the parahippocampal region may be involved in stimulus discrimination but only the perirhinal cortex is needed to form a memory based on discrimination (see Section 4.3 for a more in depth review of the perirhinal cortex's role in recognition memory).

However, over the last decade there has been a growing body of evidence to suggest that the perirhinal cortex has a role in nonmnemonic functions such as perception (Murray and Bussey, 1999; Bussey et al., 2002, 2005). In the perceptual-mnemonic/ feature-conjunction (PMFC) model, an argument is made using evidence from non-human primate (Bussey et al., 2003, 2005) and human studies (Lee et al., 2005) that the perirhinal cortex becomes involved in perception when the perceptual load increases. They suggest that in this capacity the perirhinal cortex acts as part of the ventral visual stream in addition to being part of the medial temporal lobe as it is traditionally classified. There have been a few studies in rats which have supported this view from primates that the perirhinal cortex may play a role in perceptual processes; rats with lesions of the perirhinal cortex are impaired on a memoryindependent visual discrimination task (Gaffan et al., 2000) and on a visual discrimination task where stimulus interference is employed (Gilbert and Kesner, 2003). Recently, antagonism of perirhinal $G_{A B A}$, NMDA and muscarinic receptors in rats prior to training disrupts acquisition of an object recognition tasks which, although not conclusive, supports the PMFC model in that the task most likely relies on both perceptual and mnemonic processing (Winters et al., 2010).

Rats have been shown to be able to discriminate between complex visual stimuli such as photographs and geometric shapes as well as typical simple stimuli such as lights (e.g. rats can competently discriminate between two different photos or two different geometric shapes; Forwood et al., 2007; Bussey et al., 2008). Additionally, the perirhinal cortex has been implicated in the discrimination of complex stimuli; rats with perirhinal lesions showed greater impairments on a visual discrimination task when the stimuli were composed of complex overlapping features (Eacott et al., 2001) and in a configural learning task utilising complex visual-tactile stimuli (Moran and Dalrymple-Alford, 2003). The PMFC model predicts that the perirhinal cortex is used to resolve feature ambiguity in situations where a particular feature of an object may represent different outcomes depending on the context it is presented in (Bussey and Saksida, 2002). Further support for the PMFC model comes from primate studies where hippocampal lesions did not impair performance on tasks utilising stimuli with ambiguous features, suggesting that the ventral visual stream rather than the medial temporal lobe was required to solve the task (Saksida et al., 2006, 2007).

This idea of the perirhinal cortex acting in an associative role to govern over the processing of complex stimuli is supported by evidence from fear conditioning studies where the rostral perirhinal cortex has been shown to be required for processing contextual and multimodal information (Rosen et al., 1992; Corodimas and LeDoux, 1995; Kyuhou et al., 2003). More recently, the PMFC model has been shown to perhaps underpin certain forms of recognition memory (Bartko et al., 2007) which indicates that the perceptual and mnemonic roles of the perirhinal cortex are not exclusive to each other. Bartko et al. (2010) have since used a computerised PMFC model and in vivo study in rats to predict that the memory impairments observed following lesions of the perirhinal and postrhinal cortices are due to a continuum of perceptual and mnemonic processes being disrupted.

However, there is still controversy over how the perirhinal acts as an association area and in what situations is the perirhinal cortex needed. Lesions of the perirhinal cortex or a combined lesion of the perirhinal and postrhinal cortices failed to impair configural learning in a biconditional visual discrimination task (Davies et al., 2007). Recently, another study again failed to find a deficit in learning a configural visual discrimination task following perirhinal lesions in rats (Aggleton et al., 2010). These findings fail to support the PMFC model, showing that rats can still learn configural tasks in the absence of the perirhinal cortex or indeed complete disruption of the parahippocampal region. Horne et al. (2010) argue against the PMFC model as it stands in their study in which rats with perirhinal cortex lesions had to solve a water maze task based on context (the hidden platform was in one of two locations indicated by the two different contexts: white walls and black walls). However, they recognise that the stimuli may not be sufficiently complex to result in an impairment which raises the question of how complex a stimulus must be in order for the perirhinal cortex to be needed? Moreover, from the rats perspective, this change in context may be regarded as a more global change (i.e. it is a new environment as opposed to a change in wall colour) and therefore may rely on areas of the brain devoted to spatial processing. This is supported by a previous study which found that the perirhinal cortex was not necessarily required for associative learning in all situations and that the relationship between stimuli and rewards determines whether the perirhinal cortex is recruited or not (Eacott et al., 2003).

One final caveat to be taken from this stream of perirhinal cortex research is that the observations made in primate studies to form the PMFC model (Bussey et al., 2003, 2005) may not translate to rats. While the perirhinal and postrhinal cortices of the rat are respectively analogous to the perirhinal and parahippocampal cortices of the primate (Burwell et al., 1995; Burwell, 2000), this is not to say that all the functions ascribed to these regions can be 
translated between these species. The brains of primates are more adapted to visual information compared to rodents and therefore more elaborate visual processing may occur in the primate parahippocampal region compared to rats. Further work needs to be undertaken to determine whether the PMFC model is as powerful in rodents as it is in primates. Provided the PMFC model holds true, it represents an intriguing alternative to the traditional view of the brain as a jigsaw of interconnected modules but instead parts of the brain can work in more than one capacity (i.e. the perirhinal cortex is both perceptual and mnemonic in its function; Bussey and Saksida, 2007; Cowell et al., 2010a,b).

\subsection{Object recognition memory}

Out of all perirhinal functions, object recognition memory has undergone the most scrutiny. Object recognition memory is an animal's capability to remember whether they have encountered an object before, i.e. the ability to detect old from new. The standard behavioural test for this recognition memory is the object recognition task. In this task, animals are exposed to a set of objects in the training phase and in the testing phase, one of the objects from the training phase is replaced with a novel object. Animals should preferentially explore this novel object over the other familiar objects (Ennaceur and Delacour, 1988). Ennaceur and Delacour (1988) propose that the strength of this task is that it reflects spontaneous behaviour in the animal, therefore it is a "pure" memory test without the need for any rule learning and as such, it is easily comparable across species. Recently, there have been a number of comprehensive reviews of the object recognition task and in particular we refer the reader to reviews on the one trial object recognition task (Dere et al., 2007) and on the neural substrates underlying recognition memory (Eichenbaum et al., 2007; Brown et al., 2010; Clark and Squire, 2010; Warburton and Brown, 2010).

Recognition memory itself can be divided into two broad processes: familiarisation and recollection (Aggleton and Brown, 2006; Brown et al., 2010; Warburton and Brown, 2010). These two processes are difficult to dissociate in animal models, where familiarity ends and recollection begins is up for debate (Wixted and Squire, 2008; and see Wixted et al., 2010 for how this is being addressed in human medial temporal lobe studies) but Brown and Aggleton (2001) have predicted that the perirhinal cortex should underlie familiarisation and the hippocampus should be involved in recollection. This hypothesis is supported by the anatomy and physiology of the hippocampal-parahippocampal network (see Section 3.1) and lesion studies where performance on recollectiontype but not familiarity-type recognition memory tasks have been impaired following hippocampal lesions (Eacott and Easton, 2007; Easton and Eacott, 2010).

Successful completion of the object recognition task requires the ability to discriminate between stimuli. Lesions of the perirhinal cortex have been shown to impair performance on a simple visual discrimination task (Myhrer, 2000) and, more recently, the perirhinal cortex's ability to perceive and discriminate between complex stimuli seems to play a role in recognition memory (Cowell et al., 2006, 2010a; Murray et al., 2007). Other research seem to confirm this hypothesis that the perirhinal cortex acts as an area where complex stimuli are processed; it has been shown to be involved in discriminating between stimuli composed of complex, overlapping components (Eacott et al., 2001) and in resolving configural feature ambiguity in object recognition memory (Bartko et al., 2007).

Evidence for the validity of the object recognition task as a test of memory come from initial studies which showed that nootropic drugs enhanced performance in the task (Ennaceur et al., 1989) and systemic antagonism of cholinergic neurotransmission causes a time-dependent impairment in object discrimination (Ennaceur and Meliani, 1992a). Immediate early gene imaging studies have shown that the perirhinal cortex is activated following object recognition tasks (Wan et al., 1999; Aggleton and Brown, 2005; Warburton et al., 2005) and following the presentation of novel visual stimuli (Zhu et al., 1995b, 1996, 1997), thus indicating that the perirhinal cortex plays a central role in novelty detection. Lesions of the perirhinal cortex have been shown to impair performance in the object recognition task (Ennaceur et al., 1996; Ennaceur and Aggleton, 1997) and more recent work has shown that the perirhinal cortex is required for the encoding, consolidation and retrieval of object recognition memory (Winters and Bussey, 2005a,b; Winters et al., 2008). Yet, recently it has been suggested that perirhinal lesions do not impair memory formation but may instead cause the occurrence of false memories; rats with perirhinal cortex lesions show a number of false positive hits on a modified version of the object recognition task as they treated novel objects as familiar (McTighe et al., 2010). McTighe et al. (2010) also demonstrated that this false memory was due to interference between the training and testing phases of the task; putting the rats in a visually restrictive environment restored the perirhinal cortex lesioned rats to the same levels of object exploration as the controls.

Nevertheless, the idea of the perirhinal cortex as a novelty detector has been confirmed in a number of studies. Electrophysiological recordings in the hippocampus and parahippocampal region of cortex in freely moving rats have shown differential neuronal responses to familiar and novel visual stimuli (Zhu et al., 1995a). The same group also demonstrated that the neuronal processing for familiarity could be separated from the neuronal processing required for recognising repetition of stimuli (Zhu and Brown, 1995; Zhu et al., 1995a). Recently, exercise-induced enhancement in performance in a novel object recognition task has been associated with concurrent increases in perirhinal BDNF expression in the rat (Hopkins and Bucci, 2010) and interference of perirhinal BDNF signalling has been shown to disrupt long-term recognition memory (Seoane et al., 2011). Immediate early gene imaging studies also show that perirhinal cortex is recruited during recognition tasks; there is increased c-Fos expression in the perirhinal cortex following exposure to novel visual stimuli (Zhu et al., 1995b, 1997; Wan et al., 1999) but not after exposure to familiar visual stimuli (Zhu et al., 1996).

Despite a large proportion of the research on recognition memory being centred around visual recognition memory, the perirhinal cortex has been shown to be involved in recognition memory in other modalities. Rats with perirhinal-entorhinal lesions were found to be impaired in an olfactory recognition memory tasks (Kaut and Bunsey, 2001; Kaut et al., 2003). Electrophysiological recordings during delayed non-matching tasks also show a role for the perirhinal cortex (Young et al., 1997) and prefrontal cortex (Ramus and Eichenbaum, 2000) in olfactory discrimination. Bearing in mind the anatomical connections between the perirhinal cortex and olfactory regions (see Section 3.2) and that many object recognition studies in rats rely on nose contact as a measure of exploration, it is surprising that more attention has not been focussed on the role of the perirhinal cortex in olfactory recognition memory. These reported findings show that there it is an area that is likely to yield interesting findings.

In comparison to visual and olfactory recognition memory, there is less evidence to suggest that it plays a role in auditory recognition memory; the perirhinal cortex showed no significant changes in c-Fos expression following an auditory recognition task (Wan et al., 2001) and a similar study in dogs reinforces this finding (Kowalska et al., 2001). However, the door on the perirhinal cortex's role in auditory recognition is not fully closed. As well as 
the perirhinal cortex being an important structure in acoustic fear conditioning tasks (see Section 4.4), there is a differential pattern of c-Fos expression in the rat brain following exposure to two different acoustic stimuli; the perirhinal cortex was only activated following exposure to the $22 \mathrm{kHz}$ stimulus and not the $50 \mathrm{kHz}$ stimulus (Sadananda et al., 2008). Although this study does not in itself look at recognition of these stimuli (both are novel stimuli), $50 \mathrm{kHz}$ vocalisations in rats are common during positive social and play interactions whereas $22 \mathrm{kHz}$ vocalisations are associated more with aversive situations (Panksepp, 2007). There is a possibility that to rats kept in captivity with adequate food, water and social interaction might be more familiar with $50 \mathrm{kHz}$-like vocalisations and $22 \mathrm{kHz}$ vocalisations may be more unusual and therefore novel in this context. The more likely explanation is that perirhinal cortex is acting as an associative area for these auditory stimuli but considering the reciprocal projections between auditory areas and the perirhinal cortex, we would be surprised if there was no novelty detection role for the perirhinal cortex for acoustic stimuli. The role of the perirhinal cortex in auditory function is reviewed further in Section 4.4 in relation to fear conditioning in the rat.

Despite the need for perirhinal cortex in novelty detection, a number of other regions are recruited during visual novelty detection. Visual cortex, temporal association cortex, entorhinal cortex, cingulate cortex, thalamus and the hippocampus all show signs of activity during visual recognition tasks although in some cases (such as the thalamus and the hippocampus) the activity is minor compared to other areas (Zhu and Brown, 1995; Zhu et al., 1995a,b, 1997). The perirhinal cortex has been shown to be connected to each of these areas and many of these projections have been shown to be capable of transferring electrophysiological information (see Sections 3.1 and 3.2). In these freely moving animal experiments, perirhinal recordings were located mainly in superficial layers and, as described in Section 3.2, this is where a large proportion of the perirhinal cortex's sensory afferents and efferents are located. As immediate early gene imaging and lesion studies have either poor or no temporal resolution, it is difficult to determine the route and order of activation across these many areas during recognition learning and recall. The need for multiarray electrophysiological and biosensor studies is apparent to deduce how these disparate regions are interacting with each other in the behaving animal.

However, even though a number of areas show activity during recognition tasks, lesion studies have shown that it is the perirhinal cortex that plays the major role in recognition memory. Lesions of the perirhinal cortex lead to impairments in tasks that require cross-modal integration; perirhinal-lesioned rats who were allowed to explore objects by tactile exploration only could not recognise the same object using visual-only information but control rats could perform this task without problem (Winters and Reid, 2010). Winters and Reid (2010) also demonstrate that this cross-modal integration requires the parietal cortex for processing tactile information whereas the perirhinal seemed to be involved only in processing of visual information. There has been a functional dissociation shown between the roles of the perirhinal cortex and the hippocampus (Aggleton and Brown, 2005). Lesions of the perirhinal cortex result in impairments in recognition but not spatial tasks whereas lesions of the hippocampus result in impairments in spatial but recognition tasks (Ennaceur and Aggleton, 1994; Bussey et al., 2000; Abe et al., 2009). Similarly, electrophysiological (Zhu and Brown, 1995; Zhu et al., 1995a) and c-Fos studies (Zhu et al., 1996, 1997; Wan et al., 1999; Jenkins et al., 2004; Amin et al., 2006) have shown that the perirhinal cortex is recruited more during recognition than spatial tasks and vice versa for the hippocampus. There is mounting evidence to suggest that the hippocampus may indeed play a role in recognition memory
(Hammond et al., 2004; Prusky et al., 2004) but the overwhelming consensus is that the perirhinal cortex alone is sufficient for completing recognition memory tasks. A pair of recent reviews compares data from human, non-human primate and rodent studies to argue that the hippocampus may be required more for aspects of recognition memory distinct from pure novelty discrimination such as in tasks that require working spatial and temporal order memory in addition to recognition memory in order to solve them (Brown et al., 2010; Warburton and Brown, 2010).

Molecular, pharmacological and physiological evidence have further strengthened the case for the importance of the perirhinal cortex in object recognition memory. Additionally, the case for synaptic plasticity being the physiological process underlying memory is also supported by these studies. Benzodiazepineinduced impairments in object recognition memory have been described, indicating that GABAergic neurotransmission is required for this form of learning (Longone et al., 1996; BertainaAnglade et al., 2006). In rats, administration of the benzodiazepine lorazepam to the perirhinal cortex impairs recognition memory and when applied to perirhinal slices, it also disrupts both LTP and LTD (Wan et al., 2004). In the perirhinal cortex, antagonism of Ltype voltage-dependent $\mathrm{Ca}^{2+}$ channels (Seoane et al., 2009) and of CREB signalling (Warburton et al., 2005) have also been shown to impair perirhinal LTD and object recognition memory. Taken together, the evidence would suggest that long-term synaptic plasticity is involved in recognition memory formation.

There is much evidence to support this claim as glutamatergic signalling, crucial for synaptic plasticity, is also required for object recognition memory (de Lima et al., 2005; Winters and Bussey, 2005b; Barker et al., 2006a; Nilsson et al., 2007; Barker and Warburton, 2008). In rats, the perirhinal administration of AP-5 (Winters and Bussey, 2005b; Barker et al., 2006a) or systemic administration of MK-801 (de Lima et al., 2005; Nilsson et al., 2007) impairs object recognition tasks performance by disrupting glutamatergic signalling via the NMDA receptor. Similar pharmacological challenges of the NMDA receptor also disrupt perirhinal LTP and LTD (Ziakopoulos et al., 1999; Cho et al., 2000; Cho and Bashir, 2002; Karasawa et al., 2008). The AMPA receptor has also been implicated in both object recognition memory (Winters and Bussey, 2005b) as well as baseline neuronal transmission (Park et al., 2006) and synaptic plasticity (Griffiths et al., 2008) in the perirhinal cortex. Additionally, a role for the kainate receptor in object recognition memory (Barker et al., 2006a) and perirhinal synaptic plasticity (Park et al., 2006) has been proposed. Functional dissociations have already been shown between NMDA and kainate receptors; kainate receptors mediate recognition memory at short but not long delays whereas NMDA receptors mediate recognition memory at long but not short delays (Barker et al., 2006a). In another study, Barker et al. (2006b) demonstrate that perirhinal mGlu receptors are also involved in recognition memory. They have shown that simultaneous antagonism of group I and II (but not group III) mGlu receptors in perirhinal cortex results in impaired acquisition in an object recognition task when tested after $24 \mathrm{~h}$. They also report that there is no short-term memory impairment, that separate antagonism of either type of mGlu receptor has no effect on recognition memory and that mGlu receptor antagonism has no effect on consolidation of recognition memory (Barker et al., 2006b). Bearing in mind the contribution of mGlu receptors to synaptic plasticity in the perirhinal cortex (McCaffery et al., 1999; Cho et al., 2000; Cho and Bashir, 2002), we predict that interactions between perirhinal NMDA and mGlu receptors may underlie object recognition memory.

Simultaneous blockade of both NR2A and NR2B NMDA receptor subtypes in the perirhinal cortex lead to impairments an object recognition task (Barker et al., 2006a). As the NR2A subunit is 
associated with LTP and the NR2B subunit is associated with LTD (Massey et al., 2004; Toyoda et al., 2005; Bartlett et al., 2007; Yashiro and Philpot, 2008), this implies that both perirhinal LTPand LTD-like processes are required for the formation of object recognition memories. Furthermore, transgenic overexpression of the NR2B subunit in hippocampal and cortical neurons enhances performance in an object recognition task yet does not promote LTD in the area CA1 (Wang et al., 2009) which is a conflicting finding compared to the majority of research in this area. There are a large number of molecular mechanisms involved in object recognition memory that are correlated with LTD including L-type voltage-dependent $\mathrm{Ca}^{2+}$ channels (Seoane et al., 2009), CREB (Warburton et al., 2005), muscarinic cholinergic receptors (Warburton et al., 2003; Massey et al., 2008), GABA receptors (Wan et al., 2004) mGlu receptors (Barker et al., 2006a; Moult et al., 2006), NMDA receptors (Cho et al., 2000, 2002; Roberts et al., 2009; Winters et al., 2010), kainate receptors (Barker et al., 2006a; Park et al., 2006; Holman et al., 2007) and AMPA receptor internalisation (Griffiths et al., 2008). Therefore, although both LTP and LTDlike processes might be involved in object recognition memory, it would appear that an LTD-like process is the principle physiological mechanism underlying recognition memory.

\subsection{The role of the perirhinal cortex in fear conditioning}

Another learning paradigm that appears to require the perirhinal cortex in the rat is fear conditioned learning (Falls et al., 1997; Sacchetti et al., 1999; Otto et al., 2000; Schulz et al., 2004; Davis, 2006; Albrechet-Souza et al., 2011). Here the perirhinal cortex plays more of an associative role compared to its role in recognition memory (Kholodar-Smith et al., 2008b). Based on the anatomical projections described in Sections 3.2 and 3.3 , it is not surprising that the perirhinal cortex is required for such associational learning as it forms a significant reciprocal connections with the amygdala (Krettek and Price, 1974, 1977; Ottersen, 1982; McDonald and Jackson, 1987; Pitkänen et al., 2000; Pikkarainen and Pitkänen, 2001; Furtak et al., 2007b), thalamus (Cornwall and Phillipson, 1988; Wouterlood et al., 1990; Shibata, 1993; McIntyre et al., 1996; Van Groen et al., 1999; Vertes et al., 2006), medial prefrontal cortex (Deacon et al., 1983; Sesack et al., 1989; Burwell and Amaral, 1998b; Delatour and Witter, 2002; Heidbreder and Groenewegen, 2003; Jones and Witter, 2007; Agster and Burwell, 2009) and hippocampus (Swanson and Cowan, 1977; Deacon et al., 1983; Kosel et al., 1983; Van Groen and Wyss, 1990; McIntyre et al., 1996; Naber et al., 1999; Shi and Cassell, 1999; Witter et al., 1999; Kloosterman et al., 2003b); regions of the brain which have been strongly linked with fear conditioning (Milad et al., 2006; Rosen and Donley, 2006).

Fear conditioning tasks can be quite varied with different studies using different forms of stimuli across the various sensory modalities to condition subjects and visual, auditory, olfactory, and contextual paradigms have all been explored in the general fear conditioning literature and a number of studies have implicated the perirhinal cortex in visual (Rosen et al., 1992; Campeau et al., 1997; Shi and Davis, 2001), auditory (Campeau et al., 1997; Sacchetti et al., 1999; Kyuhou et al., 2003; Bruchey and GonzalezLima, 2006; Kholodar-Smith et al., 2008a,b; Bang and Brown, 2009a,b), olfactory (Herzog and Otto, 1997, 1998; Otto et al., 2000) and contextual fear conditioning (Sacchetti et al., 1999; Bucci et al., 2000; Burwell et al., 2004a; Kholodar-Smith et al., 2008a,b; SchulzKlaus, 2009). Electrophysiological recordings made in the perirhinal cortex during trace conditioning using auditory stimuli (Furtak et al., 2007c) and immediate early gene imaging shows increased levels of c-Fos in the perirhinal cortex following a fear conditioning task (Campeau et al., 1997). Antagonism of perirhinal muscarinic acetylcholinergic receptors using scopolamine has been shown to disrupt trace conditioning using auditory stimuli (Bang and Brown, 2009a). Perirhinal lesions also disrupt trace conditioning using auditory stimuli (Kholodar-Smith et al., 2008a,b).

However there is some controversy as to when and how the perirhinal cortex is utilised during fear conditioning and indeed, the entire parahippocampal region has been implicated in contextual fear conditioning (Burwell et al., 2004b; AlbrechetSouza et al., 2011). Initial work suggested that the perirhinal cortex was required only for the retrieval of fear conditioning-related memory (Campeau and Davis, 1995) but that view is not widely held now. The perirhinal cortex seems to be not only required for different forms of the task but also that there seems to be subdivision within the perirhinal cortex; temporary lesions of area 36 have no impact on the retrieval of fear memories using auditory stimuli (Sacchetti et al., 2007) nor do permanent lesions of the caudal perirhinal cortex on the retrieval of visual conditioned fear memories (Rosen et al., 1992). Yet lesions of the rostral perirhinal cortex cause a complete attenuation of fear conditioned responses (Rosen et al., 1992) and prevent the electrophysiological propagation of auditory stimuli to the motor cortices in a fear conditioning study (Kyuhou et al., 2003). Lesions of the rostral perirhinal cortex also lead to an attenuation of olfactory fear conditioning while sparing contextual fear conditioning (Herzog and Otto, 1997, 1998; Otto et al., 2000) and this sparing of contextual fear conditioning following perirhinal lesions has been confirmed by other groups (Phillips and LeDoux, 1995). However, other studies have shown that similar sized lesions in the same location (Corodimas and LeDoux, 1995) and larger ablations of the entire perirhinal cortex disrupt contextual fear conditioning (Sacchetti et al., 1999; Bucci et al., 2000, 2002; Burwell et al., 2004a). More generally temporary inactivation of the rostral perirhinal cortex seems to have an anxiolytic effect in an unconditioned fear task (Schulz-Klaus et al., 2005), this along with many of the above studies singling out the rostral region of the perirhinal cortex as being particularly important when it comes to emotional learning.

In studies which have used specific ultrasonic vocalisations as auditory stimuli instead of "abstract" continuous tones, some intriguing findings have turned up. As mentioned in Section 4.3, the perirhinal cortex only activates following exposure to $22 \mathrm{kHz}$ ultrasonic vocalisations and not following $50 \mathrm{kHz}$ ultrasonic vocalisations (Sadananda et al., 2008). Furthermore, a multitude of recent studies have shown that discontinuous tones (including ultrasonic vocalisations) recruit the perirhinal cortex but continuous tones do not (Kholodar-Smith et al., 2008a; Bang and Brown, 2009b). Confirmation of these findings come from electrophysiological data which shows that there are different firing patterns observed in the perirhinal cortex during exposure to discontinuous tones compared to continuous tones (Furtak et al., 2007c) and from lesions of the perirhinal cortex where there is impairment of conditioning to ultrasonic vocalisations but not to continuous tones (Lindquist et al., 2004). These results fit with the data generated from recognition and fear conditioning tasks where the perirhinal cortex is required for processing more complex stimuli and contexts (Corodimas and LeDoux, 1995; Sacchetti et al., 1999; Bucci et al., 2000, 2002; Bussey et al., 2000; Eacott et al., 2001; Burwell et al., 2004a).

Overall, this points to an associative role for the perirhinal cortex and, as in recognition memory, contextual processing most likely require interaction with the amygdala (Romanski and LeDoux, 1992b; Campeau and Davis, 1995; Sacchetti et al., 1999, 2007), thalamus (Romanski and LeDoux, 1992a,b; Sacchetti et al., 1999; Shi and Davis, 2001), medial prefrontal cortex (Goldstein et al., 1994; Campeau et al., 1997; Sacchetti et al., 2002) or the hippocampus (Phillips and LeDoux, 1995; Sacchetti et al., 1999). However, the perirhinal cortex's role in recognition memory 
cannot be discounted as recognition and familiarity do seem to be part of the perirhinal cortex's role in fear conditioning; the rostral ventral perirhinal cortex shows increased c-Fos expression when the animal is exposed to previously acquired (i.e. familiar) associations (Schettino and Otto, 2001). However, it is clear from the research that the rostral perirhinal cortex along with its connections with the amygdala, thalamus, medial prefrontal cortex and hippocampus is subserving functions distinct from its traditional role as a novelty detector.

\subsection{The role of the perirhinal cortex in context and spatial memory}

Initial research into the roles of the hippocampus and the perirhinal cortex and their respective contributions to spatial memory portrayed a simple dissociation between the two areas; animals with perirhinal lesions are impaired on object recognition but not spatial memory tasks (Aggleton et al., 1997; Ennaceur and Aggleton, 1997; Glenn and Mumby, 1998; Bussey et al., 1999; Machin et al., 2002) and animals with hippocampal lesions are impaired on spatial but not object recognition memory tasks (Ennaceur et al., 1997; Mumby et al., 2002a). Double dissociation studies confirmed these findings showing that animals with hippocampal lesions showed impairments in recognition memory but not in spatial memory and those with perirhinal lesions showed impairments in spatial memory but not in recognition memory (Ennaceur et al., 1996; Bussey et al., 2000; Winters et al., 2004). This dissociation between hippocampal and perirhinal function was conserved across rat strains (Futter et al., 2006) and species (Pihlajamäki et al., 2004; Buckley, 2005; Köhler et al., 2005). Furthermore, immediate early gene imaging supports these lesion studies whereby c-Fos levels are increased in the hippocampus but not the perirhinal cortex during spatial learning tasks and they are increased in the perirhinal cortex but not the hippocampus during recognition tasks (Vann et al., 2000a; Aggleton and Brown, 2005).

Although the perirhinal cortex is not required for learning spatial memory-dependent tasks like the Morris water maze (MWM; Machin et al., 2002; Burwell et al., 2004b; Moses et al., 2005) or the radial arm maze (Vann et al., 2000; Machin et al., 2002; Moran and Dalrymple-Alford, 2003), it has been implicated in solving tasks that require a spatial awareness if not specifically tests of spatial memory. For example, the perirhinal cortex has been implicated in object-in-place associative learning (Bussey et al., 2000, 2001; Barker and Warburton, 2008, 2009), spatial reference memory (Wiig and Bilkey, 1994; Abe et al., 2009) and long-term spatial memory (Glenn et al., 2003). However, these impairments are probably not due to the perirhinal cortex playing a specific role in encoding spatial memory but possibly due to impairments in cue or context recognition (see Aggleton et al., 2004 for a review of this problem in the human research literature).

Yet, there are aspects of spatial memory that have been reported to require the perirhinal cortex (Aggleton and Brown, 2005); for example, situations involving spatial novelty may require dual activation of the hippocampus and the perirhinal cortex (VanElzakker et al., 2008). However, it has also been shown that activation of the hippocampus and not the perirhinal cortex was observed following successful performance in tasks requiring the learning of novel spatial locations for familiar objects (Jenkins et al., 2004) and temporal changes in spatial order (Amin et al., 2006). This apparent spatial component of perirhinal function may be explained by anatomical classifications; that different research groups use one of the two main alternative definitions of the perirhinal cortex (one that includes the postrhinal cortex as being part of the perirhinal cortex and the other that classifies the perirhinal and postrhinal cortices as separate regions, see Section 2.1).
Therefore, the variance in the literature may be due to reporting deficits associated with the postrhinal cortex to the perirhinal cortex. The majority of perirhinal lesion studies that spare the postrhinal cortex do not show deficits in spatial memory (Ennaceur et al., 1996; Ennaceur and Aggleton, 1997; Glenn and Mumby, 1998; Liu and Bilkey, 1998a; Machin et al., 2002; Moran and Dalrymple-Alford, 2003; Moses et al., 2005; Futter et al., 2006) but one study of perirhinal-only lesions has demonstrated deficits in object-place memory but not allocentric spatial memory (Bussey et al., 2001). Perirhinal lesion studies that do report spatial memory deficits also show some damage to the postrhinal cortex (Mumby and Glenn, 2000; Glenn et al., 2003) or also involve entorhinal cortex lesions (Nagahara et al., 1995). One combined perirhinal and postrhinal lesion study has reported impairments in spatial memory (Liu and Bilkey, 2001) but a number of other combined perirhinal and postrhinal lesion studies showed no deficits in spatial memory (Aggleton et al., 1997; Bussey et al., 1999, 2000; Winters et al., 2004).

Functional differences between the perirhinal and postrhinal cortices have also been demonstrated; there is differential activity between the postrhinal and perirhinal cortices following spatial memory tasks (Vann et al., 2000a). Lesions of the postrhinal cortex do not result in substantial changes in place cell firing in the area CA1 (Nerad et al., 2009) whereas lesions of the perirhinal cortex result do cause disruption of CA1 place cell function (Muir and Bilkey, 2001). However, in this latter study there appeared to be some damage to the postrhinal cortex which prevents its role in spatial processing from being ruled out and as both of these investigations in parahippocampal effects on place cell function utilised different lesioning techniques which may have resulted in differential secondary effects in the hippocampus (Glenn et al., 2005). In spite of some contradictions, these studies indicate that the postrhinal cortex may form part of a separate functional circuit in the hippocampal-parahippocampal network compared to the perirhinal cortex (Aggleton et al., 2000; Furtak et al., 2007b; and see Section 5 below for physiological justification of this proposal). These perirhinal and postrhinal functional circuits may govern different aspects of associative memory and as perirhinal cortex lesions more often than not spare spatial memory function, the postrhinal cortex may play a larger role in spatial memory. However, there does not appear to be a complete dissociation between the two cortical areas across all aspects of spatial memory.

The divergence in the literature as regards hippocampal and perirhinal contributions to spatial memory may also be due to the types of test utilised (Mumby and Glenn, 2000). Allocentric spatial memory tests like the MWM may exploit a completely different set of neuronal processes compared to tests of spatial memory that do not rely on navigation (Aggleton et al., 2000). Both the perirhinal and postrhinal cortex contribute to contextual associations for long-term memory (Burwell et al., 2004a) but this contextual association does not appear to be necessary for all forms of spatial learning; lesions of the hippocampus and the parahippocampal region suggest allocentric spatial memory can occur without the need for parahippocampal-dependent contextual associative learning (Burwell et al., 2004b) and rats with lesions of the perirhinal cortex are unimpaired in a delayed-matching-to-place task (Glenn and Mumby, 1998). Therefore, in studying the role of the perirhinal cortex in spatial memory, tasks that focus on the contextual properties and not on allocentric properties of spatial memory have been developed.

In order to study the effect of context on perirhinal cortex function, two main spatial variations of the object recognition task have been developed which require integration of spatial and novelty awareness without being strictly spatial memory tasks. In the object displacement task, animals are again exposed to a set of 
objects in the training phase but in the testing phase, instead of a novel object being introduced, one of the familiar objects is moved to a novel location where there was no object previously and animals should explore this moved object preferentially over the other objects (Ennaceur and Meliani, 1992b). Training regimes that can impair allocentric spatial memory can also impair performance in the object displacement task (Commins et al., 2003) and manipulation of distal and proximal cues can also result in object displacement task deficits (Craig et al., 2005). These findings suggest that the hippocampus may have a role in this type of spatial learning. This form of learning appears to require expression of neurotrophins (Calamandrei et al., 2002; Niewiadomska et al., 2006) and exercise-induced enhancement of task performance has been associated with increases in hippocampal and perirhinal BDNF (Griffin et al., 2009). Furthermore, successful performance of the task is dependent on glutamatergic signalling through NMDA (Roullet et al., 1996; Usiello et al., 1998; Larkin et al., 2008) and AMPA receptors (Roullet et al., 2001). A dopaminergic component has also been identified (Roullet et al., 1996; Mele et al., 2004) and interactions between these glutamate and dopamine systems in the nucleus accumbens have been implicated in the consolidation of this task (Ferretti et al., 2005).

In the second spatial variation of the object recognition task, the object-in-place task, rats are exposed to four objects in the training phase and two of the objects switch their positions in the testing phase (although, unlike the object displacement, they are still occupying positions where an object had been previously located in the training phase) and animals should explore these moved objects preferentially over the other objects (Bussey et al., 2000). Although no lesion studies have yet been published on the roles of the hippocampus and perirhinal cortex in the object-in-place task, perirhinal lesions lead to impairments on a radial arm maze variation of the object-in-place task (Bussey et al., 2001). However, Brown et al. (2010) have reported that Barker and Warburton have submitted a study for publication which shows that interaction between the hippocampus and perirhinal cortex in order to complete the object-in-place task. Additionally, perirhinal NMDA receptors have been demonstrated to underlie short-term objectin-place memory (Barker and Warburton, 2008). However, these findings do not rule out hippocampal contributions to the objectin-place task. Lesions of the hippocampus cause impairments in a similarly designed task in the monkey (Gaffan and Harrison, 1989) and also in the rat (Bussey et al., 2000, 2001). Hippocampal lesions in the rat have also shown that the hippocampus does not contribute to object recognition nor object context memories but only to the spatial location where an object has been previously encountered (Piterkin et al., 2008). An elegant study by Barker et al. (2007) have shown that interaction between the perirhinal and medial prefrontal cortices is required in order to solve tasks where association between different forms of memory are required such as the object-in-place task. Functional disconnection of the hippocampus and perirhinal cortex circuit has also been shown to impair performance on an object-place associative memory task (Jo and Lee, 2010). These findings makes sense based on the anatomical projections between the medial prefrontal cortex, the hippocampus and parahippocampal region (see Sections 3.1 and 3.2); these interconnections must serve some functional role and it is logical that this functional role would combine the known functions of these areas (i.e. integration of spatial and object information).

These findings suggest that, although the perirhinal cortex and hippocampus are normally associated with object recognition memory and spatial memory respectively, the contributions of the hippocampus and parahippocampal region to spatial memory are not clearly defined. Further analysis of the hippocampal-parahippocampal network is required in order to fully determine the roles of these various cortical and subcortical areas in the various forms of spatial memory needed to solve these different tasks.

\section{Implications of segregation and functionality}

Examination of the anatomical and electrophysiological properties of the perirhinal cortex reveals that segregation exists both within the structure, within a parahippocampal-hippocampal network, and between the perirhinal cortex and other cortical/ subcortical structures. Unfortunately, many of the lesion and IEG experiments do not take these segregations into account, thereby attributing a particular function to the perirhinal rather than considering this structure (or indeed subregions of this structure) as part of network. Future lesion studies should target multiple regions along this network and from this we should be able to gain a greater sense of how a particular region contributes to this network.

As an example, if we were to accept the idea that there is segregation within the parahippocampal-hippocampal network and the perirhinal contributes in some way to this network what would be the implications of this? Firstly, it may represent a means for separate forms of sensory information to be processed differentially. This would allow visuospatial information from the postrhinal cortex (Burwell and Amaral, 1998b; Burwell and Hafeman, 2003; Furtak et al., 2007b) to be processed while keeping olfactory information from the perirhinal cortex (Herzog and Otto, 1998; Canning et al., 2000; Biella et al., 2003; Santiago and Shammah-Lagnado, 2004) in a separate circuit, perhaps allowing the hippocampus to associate the disparate sensory information if necessary. Secondly, if there is an electrophysiological segregation as well as an anatomical one (along the lines suggested in Fig. 5), these separate excitatory and inhibitory circuits may be involved in regulating neuronal activity along the back-projections from the hippocampus to the neocortex. This, in turn, may not only serve as a means to distinguish and separate different types of information to be consolidated (specific pathways may subserve different types of memories) but may offer a mechanisms of how these memories are consolidated. Interestingly, abnormal perirhinal functioning has been identified as a possible mechanism underlying epileptogenesis (Ferland et al., 1998; Schwabe et al., 2000). Failure of electrophysiologically inhibitory interactions between the perirhinal, postrhinal and entorhinal cortices and the hippocampus leads to increased electrophysiological excitability that may drive epileptogenesis (de Curtis and Paré, 2004). Input from olfactory areas into the perirhinal cortex (Kemppainen et al., 2002; Majak and Pitkänen, 2003) has been shown to increase electrophysiologically excitatory activity within the hippocampal-parahippocampal region (Kelly and McIntyre, 1996). There have been analogous findings in epilepsy studies in humans whereby epilepsy patients exhibit lower tissue volumes in the parahippocampal region compared to controls (Bernasconi et al., 2003a,b).

There could be an important role for these electrophysiologically excitatory and inhibitory projections from the hippocampus to cortical regions in epileptogenesis, with perhaps the 'electrophysiologically inhibitory' projections acting as a control to prevent the spread of seizure like activity through the region. Uncontrolled electrophysiologically excitatory activity (due to over-activation of the excitatory projections or under-activation of the inhibitory projections) may play role medial temporal lobe epilepsy and as such, further electrophysiological examination of the interconnectivity within the hippocampal-parahippocampal network would be a vital step in understanding how epileptiform activity is propagated through the medial temporal lobe. Disconnection studies between the cortices of the parahippocampal region in the rat may provide a way to control kindling activity and prevent seizures from spreading to other neocortical areas. 
Equally, pharmacological dampening of glutamatergic signalling may prevent surplus electrophysiologically excitatory activity from manifesting itself as epileptiform activity. As AMPA receptor antagonism successfully impaired LTP in the CA1 to perirhinal projection and kainate receptors have been implicated in perirhinal functioning (Barker et al., 2006a), focussed research on this system may yield beneficial results for epilepsy treatments.

\section{Conclusions}

This review brings together research encompassing the anatomical nature of the perirhinal cortex, its projections and connectivity, the physiological and plastic properties of the projections, and its role in perception, object recognition, fear conditioning and spatial and/or contextual memory. In addition, we emphasise the idea of an anatomical and electrophysiological segregation. The perirhinal cortex should be considered in terms of segregation within the structure itself, as part of a segregated parahippocampal-hippocampal network and segregated connectivity with other cortical/subcortical structures. The functionality of the perirhinal and the contribution that different regions of the perirhinal make to various circuits may depend on this segregation and therefore should be of primary concern.

\section{Acknowledgement}

\section{Science Foundation Ireland (SFI).}

\section{References}

Abe, H., Ishida, Y., Nonaka, H., Iwasaki, T., 2009. Functional difference between rat perirhinal cortex and hippocampus in object and place discrimination tasks. Behav. Brain Res. 197, 388-397.

Abe, H., Iwasaki, T., 2001. NMDA and muscarinic blockade in the perirhinal cortex impairs object discrimination in rats. Neuroreport 12, 3375-3379.

Aggleton, J.P., Albasser, M.M., Aggleton, D.J., Poirier, G.L., Pearce, J.M., 2010. Lesions of the rat perirhinal cortex spare the acquisition of a complex configural visual discrimination yet impair object recognition. Behav. Neurosci. 124, 55-68.

Aggleton, J.P., Brown, M.W., 2005. Contrasting hippocampal and perirhinal cortex function using immediate early gene imaging. Q. J. Exp. Psychol. B 58, 218-233.

Aggleton, J.P., Brown, M.W., 2006. Interleaving brain systems for episodic and recognition memory. Trends Cogn. Sci. 10, 455-463.

Aggleton, J.P., Keen, S., Warburton, E.C., Bussey, T.J., 1997. Extensive cytotoxic lesions involving both the rhinal cortices and area TE impair recognition but spare spatial alternation in the rat. Behav. Brain Bull. 43, 279-287.

Aggleton, J.P., Kyd, R.J., Bilkey, D.K., 2004. When is the perirhinal cortex necessary for the performance of spatial memory tasks? Neurosci. Biobehav. Rev. 28, 611624.

Aggleton, J.P., Vann, S.D., Oswald, C.J., Good, M., 2000. Identifying cortical inputs to the rat hippocampus that subserve allocentric spatial processes: a simple problem with a complex answer. Hippocampus 10, 466-474.

Agster, K.L., Burwell, R.D., 2009. Cortical efferents of the perirhinal, postrhinal, and entorhinal cortices of the rat. Hippocampus 19, 1159-1186.

Aicardi, G., Argilli, E., Capello, S., Santi, S., Riccio, M., Thoenend, H., Canossa, M., 2004 Induction of long-term potentiation and depression is reflected by corresponding changes in secretion of endogenous brain-derived neurotrophic factor. Proc. Natl. Acad. Sci. U.S.A. 101, 15788-15792.

Albasser, M.M., Davies, M., Futter, J.E., Aggleton, J.P., 2009. Magnitude of the object recognition deficit associated with perirhinal cortex damage in rats: effects of varying the lesion extent and the duration of the sample period. Behav. Neurosci. 123, 115-124.

Albasser, M.M., Poirier, G.L., Aggleton, J.P., 2010. Qualitatively different modes of perirhinal-hippocampal engagement when rats explore novel vs. familiar objects as revealed by c-Fos imaging. Eur. J. Neurosci. 31, 134-147.

Albrechet-Souza, L., Borelli, K.G., Almada, R.C., Brandão, M.L., 2011. Midazolam reduces the selective activation of the rhinal cortex by contextual fear stimuli. Behav. Brain Res. 216, 631-638.

Altar, C.A., O'Neil, S., Walter Jr., R.J., Marshall, J.F., 1985. Brain dopamine and serotonin receptor sites revealed by digital subtraction autoradiography. Science 228, 597-600.

Altar, C.A., Burton, L.E., Bennett, G.L., Dugich-Djordjevic, M., 1991. Recombinant human nerve growth factor is biologically active and labels novel high-affinity binding sites in rat brain. Proc. Natl. Acad. Sci. U.S.A. 88, 281-285.

Altar, C.A., Siuciak, J.A., Wright, P., Ip, N.Y., Lindsay, R.M., Wiegand, S.J., 1994. In situ hybridization of trkB and trkC receptor mRNA in rat forebrain and association with high-affinity binding of [125I]BDNF, [125I]NT-4/5 and [125I]NT-3. Eur. J. Neurosci. 6, 1389-1405.
Amin, E., Pearce, J.M., Brown, M.W., Aggleton, J.P., 2006. Novel temporal configurations of stimuli produce discrete changes in immediate-early gene expression in the rat hippocampus. Eur. J. Neurosci. 24, 2611-2621.

Ansah, O.B., Bourbia, N., Gonçalves, L., Almeida, A., Pertovaara, A., 2010. Influence of amygdaloid glutamatergic receptors on sensory and emotional pain-related behavior in the neuropathic rat. Behav. Brain Res. 209, 174-178.

Arnault, P., Roger, M., 1990. Ventral temporal cortex in the rat: connections of secondary auditory areas Te2 and Te3. J. Comp. Neurol. 302, 110-123.

Bai, W.Z., Ishida, M., Arimatsu, Y., 2004. Chemically defined feedback connections from infragranular layers of sensory association cortices in the rat. Neuroscience 123, 257-267.

Bang, S.J., Brown, T.H., 2009a. Muscarinic receptors in perirhinal cortex control trace conditioning. J. Neurosci. 29, 4346-4350.

Bang, S.J., Brown, T.H., 2009b. Perirhinal cortex supports acquired fear of auditory objects. Neurobiol. Learn. Mem. 92, 53-62.

Barkai, E., Saar, D., 2001. Cellular correlates of olfactory learning in the rat piriform cortex. Rev. Neurosci. 12, 111-120.

Barker, G.R., Bashir, Z.I., Brown, M.W., Warburton, E.C., 2006b. A temporally distinct role for group I and group II metabotropic glutamate receptors in object recognition memory. Learn. Mem. 13, 178-186.

Barker, G.R., Bird, F., Alexander, V., Warburton, E.C., 2007. Recognition memory for objects, place, and temporal order: a disconnection analysis of the role of the medial prefrontal cortex and perirhinal cortex. J. Neurosci. 27, 2948-2957.

Barker, G.R.I., Warburton, E.C., 2008. NMDA receptor plasticity in the perirhinal and prefrontal cortices is crucial for the acquisition of long-term object-in-place associative memory. J. Neurosci. 28, 2837-2844.

Barker, G.R.I., Warburton, E.C., 2009. Critical role of the cholinergic system for object-in-place associative recognition memory. Learn. Mem. 16, 8-11.

Barker, G.R.I., Warburton, E.C., Koder, T., Dolman, N.P., More, J.C., Aggleton, J.P., Bashir, Z.I., Auberson, Y.P., Jane, D.E., Brown, M.W., 2006a. The different effects on recognition memory of perirhinal kainate and NMDA glutamate receptor antagonism: implications for underlying plasticity mechanisms. J. Neurosci. 26, 3561-3566.

Bartko, S.J., Cowell, R.A., Winters, B.D., Bussey, T.J., Saksida, L.M., 2010. Heightened susceptibility to interference in an animal model of amnesia: impairment in encoding, storage, retrieval-or all three? Neuropsychologia 48, 2987-2997.

Bartko, S.J., Winters, B.D., Cowell, R.A., Saksida, L.M., Bussey, T.J., 2007. Perirhinal cortex resolves feature ambiguity in configural object recognition and perceptual oddity tasks. Learn. Mem. 14, 821-832.

Bartlett, T.E., Bannister, N.J., Collett, V.J., Dargan, S.L., Massey, P.V., Bortolotto, Z.A Fitzjohn, S.M., Bashir, Z.I., Collingridge, G.L., Lodge, D., 2007. Differential roles of NR2A and NR2B-containing NMDA receptors in LTP and LTD in the CA1 region of two-week old rat hippocampus. Neuropharmacology 52, 60-70.

Beart, P.M., Summers, R.J., Stephenson, J.A., Cook, C.J., Christie, M.J., 1990. Excitatory amino acid projections to the periaqueductal gray in the rat: a retrograde transport study utilizing D[3H] aspartate and [3H]GABA. Neuroscience 34, $163-$ 176.

Beggs, J.M., Moyer Jr., J.R., McGann, J.P., Brown, T.H., 2000. Prolonged synaptic integration in perirhinal cortical neurons. J. Neurophysiol. 83, 3294-3298.

Behan, M., Haberly, L.B., 1999. Intrinsic and efferent connections of the endopiriform nucleus in rat. J. Comp. Neurol. 14, 532-548.

Belcher, A.M., O’Dell, S.J., Marshall, J.F., 2005. Impaired object recognition memory following methamphetamine, but not p-chloroamphetamine- or d-amphetamine-induced neurotoxicity. Neuropsychopharmacology 30, 2026-2034.

Beltramino, C., Taleisnik, S., 1978. Facilitatory and inhibitory effects of electrochemical stimulation of the amygdala on the release of luteinizing hormone. Brain Res. 144, 95-107.

Beltramino, C., Taleisnik, S., 1980. Dual action of electrochemical stimulation of the bed nucleus of the stria terminalis on the release of LH. Neuroendocrinology 30 238-242.

Bengzon, J., Kokaia, Z., Ernfors, P., Kokaia, M., Leanza, G., Nilsson, O.G., Persson, H., Lindvall, O., 1993. Regulation of neurotrophin and trkA, trkB and trkC tyrosine kinase receptor messenger RNA expression in kindling. Neuroscience 53, 433 446.

Bernasconi, N., Andermann, F., Arnold, D.L., Bernasconi, A., 2003a. Entorhinal cortex MRI assessment in temporal, extratemporal, and idiopathic generalized epilepsy. Epilepsia 44, 1070-1074.

Bernasconi, N., Bernasconi, A., Caramanos, Z., Antel, S.B., Andermann, F., Arnold, D.L 2003b. Mesial temporal damage in temporal lobe epilepsy: a volumetric MRI study of the hippocampus, amygdala and parahippocampal region. Brain 126, 462-469.

Bertaina-Anglade, V., Enjuanes, E., Morillon, D., Drieu la Rochelle, C., 2006. The object recognition task in rats and mice: a simple and rapid model in safety pharmacology to detect amnesic properties of a new chemical entity. J. Pharmacol. Toxicol. Methods 54, 99-105.

Biella, G.R., Gnatkovsky, V., Takashima, I., Kajiwara, R., Iijima, T., de Curtis, M., 2003. Olfactory input to the parahippocampal region of the isolated guinea pig brain reveals weak entorhinal-to-perirhinal interactions. Eur. J. Neurosci. 18, 95101.

Biella, G.R., Spaiardi, P., Jimenez-Moreno, R., Magistretti, J., Taglietti, V., Toselli, M., 2007. A fast transient outward current in layer II/III neurons of rat perirhinal cortex. Pflugers Arch. 455, 515-525.

Biella, G., Spaiardi, P., Toselli, M., de Curtis, M., Gnatkovsky, V., 2010. Functional interactions within the parahippocampal region revealed by voltage-sensitive dye imaging in the isolated guinea pig brain. J. Neurophysiol. 103, 725-732. 
Bienenstock, E.L., Cooper, L.N., Munro, P.W., 1982. Theory for the development of neuron selectivity: orientation specificity and binocular interaction in visual cortex. J. Neurosci. 2, 32-48.

Bilkey, D.K., 1996. Long-term potentiation in the in vitro perirhinal cortex displays associative properties. Brain Res. 733, 297-300.

Brodmann, K., 1909. Localisation in the Cerebral Cortex. Trans Garey, L.J. (Ed.), Springer, U.S.A

Brog, J.S., Salyapongse, A., Deutch, A.Y., Zahm, D.S., 1993. The patterns of afferent innervation of the core and shell in the "accumbens" part of the rat ventral striatum: immunohistochemical detection of retrogradely transported fluorogold. J. Comp. Neurol. 338, 255-278.

Brown, M.W., Aggleton, J.P., 2001. Recognition memory: what are the roles of the perirhinal cortex and hippocampus? Nat. Rev. Neurosci. 2, 51-61.

Brown, M.W., Warburton, E.C., Aggleton, J.P., 2010. Recognition memory: material, processes, and substrates. Hippocampus 20, 1228-1244.

Bruchey, A.K., Gonzalez-Lima, F., 2006. Brain activity associated with fear renewal. Eur. J. Neurosci. 24, 3567-3577.

Bucci, D.J., 2009. Posterior parietal cortex: an interface between attention and learning? Neurobiol. Learn. Mem. 91, 114-120.

Bucci, D.J., Phillips, R.G., Burwell, R.D., 2000. Contributions of postrhinal and perirhinal cortex to contextual information processing. Behav. Neurosci. 114, 882-894.

Bucci, D.J., Saddoris, M.P., Burwell, R.D., 2002. Contextual fear discrimination is impaired by damage to the postrhinal or perirhinal cortex. Behav. Neurosci. $116,479-488$.

Buckley, M.J., 2005. The role of the perirhinal cortex and hippocampus in learning, memory, and perception. Q. J. Exp. Psychol. B 58, 246-268.

Burwell, R.D., 2000. The parahippocampal region: corticocortical connectivity. Ann. N. Y. Acad. Sci. 911, 25-42.

Burwell, R.D., 2001. Borders and cytoarchitecture of the perirhinal and postrhinal cortices in the rat. J. Comp. Neurol. 437, 17-41.

Burwell, R.D., Amaral, D.G., 1998a. The perirhinal and postrhinal cortices of the rat: interconnectivity and connections with the entorhinal cortex. J. Comp. Neurol. 391, 293-321.

Burwell, R.D., Amaral, D.G., 1998b. Cortical afferents of the perirhinal, postrhinal, and entorhinal cortices of the rat. J. Comp. Neurol. 398, 179-205.

Burwell, R.D., Hafeman, D.M., 2003. Positional firing properties of postrhinal cortex neurons. Neuroscience 119, 577-588.

Burwell, R.D., Witter, M.P., Amaral, D.G., 1995. Perirhinal and postrhinal cortices of the rat: a review of the neuroanatomical literature and comparison with findings from the monkey brain. Hippocampus 5, 390-408.

Burwell, R.D., Bucci, D.J., Sanborn, M.R., Jutras, M.J., 2004a. Perirhinal and postrhinal contributions to remote memory for context. J. Neurosci. 24, 11023-11028.

Burwell, R.D., Saddoris, M.P., Bucci, D.J., Wiig, K.A., 2004b. Corticohippocampa contributions to spatial and contextual learning. J. Neurosci. 24, 3826-3836.

Bussey, T.J., Dias, R., Amin, E., Muir, J.L., Aggleton, J.P., 2001. Perirhinal cortex and place-object conditional learning in the rat. Behav. Neurosci. 115, 776-785.

Bussey, T.J., Duck, J., Muir, J.L., Aggleton, J.P., 2000. Distinct patterns of behavioural impairments resulting from fornix transection or neurotoxic lesions of the perirhinal and postrhinal cortices in the rat. Behav. Brain Res. 111, 187-202.

Bussey, T.J., Muir, J.L., Aggleton, J.P., 1999. Functionally dissociating aspects of event memory: the effects of combined perirhinal and postrhinal cortex lesions on object and place memory in the rat. J. Neurosci. 19, 495-502.

Bussey, T.J., Padain, T.L., Skillings, E.A., Winters, B.D., Morton, A.J., Saksida, L.M. 2008. The touchscreen cognitive testing method for rodents: how to get the best out of your rat. Learn. Mem. 15, 516-523.

Bussey, T.J., Saksida, L.M., 2002. The organization of visual object representations: a connectionist model of effects of lesions in perirhinal cortex. Eur. J. Neurosci. 15 355-364.

Bussey, T.J., Saksida, L.M., 2007. Memory, perception, and the ventral visualperirhinal-hippocampal stream: thinking outside of the boxes. Hippocampus $17,898-908$

Bussey, T.J., Saksida, L.M., Murray, E.A., 2002. Perirhinal cortex resolves feature ambiguity in complex visual discriminations. Eur. J. Neurosci. 15, 365-374

Bussey, T.J., Saksida, L.M., Murray, E.A., 2003. Impairments in visual discrimination after perirhinal cortex lesions: testing 'declarative' vs. 'perceptual-mnemonic' views of perirhinal cortex function. Eur. J. Neurosci. 17, 649-660.

Bussey, T.J., Saksida, L.M., Murray, E.A., 2005. The perceptual-mnemonic/feature conjunction model of perirhinal cortex function. O. J. Exp. Psychol. B 58, 269-282.

Calamandrei, G., Valanzano, A., Ricceri, L., 2002. NGF induces appearance of adultlike response to spatial novelty in 18-day male mice. Behav. Brain Res. 136, 289-298.

Campeau, S., Davis, M., 1995. Involvement of subcortical and cortical afferents to the lateral nucleus of the amygdala in fear conditioning measured with fearpotentiated startle in rats trained concurrently with auditory and visual conditioned stimuli. J. Neurosci. 15, 2312-2327.

Campeau, S., Falls, W.A., Cullinan, W.E., Helmreich, D.L., Davis, M., Watson, S.J., 1997. Elicitation and reduction of fear: behavioural and neuroendocrine indices and brain induction of the immediate-early gene c-fos. Neuroscience 78, 10871104.

Canning, K.J., Leung, L.S., 1997. Lateral entorhinal, perirhinal, and amygdala-entorhinal transition projections to hippocampal CA1 and dentate gyrus in the rat: current source density study. Hippocampus 7, 643-655.

Canning, K.J., Wu, K., Peloquin, P., Kloosterman, F., Leung, L.S., 2000. Physiology of the entorhinal and perirhinal projections to the hippocampus studied by current source density analysis. Ann. N. Y. Acad. Sci. 911, 55-72.
Canteras, N.S., Simerly, R.B., Swanson, L.W., 1994. Organization of projections from the ventromedial nucleus of the hypothalamus: a Phaseolus vulgaris-leucoagglutinin study in the rat. J. Comp. Neurol. 348, 41-79.

Canto, C.B., Wouterlood, F.G., Witter, M.P., 2008. What does the anatomical organization of the entorhinal cortex tell us? Neural Plast. 2008, 381243

Carrer, H.F., 1978. Mesencephalic participation in the control of sexual behavior in the female rat. J. Comp. Physiol. Psychol. 92, 877-887.

Carrer, H.F., Asch, G., Aron, C., 1973. New facts concerning the role played by the ventromedial nucleus in the control of estrous cycle duration and sexual receptivity in the rat. Neuroendocrinology 13, 129-139.

Castelli, L., Biella, G., Toselli, M., Magistretti, J., 2007. Resurgent Na+ current in pyramidal neurones of rat perirhinal cortex: axonal location of channels and contribution to depolarizing drive during repetitive firing. J. Physiol. 582, 11791193.

Cho, K., Kemp, N., Noel, J., Aggleton, J.P., Brown, M.W., Bashir, Z.I., 2000. A new form of long-term depression in the perirhinal cortex. Nat. Neurosci. 3, 150-156.

Cho, K., Aggleton, J.P., Brown, M.W., Bashir, Z.I., 2001. An experimental test of the role of postsynaptic calcium levels in determining synaptic strength using perirhinal cortex of rat. J. Physiol. 532, 459-466.

Cho, K., Bashir, Z.I., 2002. Cooperation between mglu receptors: a depressing mechanism? Trends Neurosci. 25, 405-411.

Cho, K., Brown, M.W., Bashir, Z.I., 2002. Mechanisms and physiological role of enhancement of mGlu5 receptor function by group II mGlu receptor activation in rat perirhinal cortex. J. Physiol. 540, 895-906.

Christie, M.J., Summers, R.J., Stephenson, J.A., Cook, C.J., Beart, P.M., 1987. Excitatory amino acid projections to the nucleus accumbens septi in the rat: a retrograde transport study utilizing D[3H] aspartate and [3H]GABA. Neuroscience 22, 425439 .

Clark, R.E., Squire, L.R., 2010. An animal model of recognition memory and medial temporal lobe amnesia: history and current issues. Neuropsychologia 48, 22342244.

Commins, S., Cunningham, L., Harvey, D., Walsh, D., 2003. Massed but not spaced training impairs spatial memory. Behav. Brain Res. 139, 215-223.

Conti, G., Gale, K., Kondratyev, A., 2009. Immunohistochemical evaluation of the protein expression of nerve growth factor and its TrkA receptor in rat limbic regions following electroshock seizures. Neurosci. Res. 65, 201-209.

Cornwall, J., Phillipson, O.T., 1988. Afferent projections to the dorsal thalamus of the rat as shown by retrograde lectin transport. II. The midline nuclei. Brain Res. Bull. 21, 147-161.

Corodimas, K.P., LeDoux, J.E., 1995. Disruptive effects of posttraining perirhinal cortex lesions on conditioned fear: contributions of contextual cues. Behav. Neurosci. 109, 613-619.

Cousens, G., Otto, T.A., 1998. Induction and transient suppression of long-term potentiation in the peri- and postrhinal cortices following theta-related stimulation of hippocampal field CA1. Brain Res. 780, 95-101.

Cowell, R.A., Bussey, T.J., Saksida, L.M., 2006. Why does brain damage impair memory? A connectionist model of object recognition memory in perirhinal cortex. J. Neurosci. 26, 12186-12197.

Cowell, R.A., Bussey, T.J., Saksida, L.M., 2010a. Components of recognition memory: dissociable cognitive processes or just differences in representational complexity? Hippocampus 20, 1245-1262.

Cowell, R.A., Bussey, T.J., Saksida, L.M., 2010b. Functional dissociations within the ventral object processing pathway: cognitive modules or a hierarchical continuum? J. Cogn. Neurosci. 22, 2460-2479.

Craig, S., Commins, S., 2005. Interaction between paired-pulse facilitation and longterm potentiation in the projection from hippocampal area CA1 to the entorhinal cortex. Neurosci. Res. 53, 140-146.

Craig, S., Commins, S., 2006. The subiculum to entorhinal cortex projection is capable of sustaining both short- and long-term plastic changes. Behav. Brain Res. 174, 281-288.

Craig, S., Commins, S., 2007. Plastic and metaplastic changes in the CA1 and subicular projections to the entorhinal cortex. Brain Res. 1147, 124-139.

Craig, S., Cunningham, L., Kelly, L., Commins, S., 2005. Long-term retention and overshadowing of proximal and distal cues following habituation in an object exploration task. Behav. Process. 68, 117-128.

Cummings, D.M., Milnerwood, A.J., Dallérac, G.M., Waights, V., Brown, J.Y., Vatsavayai, S.C., Hirst, M.C., Murphy, K.P., 2006. Aberrant cortical synaptic plasticity and dopaminergic dysfunction in a mouse model of Huntington's disease. Hum. Mol. Genet. 15, 2856-2868.

Cummings, D.M., Milnerwood, A.J., Dallérac, G.M., Vatsavayai, S.C., Hirst, M.C., Murphy, K.P., 2007. Abnormal cortical synaptic plasticity in a mouse model of Huntington's disease. Behav. Brain Bull. 72, 103-107.

D’Antuono, M., Biagini, G., Tancredi, V., Avoli, M., 2001. Electrophysiology of regular firing cells in the rat perirhinal cortex. Hippocampus 11 (6), 662-672.

Davies, M., Machin, P.E., Sanderson, D.J., Pearce, J.M., Aggleton, J.P., 2007. Neurotoxic lesions of the rat perirhinal and postrhinal cortices and their impact on biconditional visual discrimination tasks. Behav. Brain Res. 176, 274-283.

Davis, M., 2006. Neural systems involved in fear and anxiety measured with fearpotentiated startle. Am. Psychol. 61, 741-756.

Deacon, T.W., Eichenbaum, H., Rosenberg, P., Eckmann, K.W., 1983. Afferent connections of the perirhinal cortex in the rat. J. Comp. Neurol. 220, 168-190.

de Curtis, M., Biella, G., 2002. Communication between subregions of the parahippocampal region. In: Witter, M., Wouterloud, F. (Eds.), The Parahippocampal Region. Oxford University Press, New York, pp. 107-126.

de Curtis, M., Paré, D., 2004. The rhinal cortices: a wall of inhibition between the neocortex and the hippocampus. Prog. Neurobiol. 74, 101-110. 
de Lima, M.N., Laranja, D.C., Bromberg, E., Roeslef, R., Schröder, N., 2005. Pre- or post-training administration of the NMDA receptor blocker MK-801 impairs object recognition memory in rats. Behav. Brain Res. 156, 139-143.

de Olmos, J.S., Beltramino, C.A., Alheid, G., 2004. Amygdala and extended amygdala of the rat: a cytoarchitectonical, fibroartchitectonical, and chemoarchitectonical survey. In: Paxinos, G. (Ed.), The Rat Nervous System. 3rd ed. Elsevier, China, pp. 509-603.

de Vito, J.L., Smith, O.A., 1982. Afferent projections to the hypothalamic area controlling emotional responses (HACER). Brain Res. 252, 213-226.

Delatour, B., Witter, M.P., 2002. Projections from the parahippocampal region to the prefrontal cortex in the rat: evidence of multiple pathways. Eur. J. Neurosci. 15, 1400-1407.

Dere, E., Huston, J.P., De Souza Silva, M.A., 2007. The pharmacology, neuroanatomy and neurogenetics of one-trial object recognition in rodents. Neurosci. Biobehav. Rev. 31, 673-704.

Dolleman-Van Der Weel, M.J., Witter, M.P., 1996. Projections from the nucleus reuniens thalami to the entorhinal cortex, hippocampal field CA1, and the subiculum in the rat arise from different populations of neurons. J. Comp. Neurol. 364, 637-650.

Dolorfo, C.L., Amaral, D.G., 1998. Entorhinal cortex of the rat: topographic organization of the cells of origin of the perforant path projection to the dentate gyrus. J. Comp. Neurol. 398, 25-48.

Doron, N.N., LeDoux, J.E., 2000. Cells in the posterior thalamus project to both amygdala and temporal cortex: a quantitative retrograde double-labeling study in the rat. J. Comp. Neurol. 425, 257-274.

Eacott, M.J., Easton, A., 2007. On familiarity and recall of events by rats. Hippocampus $17,890-897$.

Eacott, M.J., Gaffan, E.A., 2005. The roles of perirhinal cortex, postrhinal cortex, and the fornix in memory for objects, contexts, and events in the rat. Q. J. Exp. Psychol. B 58, 202-217.

Eacott, M.J., Machin, P.E., Gaffan, E.A., 2001. Elemental and configural visual discrimination learning following lesions to perirhinal cortex in the rat. Behav. Brain Res. 124, 55-70.

Eacott, M.J., Norman, G., Gaffan, E.A., 2003. The role of perirhinal cortex in visual discrimination learning for visual secondary reinforcement in rats. Behav. Neurosci. 117, 1318-1325.

Eagleson, K.L., Fairfull, L.D., Salton, S.R.J., Levitt, P., 2001. Regional differences in neurotrophin availability regulate selective expression of VGF in the developing limbic cortex. J. Neurosci. 21, 9315-9324.

Easton, A., Eacott, M.J., 2010. Recollection of episodic memory within the medial temporal lobe: behavioural dissociations from other types of memory. Behav. Brain Res. 215, 310-317.

Eichenbaum, H., Yonelinas, A.P., Ranganath, C., 2007. The medial temporal lobe and recognition memory. Annu. Rev. Neurosci. 30, 123-152.

Engler-Chiurazzi, E., Tsang, C., Nonnenmacher, S., Liang, W.S., Corneveaux, J.J., Prokai, L., Huentelman, M.J., Bimonte-Nelson, H.A., in press. Tonic Premarin dose-dependently enhances memory, affects neurotrophin protein levels and alters gene expression in middle-aged rats. Neurobiol. Aging.

Ennaceur, A., Aggleton, J.P., 1994. Spontaneous recognition of object configurations in rats: effects of fornix lesions. Exp. Brain Res. 100, 85-92.

Ennaceur, A., Aggleton, J.P., 1997. The effects of neurotoxic lesions of the perirhinal cortex combined to fornix transection on object recognition memory in the rat. Behav. Brain Res. 88, 181-193.

Ennaceur, A., Cavoy, A., Costa, J.C., Delacour, J., 1989. A new one-trial test for neurobiological studies of memory in rats. II: Effects of piracetam and pramiracetam. Behav. Brain Res. 33, 197-207.

Ennaceur, A., Delacour, J., 1988. A new one-trial test for neurobiological studies of memory in rats. 1: Behavioral data. Behav. Brain Res. 31, 47-59.

Ennaceur, A., Meliani, K., 1992a. Effects of physostigmine and scopolamine on rats' performances in object-recognition and radial-maze tests. Psychopharmacology (Berl.) 109, 321-330.

Ennaceur, A., Meliani, K., 1992b. A new one-trial test for neurobiological studies of memory in rats. III. Spatial vs. non-spatial working memory. Behav. Brain Res. 51, 83-92.

Ennaceur, A., Neave, N., Aggleton, J.P., 1996. Neurotoxic lesions of the perirhinal cortex do not mimic the behavioural effects of fornix transection in the rat. Behav. Brain Res. 80, 9-25.

Ennaceur, A., Neave, N., Aggleton, J.P., 1997. Spontaneous object recognition and object location memory in rats: the effects of lesions in the cingulate cortices, the medial prefrontal cortex, the cingulum bundle and the fornix. Exp. Brain Res. 113, 509-519.

Falls, W.A., Bakken, K.T., Heldt, S.A., 1997. Lesions of the perirhinal cortex interfere with conditioned excitation but not with conditioned inhibition of fear. Behav. Neurosci. 111, 476-486.

Faulkner, B., Brown, T.H., 1999. Morphology and physiology of neurons in the rat perirhinal-lateral amygdala area. J. Comp. Neurol. 411, 613-642.

Ferland, R.J., Nierenberg, J., Applegate, C.D., 1998. A role for the bilateral involvement of perirhinal cortex in generalized kindled seizure expression. Exp. Neurol. 151, 124-137.

Ferretti, V., Florian, C., Costantini, V.J., Roullet, P., Rinaldi, A., De Leonibus, E., Oliverio, A., Mele, A., 2005. Co-activation of glutamate and dopamine receptors within the nucleus accumbens is required for spatial memory consolidation in mice. Psychopharmacology (Berl.) 179, 108-116.

Forwood, S.E., Bartko, S.J., Saksida, L.M., Bussey, T.J., 2007. Rats spontaneously discriminate purely visual, two-dimensional stimuli in tests of recognition memory and perceptual oddity. Behav. Neurosci. 121, 1032-1042.
Furtak, S.C., Allen, T.A., Brown, T.H., 2007c. Single-unit firing in rat perirhinal cortex caused by fear conditioning to arbitrary and ecological stimuli. J. Neurosci. 27, 12277-12291.

Furtak, S.C., Moyer Jr., J.R., Brown, T.H., 2007a. Morphology and ontogeny of rat perirhinal cortical neurons. J. Comp. Neurol. 505, 493-510.

Furtak, S.C., Wei, S.M., Agster, K.L., Burwell, R.D., 2007b. Functional neuroanatomy of the parahippocampal region in the rat: the perirhinal and postrhinal cortices. Hippocampus 17, 709-722.

Futter, J.E., Davies, M., Bilkey, D.K., Aggleton, J.P., 2006. The effects of cytotoxic perirhinal cortex lesions on spatial learning by rats: a comparison of the dark agouti and Sprague-Dawley strains. Behav. Neurosci. 120, 150-161.

Gaffan, D., Harrison, S., 1989. A comparison of the effects of fornix transection and sulcus principalis ablation upon spatial learning by monkeys. Behav. Brain Res. 31, 207-220.

Gaffan, E.A., Eacott, M.J., Simpson, E.L., 2000. Perirhinal cortex ablation in rats selectively impairs object identification in a simultaneous visual comparison task. Behav. Neurosci. 114, 18-31.

Garden, D.L., Kemp, N., Bashir, Z.I., 2002. Differences in GABAergic transmission between two inputs into the perirhinal cortex. Eur. J. Neurosci. 16, 437-444.

Gardier, A.M., Malagié, I., Trillat, A.C., Jacquot, C., Artigas, F., 1996. Role of 5-HT1A autoreceptors in the mechanism of action of serotoninergic antidepressant drugs: recent findings from in vivo microdialysis studies. Fundam. Clin. Pharmacol. 10, 16-27.

Gerfen, C.R., 2004. Basal ganglia. In: Paxinos, G. (Ed.), The Rat Nervous System. 3rd ed. Elsevier, China, pp. 455-508.

Giblin, K.A., Blumenfeld, H., 2010. Is epilepsy a preventable disorder? New evidence from animal models. Neuroscientist 16, 253-275.

Gilbert, P.E., Kesner, R.P., 2003. Recognition memory for complex visual discriminations is influenced by stimulus interference in rodents with perirhinal cortex damage. Learn. Mem. 10, 525-530.

Glenn, M.J., Nesbitt, C., Mumby, D.G., 2003. Perirhinal cortex lesions produce variable patterns of retrograde amnesia in rats. Behav. Brain Res. 141, 183-193.

Glenn, M.J., Lehmann, H., Mumby, D.G., Woodside, B., 2005. Differential fos expression following aspiration, electrolytic, or excitotoxic lesions of the perirhinal cortex in rats. Behav. Neurosci. 119, 806-813.

Glenn, M.J., Mumby, D.G., 1998. Place memory is intact in rats with perirhinal cortex lesions. Behav. Neurosci. 112, 1353-1365.

Goddard, G.V., 1967. Development of epileptic seizures through brain stimulation at low intensity. Nature 214, 1020-1021.

Goldsmith, S.K., Joyce, J.N., 1994. Dopamine D2 receptor expression in hippocampus and parahippocampal cortex of rat, cat, and human in relation to tyrosine hydroxylase-immunoreactive fibers. Hippocampus 4, 354-373.

Goldstein, L.E., Rasmusson, A.M., Bunney, B.S., Roth, R.H., 1994. The NMDA glycine site antagonist (+)-HA-966 selectively regulates conditioned stress-induced metabolic activation of the mesoprefrontal cortical dopamine but not serotonin systems: a behavioral, neuroendocrine, and neurochemical study in the rat. J. Neurosci. 14, 4937-4950.

Griffin, E.W., Bechara, R.G., Birch, A.M., Kelly, Á.M., 2009. Exercise enhances hippocampal-dependent learning in the rat: evidence for a BDNF-related mechanism. Hippocampus 19, 973-980.

Griffiths, S., Scott, H., Glover, C., Bienemann, A., Ghorbel, M.T., Uney, J., Brown, M.W. Warburton, E.C., Bashir, Z.I., 2008. Expression of long-term depression underlies visual recognition memory. Neuron 58, 186-194.

Groenewegen, H.J., Witter, M.P., 2004. Thalamus. In: Paxinos, G. (Ed.), The Rat Nervous System. 3rd ed. Elsevier, China, pp. 407-453.

Grove, E.A., 1988a. Neural associations of the substantia innominata in the rat: afferent connections. J. Comp. Neurol. 277, 315-346.

Grove, E.A., 1988b. Efferent connections of the substantia innominata in the rat. J. Comp. Neurol. 277, 347-364.

Guldin, W.O., Markowitsch, H.J., 1983. Cortical and thalamic afferent connections of the insular and adjacent cortex of the rat. J. Comp. Neurol. 215, 135-153.

Haberly, L.B., 2001. Parallel-distributed processing in olfactory cortex: new insights from morphological and physiological analysis of neuronal circuitry. Chem. Senses 26, 551-576.

Hammond, R.S., Tull, L.E., Stackman, R.W., 2004. On the delay-dependent involvement of the hippocampus in object recognition memory. Neurobiol. Learn. Mem. 82, 26-34.

Hannesson, D.K., Howland, J.G., Pollock, M., Mohapel, P., Wallace, A.E., Corcoran, M.E., 2005. Anterior perirhinal cortex kindling produces long-lasting effects on anxiety and object recognition memory. Eur. J. Neurosci. 21, 1081-1090.

Harding, A., Paxinos, G., Halliday, G., 2004. The serotonin and tachykinin systems. In: Paxinos, G. (Ed.), The Rat Nervous System. 3rd ed. Elsevier, China, pp. $1203-$ 1256.

Harris, S.L., Cho, K., Bashir, Z.I., Molnar, E., 2004a. Metabotropic glutamate receptor signalling in perirhinal cortical neurons. Mol. Cell. Neurosci. 25, 275-287.

Harris, S.L., Gallyas Jr., F., Molnar, E., 2004b. Activation of metabotropic glutamate receptors does not alter the phosphorylation state of GluR1 AMPA receptor subunit at serine 845 in perirhinal cortical neurons. Neurosci. Lett. 372, 132-136.

Hasselmo, M.E., McClelland, J.L., 1999. Neural models of memory. Curr. Opin. Neurobiol. 9, 184-188.

Hébert, C., Habimana, A., Elie, R., Reader, T.A., 2001. Effects of chronic antidepressant treatments on 5-HT and NA transporters in rat brain: an autoradiographic study. Neurochem. Int. 38, 63-74.

Heidbreder, C.A., Groenewegen, H.J., 2003. The medial prefrontal cortex in the rat: evidence for a dorso-ventral distinction based upon functional and anatomical characteristics. Neurosci. Biobehav. Rev. 27, 555-579. 
Hermann, D.M., Luppi, P.H., Peyron, C., Hinckel, P., Jouvet, M., 1997. Afferent projections to the rat nuclei raphe magnus, raphe pallidus and reticularis gigantocellularis pars alpha demonstrated by iontophoretic application of choleratoxin (subunit b). J. Chem. Neuroanat. 13, 1-21.

Herzog, C., Otto, T., 1997. Odor-guided fear conditioning in rats: 2. Lesions of the anterior perirhinal cortex disrupt fear conditioned to the explicit conditioned stimulus but not to the training context. Behav. Neurosci. 111, 12651272.

Herzog, C., Otto, T., 1998. Contributions of anterior perirhinal cortex to olfactory and contextual fear conditioning. Neuroreport 9, 1855-1859.

Holder, M.K., Mong, J.A., 2010. Methamphetamine enhances paced mating behaviors and neuroplasticity in the medial amygdala of female rats. Horm. Behav. $58,519-525$.

Holman, D., Feligioni, M., Henley, J.M., 2007. Differential redistribution of native AMPA receptor complexes following LTD induction in acute hippocampal slices. Neuropharmacology 52, 92-99.

Hoover, W.B., Vertes, R.P., 2007. Anatomical analysis of afferent projections to the medial prefrontal cortex in the rat. Brain Struct. Funct. 212, 149-179.

Hopkins, M.E., Bucci, D.J., 2010. BDNF expression in perirhinal cortex is associated with exercise-induced improvement in object recognition memory. Neurobiol. Learn. Mem. 94, 278-284.

Horne, M.R., Iordanova, M.D., Albasser, M.M., Aggleton, J.P., Honey, R.C., Pearce, J.M., 2010. Lesions of the perirhinal cortex do not impair integration of visual and geometric information in rats. Behav. Neurosci. 124, 311-320.

Hurley, K.M., Herbert, H., Moga, M.M., Saper, C.B., 1991. Efferent projections of the infralimbic cortex of the rat. J. Comp. Neurol. 308, 249-276.

Insausti, R., Herrero, M.T., Witter, M.P., 1997. Entorhinal cortex of the rat: cytoarchitectonic subdivisions and the origin and distribution of cortical efferents. Hippocampus 7, 146-183.

Ivanco, T.L., Racine, R.J., 2000. Long-term potentiation in the reciprocal corticohippocampal and corticocortical pathways in the chronically implanted, freely moving rat. Hippocampus $10,143-152$.

Jenkins, T.A., Amin, E., Pearce, J.M., Brown, M.W., Aggleton, J.P., 2004. Novel spatia arrangements of familiar visual stimuli promote activity in the rat hippocampal formation but not the parahippocampal cortices: a c-fos expression study. Neuroscience 124, 43-52.

Jerusalinsky, D., Kornisiuk, E., Izquierdo, I., 1997. Cholinergic neurotransmission and synaptic plasticity concerning memory processing. Neurochem. Res. 22, 507-515.

Jo, J., Ball, S.M., Seok, H., Oh, S.B., Massey, P.V., Molnar, E., Bashir, Z.I., Cho, K., 2006 Experience-dependent modification of mechanisms of long-term depression. Nat. Neurosci. 9, 170-172.

Jo, J., Heon, S., Kim, M.J., Son, G.H., Park, Y., Henley, J.M., Weiss, J.L., Sheng, M., Collingridge, G.L., Cho, K., 2008. Metabotropic glutamate receptor-mediated LTD involves two interacting $\mathrm{Ca}(2+)$ sensors, NCS-1 and PICK1. Neuron 60, 1095-1111.

Jo, Y.S., Lee, I., 2010. Disconnection of the hippocampal-perirhinal cortical circuits severely disrupts object-place paired associative memory. J. Neurosci. 30, 9850-9858.

Jones, B.F., Witter, M.P., 2007. Cingulate cortex projections to the parahippocampal region and hippocampal formation in the rat. Hippocampus 17, 957-976.

Kajiwara, R., Takashima, I., Mimura, Y., Witter, M.P., Iijima, T., 2003. Amygdala input promotes spread of excitatory neural activity from perirhinal cortex to the entorhinal-hippocampal circuit. J. Neurophysiol. 89, 2176-2184.

Kajiwara, R., Wouterlood, F.G., Sah, A., Boekel, A.J., Baks-te Bulte, L.T., Witter, M.P. 2008. Convergence of entorhinal and CA3 inputs onto pyramidal neurons and interneurons in hippocampal area CA1-an anatomical study in the rat. Hippocampus $18,266-280$

Karasawa, J., Hashimoto, K., Chaki, S., 2008. D-Serine and a glycine transporter inhibitor improve MK-801-induced cognitive deficits in a novel object recognition test in rats. Behav. Brain Res. 186, 78-83.

Kaut, K.P., Bunsey, M.D., 2001. The effects of lesions to the rat hippocampus or rhinal cortex on olfactory and spatial memory: retrograde and anterograde findings. Cogn. Affect. Behav. Neurosci. 1, 270-286.

Kaut, K.P., Bunsey, M.D., Riccio, D.C., 2003. Olfactory learning and memory impairments following lesions to the hippocampus and perirhinal-entorhinal cortex. Behav. Neurosci. 117, 304-319.

Kealy, J., Commins, S., 2009. Antagonism of glutamate receptors in the CA1 to perirhinal cortex projection prevents long-term potentiation and attenuates levels of brain-derived neurotrophic factor. Brain Res. 1265, 53-64.

Kealy, J., Commins, S., 2010. Frequency-dependent changes in synaptic plasticity and brain-derived neurotrophic factor (BDNF) expression in the CA1 to perirhinal cortex projection. Brain Res. 1326, 51-61.

Kelly, M.E., McIntyre, D.C., 1996. Perirhinal cortex involvement in limbic kindled seizures. Epilepsy Res. 26, 233-243.

Kemppainen, S., Jolkkonen, E., Pitkänen, A., 2002. Projections from the posterior cortical nucleus of the amygdala to the hippocampal formation and parahippocampal region in rat. Hippocampus $12,735-755$.

Kholodar-Smith, D.B., Allen, T.A., Brown, T.H., 2008a. Fear conditioning to discontinuous auditory cues requires perirhinal cortical function. Behav. Neurosci. 122, 1178-1185.

Kholodar-Smith, D.B., Boguszewski, P., Brown, T.H., 2008b. Auditory trace fear conditioning requires perirhinal cortex. Neurobiol. Learn. Mem. 90, 537-543.

King, P.R., Gundlach, A.L., Louis, W.J., 1995. Quantitative autoradiographic localization in rat brain of alpha 2-adrenergic and non-adrenergic I-receptor binding sites labelled by [3H]rilmenidine. Brain Res. 675, 264-278.
Klein, R., Conway, D., Parada, L.F., Barbacid, M., 1990. The trkB tyrosine protein kinase gene codes for a second neurogenic receptor that lacks the catalytic kinase domain. Cell 61, 647-656.

Kloosterman, F., Van Haeften, T., Witter, M.P., Lopes Da Silva, F.H., 2003a. Electrophysiological characterization of interlaminar entorhinal connections: an essential link for re-entrance in the hippocampal-entorhinal system. Eur. J. Neurosci. 18, 3037-3052.

Kloosterman, F., Witter, M.P., Van Haeften, T., 2003b. Topographical and laminar organization of subicular projections to the parahippocampal region of the rat. J. Comp. Neurol. 455, 156-171.

Kloosterman, F., van Haeften, T., Lopes da Silva, F.H., 2004. Two reentrant pathways in the hippocampal-entorhinal system. Hippocampus 14, 1026-1039.

Koganezawa, N., Taguchi, A., Tominaga, T., Ohara, S., Tsutsui, K., Witter, M.P., Iijima, T., 2008. Significance of the deep layers of entorhinal cortex for transfer of both perirhinal and amygdala inputs to the hippocampus. Neurosci. Res. 61, 172181

Köhler, C., 1988. Intrinsic connections of the retrohippocampal region in the rat brain: III. The lateral entorhinal area. J. Comp. Neurol. 271, 208-228.

Köhler, S., Danckert, S., Gati, J.S., Menon, R.S., 2005. Novelty responses to relational and non-relational information in the hippocampus and the parahippocampal region: a comparison based on event-related fMRI. Hippocampus $15,763-774$

Kosaka, T., Hama, K., Nagatsu, I., 1987. Tyrosine hydroxylase-immunoreactive intrinsic neurons in the rat cerebral cortex. Exp. Brain Res. 68, 393-405.

Kosel, K.C., Van Hoesen, G.W., Rosene, D.L., 1982. Non-hippocampal cortical projections from the entorhinal cortex in the rat and rhesus monkey. Brain Res. 244, 201-213.

Kosel, K.C., Van Hoesen, G.W., Rosene, D.L., 1983. A direct projection from the perirhinal cortex (area 35) to the subiculum in the rat. Brain Res. 269, 347-351.

Kowalska, D.M., Kuśmierek, P., Kosmal, A., Mishkin, M., 2001. Neither perirhinal/ entorhinal nor hippocampal lesions impair short-term auditory recognition memory in dogs. Neuroscience 104, 965-978.

Krettek, J.E., Price, J.L., 1974. Projections from the amygdala to the perirhinal and entorhinal cortices and the subiculum. Brain Res. 71, 150-154.

Krettek, J.E., Price, J.L., 1977. Projections from the amygdaloid complex to the cerebral cortex and thalamus in the rat and cat. J. Comp. Neurol. 172, 687-722.

Krieg, W.J.S., 1946a. Connections of the cerebral cortex: I. The albino rat. A Topography of the cortical areas. J. Comp. Neurol. 84, 221-275.

Krieg, W.J.S., 1946b. Connections of the cerebral cortex: I. The albino rat. B. Structure of the cortical areas. J. Comp. Neurol. 84, 277-323.

Krout, K.E., Kawano, J., Mettenleiter, T.C., Loewy, A.D., 2002. CNS inputs to the suprachiasmatic nucleus of the rat. Neuroscience 110, 73-92.

Kyuhou, S., Matsuzaki, R., Gemba, H., 2003. Perirhinal cortex relays auditory information to the frontal motor cortices in the rat. Neurosci. Lett. 353, 181184.

Larkin, A.E., Fahey, B., Gobbo, O., Callaghan, C.K., Cahill, E., O’Mara, S.M., Kelly, Á.M., 2008. Blockade of NMDA receptors pre-training, but not post-training, impairs object displacement learning in the rat. Brain Res. 1199, 126-132.

Lee, A.C., Bussey, T.J., Murray, E.A., Saksida, L.M., Epstein, R.A., Kapur, N., Hodges, J.R., Graham, K.S., 2005. Perceptual deficits in amnesia: challenging the medial temporal lobe 'mnemonic' view. Neuropsychologia 43, 1-11.

Lin, T.N., Chen, J.J., Wang, S.J., Cheng, J.T., Chi, S.I., Shyu, A.B., Sun, G.Y., Hsu, C.Y., 1996. Expression of NGFI-B mRNA in a rat focal cerebral ischemia-reperfusion model. Mol. Brain Res. 43, 149-156.

Lindquist, D.H., Jarrard, L.E., Brown, T.H., 2004. Perirhinal cortex supports delay fear conditioning to rat ultrasonic social signals. J. Neurosci. 24, 3610-3617.

Linke, R., 1999. Organization of projections to temporal cortex originating in the thalamic posterior intralaminar nucleus of the rat. Exp. Brain Res. 127, 314-320.

Liu, P., Bilkey, D.K., 1996a. Long-term potentiation in the perirhinal-hippocampal pathway is NMDA dependent. Neuroreport 7, 1241-1244.

Liu, P., Bilkey, D.K., 1996b. Direct connection between perirhinal cortex and hippocampus is a major constituent of the lateral perforant path. Hippocampus 6, 125-135.

Liu, P., Bilkey, D.K., 1998a. Lesions of perirhinal cortex produce spatial memory deficits in the radial maze. Hippocampus $8,114-121$.

Liu, P., Bilkey, D.K., 1998b. Is there a direct connection from perirhinal cortex to the hippocampus. Hippocampus 8, 424-425

Liu, P., Bilkey, D.K., 2001. The effect of excitotoxic lesions centered on the hippocampus or perirhinal cortex in object recognition and spatial memory tasks. Behav. Neurosci. 115, 94-111.

Longone, P., Impagnatiello, F., Guidotti, A., Costa, E., 1996. Reversible modification of $\mathrm{GABA}_{\mathrm{A}}$ receptor subunit mRNA expression during tolerance to diazepam-induced cognition dysfunction. Neuropharmacology 35, 1465-1473.

Machin, P., Vann, S.D., Muir, J.L., Aggleton, J.P., 2002. Neurotoxic lesions of the rat perirhinal cortex fail to disrupt the acquisition or performance of tests of allocentric spatial memory. Behav. Neurosci. 116, 232-240.

Majak, K., Pitkänen, A., 2003. Projections from the periamygdaloid cortex to the amygdaloid complex, the hippocampal formation, and the parahippocampal region: a PHA-L study in the rat. Hippocampus 13, 922-942.

Maren, S., 1999. Long-term potentiation in the amygdala: a mechanism for emotional learning and memory. Trends Neurosci. 22, 561-567.

Massey, P.V., Bhabra, G., Cho, K., Brown, M.W., Bashir, Z.I., 2001. Activation of muscarinic receptors induces protein synthesis-dependent long-lasting depression in the perirhinal cortex. Eur. J. Neurosci. 14, 145-152.

Massey, P.V., Johnson, B.E., Moult, P.R., Auberson, Y.P., Brown, M.W., Molnar, E., Collingridge, G.L., Bashir, Z.I., 2004. Differential roles of NR2A and NR2B-con- 
taining NMDA receptors in cortical long-term potentiation and long-term depression. J. Neurosci. 24, 7821-7828.

Massey, P.V., Phythian, D., Narduzzo, K., Warburton, E.C., Brown, M.W., Bashir, Z.I., 2008. Learning-specific changes in long-term depression in adult perirhinal cortex. J. Neurosci. 28, 7548-7554.

Matsumoto, Y., Yamada, N., Morimoto, K., Bilkey, D.K., Kuroda, S., 1996. Characterization of epileptiform field potentials recorded in the in vitro perirhinal cortex of amygdala-kindled epileptogenesis. Brain Res. 741, 44-51.

McCaffery, B., Cho, K., Bortolotto, Z.A., Aggleton, J.P., Brown, M.W., Conquet, F., Collingridge, G.L., Bashir, Z.I., 1999. Synaptic depression induced by pharmacological activation of metabotropic glutamate receptors in the perirhinal cortex in vitro. Neuroscience 93, 977-984.

McDonald, A.J., Jackson, T.R., 1987. Amygdaloid connections with posterior insular and temporal cortical areas in the rat. J. Comp. Neurol. 262, 59-77.

McDonald, A.J., Mascagni, F., 1996. Cortico-cortical and cortico-amygdaloid projections of the rat occipital cortex: a Phaseolus vulgaris leucoagglutinin study. Neuroscience 71, 37-54.

McGann, J.P., Moyer Jr., J.R., Brown, T.H., 2001. Predominance of late-spiking neurons in layer VI of rat perirhinal cortex. J. Neurosci. 21, 4969-4976.

McGeorge, A.J., Faull, R.L., 1989. The organization of the projection from the cerebral cortex to the striatum in the rat. Neuroscience 29, 503-537.

McIntyre, D.C., Kelly, M.E., Staines, W.A., 1996. Efferent projections of the anterior perirhinal cortex in the rat. J. Comp. Neurol. 369, 302-318.

McKenna, J.T., Vertes, R.P., 2004. Afferent projections to nucleus reuniens of the thalamus. J. Comp. Neurol. 480, 115-142.

McTighe, S.M., Cowell, R.A., Winters, B.D., Bussey, T.J., Saksida, L.M., 2010. Paradoxical false memory for objects after brain damage. Science 330, 1408-1410.

Mele, A., Avena, M., Roullet, P., De Leonibus, E., Mandillo, S., Sargolini, F., Coccurello, R., Oliverio, A., 2004. Nucleus accumbens dopamine receptors in the consolidation of spatial memory. Behav. Pharmacol. 15, 423-431.

Merlio, J.P., Ernfors, P., Jaber, M., Persson, H., 1992. Molecular cloning of rat trkC and distribution of cells expressing messenger RNAs for members of the trk family in the rat central nervous system. Neuroscience 51, 513-532.

Milad, M.R., Rauch, S.L., Pitman, R.K., Quirk, G.J., 2006. Fear extinction in rats: implications for human brain imaging and anxiety disorders. Biol. Psychol. 73, 61-71.

Miller, M.W., Vogt, B.A., 1984. Direct connections of rat visual cortex with sensory, motor, and association cortices. J. Comp. Neurol. 226, 184-202.

Monaghan, D.T., Buller, A.L., 1994. Anatomical, pharmacological, and molecular diversity of native NMDA receptor subtypes. In: Collingridge, G.L., Watkins, J.C. (Eds.), The NMDA Receptor. 2nd ed. Oxford University Press, New York, pp. 158-176.

Monti, J.M., 2010. The role of dorsal raphe nucleus serotonergic and non-serotonergic neurons, and of their receptors, in regulating waking and rapid eye movement (REM) sleep. Sleep Med. Rev. 14, 319-327.

Moran, J.P., Dalrymple-Alford, J.C., 2003. Perirhinal cortex and anterior thalamic lesions: comparative effects on learning and memory. Behav. Neurosci. 117, 1326-1341.

Moses, S.N., Cole, C., Ryan, J.D., 2005. Relational memory for object identity and spatial location in rats with lesions of perirhinal cortex, amygdala and hippocampus. Behav. Brain Bull. 65, 501-512.

Moult, P.R., Gladding, C.M., Sanderson, T.M., Fitzjohn, S.M., Bashir, Z.I., Molnar, E., Collingridge, G.L., 2006. Tyrosine phosphatases regulate AMPA receptor trafficking during metabotropic glutamate receptor-mediated long-term depression. J. Neurosci. 26, 2544-2554.

Moyer Jr., J.R., McNay, E.C., Brown, T.H., 2002. Three classes of pyramidal neurons in layer $\mathrm{V}$ of rat perirhinal cortex. Hippocampus 12, 218-234.

Muir, G.M., Bilkey, D.K., 2001. Instability in the place field location of hippocampal place cells after lesions centered on the perirhinal cortex. J. Neurosci. 21, 40164025 .

Mumby, D.G., Glenn, M.J., 2000. Anterograde and retrograde memory for object discriminations and places in rats with perirhinal cortex lesions. Behav. Brain Res. 114, 119-134.

Mumby, D.G., Gaskin, S., Glenn, M.J., Schramek, T.E., Lehmann, H., 2002a. Hippocampal damage and exploratory preferences in rats: memory for objects, places, and contexts. Learn. Mem. 9, 49-57.

Mumby, D.G., Glenn, M.J., Nesbitt, C., Kyriazis, D.A., 2002b. Dissociation in retrograde memory for object discriminations and object recognition in rats with perirhinal cortex damage. Behav. Brain Res. 132, 215226.

Mumby, D.G., Piterkin, P., Lecluse, V., Lehmann, H., 2007. Perirhinal cortex damage and anterograde object-recognition in rats after long retention intervals. Behav. Brain Res. 185, 82-87.

Mumby, D.G., Pinel, J.P., 1994. Rhinal cortex lesions and object recognition in rats. Behav. Neurosci. 108, 11-18.

Murray, E.A., Bussey, T.J., 1999. Perceptual-mnemonic functions of the perirhinal cortex. Trends Cogn. Sci. 3, 142-151.

Murray, E.A., Bussey, T.J., Saksida, L.M., 2007. Visual perception and memory: a new view of medial temporal lobe function in primates and rodents. Annu. Rev. Neurosci. 30, 99-122.

Myhrer, T., 2000. Effects of selective perirhinal and postrhinal lesions on acquisition and retention of a visual discrimination task in rats. Neurobiol. Learn. Mem. 73, 68-78.

Myhrer, T., Wangen, K., 1996. Marked retrograde and anterograde amnesia of a visual discrimination task in rats with selective lesions of the perirhinal cortex. Neurobiol. Learn. Mem. 65, 244-252.
Naber, P.A., Caballero-Bleda, M., Jorritsma-Byham, B., Witter, M.P., 1997. Parallel input to the hippocampal memory system through peri- and postrhinal cortices. Neuroreport 8, 2617-2621.

Naber, P.A., Witter, M.P., Lopes da Silva, F.H., 1999. Perirhinal cortex input to the hippocampus in the rat: evidence for parallel pathways, both direct and indirect. A combined physiological and anatomical study. Eur. J. Neurosci. 11, 4119-4133.

Naber, P.A., Lopes da Silva, F.H., Witter, M.P., 2001a. Reciprocal connections between the entorhinal cortex and the hippocampal fields CA1 and the subiculum are in register with the projections from CA1 to the subiculum. Hippocampus 11, 99-104.

Naber, P.A., Witter, M.P., Lopes da Silva, F.H., 2000. Differential distribution of barrel or visual cortex. Evoked responses along the rostro-caudal axis of the peri- and postrhinal cortices. Brain Res. 877, 298-305.

Naber, P.A., Witter, M.P., Lopes da Silva, F.H., 2001b. Evidence for a direct projection from the postrhinal cortex to the subiculum in the rat. Hippocampus 11, 105117.

Nagahara, A.H., Nicolle, M.M., Gallagher, M., 1993. Alterations in [3H]-kainate receptor binding in the hippocampal formation of aged Long-Evans rats. Hippocampus 3, 269-277.

Nagahara, A.H., Otto, T., Gallagher, M., 1995. Entorhinal-perirhinal lesions impair performance of rats on two versions of place learning in the Morris water maze. Behav. Neurosci. 109, 3-9.

Namura, S., Takada, M., Kikuchi, H., Mizuno, N., 1997. Collateral projections of single neurons in the posterior thalamic region to both the temporal cortex and the amygdala: a fluorescent retrograde double-labeling study in the rat. J. Comp. Neurol. 384, 59-70.

Nerad, L., Liu, P., Bilkey, D.K., 2009. Bilateral NMDA lesions centered on the postrhinal cortex have minimal effects on hippocampal place cell firing. Hippocampus 19, 221-227.

Niewiadomska, G., Baksalerska-Pazera, M., Gasiorowska, A., Mietelska, A., 2006. Nerve growth factor differentially affects spatial and recognition memory in aged rats. Neurochem. Res. 31, 1481-1490.

Nilsson, M., Hansson, S., Carlsson, A., Calrsson, M.L., 2007. Differential effects of the $\mathrm{N}$-methyl-D-aspartate receptor antagonist MK-801 on different stages of object recognition memory in mice. Neuroscience 149, 123-130.

Nitz, D., 2009. Parietal cortex, navigation, and the construction of arbitrary reference frames for spatial information. Neurobiol. Learn. Mem. 91, 179-185.

Norman, G., Eacott, M.J., 2005. Dissociable effects of lesions to the perirhinal cortex and the postrhinal cortex on memory for context and objects in rats. Behav. Neurosci. 119, 557-566.

Nyakas, C., Oosterink, B.J., Keijser, J., Felszeghy, K., de Jong, G.I., Korf, J., Luiten, P.G. 1997. Selective decline of 5-HT1A receptor binding sites in rat cortex, hippocampus and cholinergic basal forebrain nuclei during aging. J. Chem. Neuroanat. $13,53-61$.

Ohara, S., Inoue, K., Yamada, M., Yamawaki, T., Koganezawa, N., Tsutsui, K., Witter, M.P., Iijima, T., 2009. Dual transneuronal tracing in the rat entorhinal-hippocampal circuit by intracerebral injection of recombinant rabies virus vectors. Front. Neuroanat. 3, 1 .

Ohishi, H., Akazawa, C., Shigemoto, R., Nakanishi, S., Mizuno, N., 1995. Distributions of the mRNAs for L-2-amino-4-phosphonobutyrate-sensitive metabotropic glutamate receptors, mGluR4 and mGluR7, in the rat brain. J. Comp. Neurol. 360, 555-570.

Olucha-Bordonau, F.E., Teruel, V., Barcia-González, J., Ruiz-Torner, A., ValverdeNavarro, A.A., Martínez-Soriano, F., 2003. Cytoarchitecture and efferent projections of the nucleus incertus of the rat. J. Comp. Neurol. 464, 62-97.

Osterlund, M.K., Overstreet, D.H., Hurd, Y.L., 1999. The flinders sensitive line rats, a genetic model of depression, show abnormal serotonin receptor mRNA expression in the brain that is reversed by 17 beta-estradiol. Mol. Brain Res. 74, 158166.

Ottersen, O.P., 1982. Connections of the amygdala of the rat. IV: corticoamygdaloid and intraamygdaloid connections as studied with axonal transport of horseradish peroxidase. J. Comp. Neurol. 205, 30-48.

Otto, T., Cousens, G., Herzog, C., 2000. Behavioral and neuropsychological foundations of olfactory fear conditioning. Behav. Brain Res. 110, 119-128.

Palomero-Gallagher, N., Zilles, K., 2004. Isocortex. In: Paxinos, G. (Ed.), The Rat Nervous System. 3rd ed. Elsevier, China, pp. 729-757.

Panksepp, J., 2007. Neuroevolutionary sources of laughter and social joy: modeling primal human laughter in laboratory rats. Behav. Brain Res. 182, 231-244.

Paperna, T., Malach, R., 1991. Patterns of sensory intermodality relationships in the cerebral cortex of the rat. J. Comp. Neurol. 308, 432-456.

Park, Y., Jo, J., Isaac, J.T., Cho, K., 2006. Long-term depression of kainate receptormediated synaptic transmission. Neuron 49, 95-106.

Paxinos, G., Watson, C., 2005. The Rat Brain in Stereotaxic Coordinates, 5th ed. Academic Press, San Diego.

Pelletier, J.G., Apergis, J., Paré, D., 2004. Low-probability transmission of neocortical and entorhinal impulses through the perirhinal cortex. J. Neurophysiol. 91 2079-2089.

Petrovich, G.D., Risold, P.Y., Swanson, L.W., 1996. Organization of projections from the basomedial nucleus of the amygdala: a PHAL study in the rat. J. Comp. Neurol. 374, 387-420.

Phillips, R.G., LeDoux, J.E., 1995. Lesions of the fornix but not the entorhinal or perirhinal cortex interfere with contextual fear conditioning. J. Neurosci. 15 5308-5315.

Phillipson, O.T., Griffiths, A.C., 1985. The topographic order of inputs to nucleus accumbens in the rat. Neuroscience 16, 275-296. 
Piterkin, P., Cole, E., Cossette, M.P., Gaskin, S., Mumby, D.G., 2008. A limited role for the hippocampus in the modulation of novel-object preference by contextual cues. Learn. Mem. 15, 785-791.

Pihlajamäki, M., Tanila, H., Könönen, M., Hänninen, T., Hämäläinen, A., Soininen, H. Aronen, H.J., 2004. Visual presentation of novel objects and new spatia arrangements of objects differentially activates the medial temporal lobe subareas in humans. Eur. J. Neurosci. 19, 1939-1949.

Pikkarainen, M., Pitkänen, A., 2001. Projections from the lateral, basal and accessory basal nuclei of the amygdala to the perirhinal and postrhinal cortices in rat. Cereb. Cortex 11, 1064-1082.

Pitkänen, A., Pikkarainen, M., Nurminen, N., Ylinen, A., 2000. Reciprocal connections between the amygdala and the hippocampal formation, perirhinal cortex, and postrhinal cortex in rat. A review. Ann. N. Y. Acad. Sci. 911, 369-391.

Ponomarev, I., Rau, V., Eger, E.I., Harris, R.A., Fanselow, M.S., 2010. Amygdala transcriptome and cellular mechanisms underlying stress-enhanced fear learning in a rat model of posttraumatic stress disorder. Neuropsychopharmacology $35,1402-1411$.

Prusky, G.T., Douglas, R.M., Nelson, L., Shabanpoor, A., Sutherland, R.J., 2004. Visual memory task for rats reveals an essential role for hippocampus and perirhinal cortex. Proc. Natl. Acad. Sci. U.S.A. 101, 5064-5068.

Pum, M., Carey, R.J., Huston, J.P., Müller, C.P., 2007. Dissociating effects of cocaine and D-amphetamine on dopamine and serotonin in the perirhinal, entorhinal, and prefrontal cortex of freely moving rats. Psychopharmacology (Berl.) 193, 375-390.

Ramus, S.J., Eichenbaum, H., 2000. Neural correlates of olfactory recognition memory in the rat orbitofrontal cortex. J. Neurosci. 20, 8199-8208.

Remondes, M., Schuman, E.M., 2003. Molecular mechanisms contributing to longlasting synaptic plasticity at the temporoammonic-CA1 synapse. Learn. Mem. 10, 247-252.

Richfield, E.K., Young, A.B., Penney, J.B., 1989. Comparative distributions of dopamine D-1 and D-2 receptors in the cerebral cortex of rats, cats, and monkeys. J. Comp. Neurol. 286, 409-426.

Rivera, A., Peñafiel, A., Megías, M., Agnati, L.F., López-Téllez, J.F., Gago, B., Gutiérrez A., de la Calle, A., Fuxe, K., 2008. Cellular localization and distribution of dopamine $\mathrm{D}(4)$ receptors in the rat cerebral cortex and their relationship with the cortical dopaminergic and noradrenergic nerve terminal networks. Neuroscience $155,997-1010$

Roberts, A.C., Díez-García, J., Rodriguiz, R.M., López, I.P., Luján, R., MartínezTurrillas, R., Picó, E., Henson, M.A., Bernardo, D.R., Jarrett, T.M., Clendeninn, D.J., López-Mascaraque, L., Feng, G., Lo, D.C., Wesseling, J.F., Wetsel, W.C., Philpot, B.D., Pérez-Otaño, I., 2009. Downregulation of NR3A-containing NMDARs is required for synapse maturation and memory consolidation. Neuron 63, 342-356.

Rodgers, K.M., Benison, A.M., Klein, A., Barth, D.S., 2008. Auditory, somatosensory, and multisensory insular cortex in the rat. Cereb. Cortex 18, 2941-2951.

Romanski, L.M., LeDoux, J.E., 1992a. Bilateral destruction of neocortical and perirhinal projection targets of the acoustic thalamus does not disrupt auditory fear conditioning. Neurosci. Lett. 142, 228-232.

Romanski, L.M., LeDoux, J.E., 1992b. Equipotentiality of thalamo-amygdala and thalamo-cortico-amygdala circuits in auditory fear conditioning. J. Neurosci. 12 4501-4509.

Romero-Granados, R., Fontán-Lozano, A., Delgado-García, J.M., Carrión, A.M., 2010. From learning to forgetting: behavioral, circuitry, and molecular properties define the different functional states of the recognition memory trace. Hippocampus 20, 584-595.

Rosen, J.B., Donley, M.P., 2006. Animal studies of amygdala function in fear and uncertainty: relevance to human research. Biol. Psychol. 73, 49-60.

Rosen, J.B., Hitchcock, J.M., Miserendino, M.J., Falls, W.A., Campeau, S., Davis, M. 1992. Lesions of the perirhinal cortex but not of the frontal, medial prefrontal, visual, or insular cortex block fear-potentiated startle using a visual conditioned stimulus. J. Neurosci. 12, 4624-4633.

Roullet, P., Mele, A., Ammassari-Teule, M., 1996. Involvement of glutamatergic and dopaminergic systems in the reactivity of mice to spatial and non-spatia changes. Psychopharmacology (Berl.) 126, 55-61.

Roullet, P., Sargolini, F., Oliverio, A., Mele, A., 2001. NMDA and AMPA antagonist infusions into the ventral striatum impair different steps of spatial information processing in a nonassociative task in mice. J. Neurosci. 21, 2143-2149.

Sacchetti, B., Baldi, E., Lorenzini, C.A., Bucherelli, C., 2002. Differential contribution of some cortical sites to the formation of memory traces supporting fear conditioning. Exp. Brain Res. 146, 223-232.

Sacchetti, B., Lorenzini, C.A., Baldi, E., Tassoni, G., Bucherelli, C., 1999. Auditory thalamus, dorsal hippocampus, basolateral amygdala, and perirhinal cortex role in the consolidation of conditioned freezing to context and to acoustic conditioned stimulus in the rat. J. Neurosci. 19, 9570-9578.

Sacchetti, B., Sacco, T., Strata, P., 2007. Reversible inactivation of amygdala and cerebellum but not perirhinal cortex impairs reactivated fear memories. Eur. J. Neurosci. 25, 2875-2884

Sadananda, M., Wöhr, M., Schwarting, R.K., 2008. Playback of 22-kHz and 50-kHz ultrasonic vocalizations induces differential c-fos expression in rat brain. Neurosci. Lett. 435, 17-23.

Santiago, A.C., Shammah-Lagnado, S.J., 2004. Efferent connections of the nucleus of the lateral olfactory tract in the rat. J. Comp. Neurol. 471, 314-332.

Santiago, A.C., Shammah-Lagnado, S.J., 2005. Afferent connections of the amygdalopiriform transition area in the rat. J. Comp. Neurol. 489, 349-371.

Saper, C.B., 1982. Convergence of autonomic and limbic connections in the insular cortex of the rat. J. Comp. Neurol. 210, 163-173.
Saksida, L.M., Bussey, T.J., Buckmaster, C.A., Murray, E.A., 2007. Impairment and facilitation of transverse patterning after lesions of the perirhinal cortex and hippocampus, respectively. Cereb. Cortex 17, 108-115.

Saksida, L.M., Bussey, T.J., Buckmaster, C.A., Murray, E.A., 2006. No effect of hippocampal lesions on perirhinal cortex-dependent feature-ambiguous visual discriminations. Hippocampus 16, 421-430.

Sato, K., Kashihara, K., Morimoto, K., Hayabara, T., 1996. Regional increases in brainderived neurotrophic factor and nerve growth factor mRNAs during amygdaloid kindling, but not in acidic and basic growth factor mRNAs. Epilepsia 37, 6-14.

Savage, L.M., Guarino, S., 2010. Memory for reward location is enhanced even though acetylcholine efflux within the amygdala is impaired in rats with damage to the diencephalon produced by thiamine deficiency. Neurobiol. Learn. Mem. 94, 554-560.

Save, E., Poucet, B., 2000. Hippocampal-parietal cortical interactions in spatial cognition. Hippocampus 10, 491-499.

Save, E., Poucet, B., 2009. Role of the parietal cortex in long-term representation of spatial information in the rat. Neurobiol. Learn. Mem. 91, 172-178.

Scalia, F., Winans, S.S., 1975. The differential projections of the olfactory bulb and accessory olfactory bulb in mammals. J. Comp. Neurol. 161, 31-55.

Schettino, L.F., Otto, T., 2001. Patterns of Fos expression in the amygdala and ventral perirhinal cortex induced by training in an olfactory fear conditioning paradigm. Behav. Neurosci. 115, 1257-1272.

Schulz, B., Fendt, M., Richardson, R., Schnitzler, H.U., 2004. Temporary inactivation of the perirhinal cortex by muscimol injections block acquisition and expression of fear-potentiated startle. Eur. J. Neurosci. 19, 713-720.

Schulz-Klaus, B., 2009. Neurotoxic lesion of the rostral perirhinal cortex blocks stress-induced exploratory behavioral changes in male rats. Stress 12, 186-192.

Schulz-Klaus, B., Fendt, M., Schnitzler, H.U., 2005. Temporary inactivation of the rostral perirhinal cortex induces an anxiolytic-like effect on the elevated plusmaze and on the yohimbine-enhanced startle response. Behav. Brain Res. 163 168-173.

Schwabe, K., Ebert, U., Löscher, W., 2000. Effects of lesions of the perirhinal cortex on amygdala kindling in rats. Epilepsy Res. 42, 33-41.

Seoane, A., Massey, P.V., Keen, H., Bashir, Z.I., Brown, M.W., 2009. L-type voltagedependent calcium channel antagonists impair perirhinal long-term recognition memory and plasticity processes. J. Neurosci. 29, 9534-9544.

Seoane, A., Tinsley, C.J., Brown, M.W., 2011. Interfering with perirhinal brainderived neurotrophic factor expression impairs recognition memory in rats. Hippocampus 21, 121-126.

Sesack, S.R., Deutch, A.Y., Roth, R.H., Bunney, B.S., 1989. Topographical organization of the efferent projections of the medial prefrontal cortex in the rat: an anterograde tract-tracing study with Phaseolus vulgaris leucoagglutinin. J. Comp. Neurol. 290, 213-242.

Shammah-Lagnado, S.J., Alheid, G.F., Heimer, L., 1996. Efferent connections of the caudal part of the globus pallidus in the rat. J. Comp. Neurol. 376, 489-507.

Shi, C.J., Cassell, M.D., 1997. Cortical, thalamic, and amygdaloid projections of rat temporal cortex. J. Comp. Neurol. 382, 153-175.

Shi, C.J., Cassell, M.D., 1999. Perirhinal cortex projections to the amygdaloid complex and hippocampal formation in the rat. J. Comp. Neurol. 406, 299-328.

Shi, C., Davis, M., 2001. Visual pathways involved in fear conditioning measured with fear-potentiated startle: behavioral and anatomic studies. J. Neurosci. 21 , 9844-9855.

Shibata, H., 1993. Direct projections from the anterior thalamic nuclei to the retrohippocampal region in the rat. J. Comp. Neurol. 337, 431-445.

Shipley, M.T., Ennis, M., Puche, A.C., 2004. Olfactory system. In: Paxinos, G. (Ed.), The Rat Nervous System. 3rd ed. Elsevier, China, pp. 923-964

Simerly, R.B., 2004. Anatomical substrates of hypothalamic integration. In: Paxinos, G. (Ed.), The Rat Nervous System. 3rd ed. Elsevier, China, pp. 335-368.

Sobreviela, T., Pagcatipunan, M., Kroin, J.S., Mufson, E.J., 1996. Retrograde transport of brain-derived neurotrophic factor (BDNF) following infusion in neo- and limbic cortex in rat: relationship to BDNF mRNA expressing neurons. J. Comp. Neurol. 375, 417-444.

Steward, O., 1976. Topographic organization of the projections from the entorhinal area to the hippocampal formation of the rat. J. Comp. Neurol. 167, 285-314.

Steward, O., Scoville, S.A., 1976. Cells of origin of entorhinal cortical afferents to the hippocampus and fascia dentata of the rat. J. Comp. Neurol. 169, 347-370.

Suzuki, W.A., 1996. The anatomy, physiology and functions of the perirhinal cortex. Curr. Opin. Neurobiol. 6, 179-186.

Swanson, L.W., Cowan, W.M., 1977. An autoradiographic study of the organization of the efferent connections of the hippocampal formation in the rat. J. Comp. Neurol. 172, 49-84.

Swanson, L.W., Sawchenko, P.E., Cowan, W.M., 1981. Evidence for collateral projections by neurons in Ammon's horn, the dentate gyrus, and the subiculum: a multiple retrograde labeling study in the rat. J. Neurosci. 1, 548-559.

Takagishi, M., Chiba, T., 1991. Efferent projections of the infralimbic (area 25) region of the medial prefrontal cortex in the rat: an anterograde tracer PHA-L study. Brain Res. 566, 26-39.

Tamamaki, N., Nojyo, Y., 1993. Projection of the entorhinal layer II neurons in the rat as revealed by intracellular pressure-injection of neurobiotin. Hippocampus 3 , 471-480.

Tamamaki, N., Nojyo, Y., 1995. Preservation of topography in the connections between the subiculum, field CA1, and the entorhinal cortex in rats. J. Comp. Neurol. 353, 379-390.

Toyoda, H., Zhao, M.G., Zhuo, M., 2005. Roles of NMDA receptor NR2A and NR2B subtypes for long-term depression in the anterior cingulate cortex. Eur. J. Neurosci. 22, 485-494. 
Usiello, A., Sargolini, F., Roullet, P., Ammassari-Teule, M., Passino, E., Oliverio, A., Mele, A., 1998. N-methyl-D-aspartate receptors in the nucleus accumbens are involved in detection of spatial novelty in mice. Psychopharmacology (Berl.) 137, 175-183.

VanElzakker, M., Fevurly, R.D., Breindel, T., Spencer, R.L., 2008. Environmental novelty is associated with a selective increase in Fos expression in the output elements of the hippocampal formation and the perirhinal cortex. Learn. Mem. 15, 899-908.

Van Groen, T., Kadish, I., Wyss, J.M., 1999. Efferent connections of the anteromedial nucleus of the thalamus of the rat. Brain Res. Rev. 30, 1-26.

Van Groen, T., Wyss, J.M., 1990. Extrinsic projections from area CA1 of the rat hippocampus: olfactory, cortical, subcortical, and bilateral hippocampal formation projections. J. Comp. Neurol. 302, 515-528.

Vann, S.D., Brown, M.W., Erichsen, J.T., Aggleton, J.P., 2000a. Fos imaging reveals differential patterns of hippocampal and parahippocampal subfield activation in rats in response to different spatial memory tests. J. Neurosci. 20, 2711-2718.

Vann, S.D., Brown, M.W., Erichsen, J.T., Aggleton, J.P., 2000b. Using fos imaging in the rat to reveal the anatomical extent of the disruptive effects of fornix lesions. J. Neurosci. 20, 8144-8152.

van Strien, N.M., Cappaert, N.L., Witter, M.P., 2010. The anatomy of memory: an interactive overview of the parahippocampal-hippocampal network. Nat. Rev. Neurosci. 10, 272-282.

Vaucher, E., Tong, X.K., Cholet, N., Lantin, S., Hamel, E., 2000. GABA neurons provide a rich input to microvessels but not nitric oxide neurons in the rat cerebral cortex: a means for direct regulation of local cerebral blood flow. J. Comp. Neurol. 421, 161-171.

Vertes, R.P., 1991. A PHA-L analysis of ascending projections of the dorsal raphe nucleus in the rat. J. Comp. Neurol. 313, 643-668.

Vertes, R.P., Crane, A.M., Colom, L.V., Bland, B.H., 1995. Ascending projections of the posterior nucleus of the hypothalamus: PHA-L analysis in the rat. J. Comp. Neurol. 359, 90-116.

Vertes, R.P., Fortin, W.J., Crane, A.M., 1999. Projections of the median raphe nucleus in the rat. J. Comp. Neurol. 407, 555-582.

Vertes, R.P., Hoover, W.B., Do Valle, A.C., Sherman, A., Rodriguez, J.J., 2006. Efferent projections of reuniens and rhomboid nuclei of the thalamus in the rat. J. Comp. Neurol. 499, 768-796.

Vezzani, A., Ravizza, T., Moneta, D., Conti, M., Borroni, A., Rizzi, M., Samanin, R., Maj, R., 1999. Brain-derived neurotrophic factor immunoreactivity in the limbic system of rats after acute seizures and during spontaneous convulsions: temporal evolution of changes as compared to neuropeptide Y. Neuroscience 90, 1445-1461.

Wan, H., Aggleton, J.P., Brown, M.W., 1999. Different contributions of the hippocampus and perirhinal cortex to recognition memory. J. Neurosci. 19, 11421148.

Wan, H., Warburton, E.C., Kuśmierek, P., Aggleton, J.P., Kowalska, D.M., Brown, M.W., 2001. Fos imaging reveals differential neuronal activation of areas of rat temporal cortex by novel and familiar sounds. Eur. J. Neurosci. 14, 118-124.

Wan, H., Warburton, E.C., Zhu, X.O., Koder, T.J., Park, Y., Aggleton, J.P., Cho, K., Bashir, Z.I., Brown, M.W., 2004. Benzodiazepine impairment of perirhinal cortical plasticity and recognition memory. Eur. J. Neurosci. 20, 2214-2224.

Wang, D., Cui, Z., Zeng, Q., Kuang, H., Wang, L.P., Tsien, J.Z., Cao, X., 2009. Genetic enhancement of memory and long-term potentiation but not CA1 long-term depression in NR2B transgenic rats. PLoS One 4, e7486.

Warburton, E.C., Brown, M.W., 2010. Findings from animals concerning when interactions between perirhinal cortex, hippocampus and medial prefrontal cortex are necessary for recognition memory. Neuropsychologia 48, 2262 2272.

Warburton, E.C., Koder, T., Cho, K., Massey, P.V., Duguid, G., Barker, G.R., Aggleton, J.P., Bashir, Z.I., Brown, M.W., 2003. Cholinergic neurotransmission is essential for perirhinal cortical plasticity and recognition memory. Neuron 38, 987-996.

Warburton, E.C., Glover, C.P., Massey, P.V., Wan, H., Johnson, B., Bienemann, A. Deuschle, U., Kew, J.N., Aggleton, J.P., Bashir, Z.I., Uney, J., Brown, M.W., 2005. cAMP responsive element-binding protein phosphorylation is necessary for perirhinal long-term potentiation and recognition memory. J. Neurosci. 25, 6296-6303.

Wiig, K.A., Bilkey, D.K., 1994. The effects of perirhinal cortical lesions on spatial reference memory in the rat. Behav. Brain Res. 63, 101-109.

Wiig, K.A., Bilkey, D.K., 1995. Lesions of rat perirhinal cortex exacerbate the memory deficit observed following damage to the fimbria-fornix. Behav. Neurosci. 109, 620-630.

Wilson, D.A., 2001. Receptive fields in the rat piriform cortex. Chem. Senses 26, 577 584.
Winters, B.D., Bartko, S.J., Saksida, L.M., Bussey, T.J., 2010. Muscimol, AP5, or scopolamine infused into perirhinal cortex impairs two-choice visual discrimination learning in rats. Neurobiol. Learn. Mem. 93, 221-228.

Winters, B.D., Bussey, T.J., 2005a. Transient inactivation of perirhinal cortex disrupts encoding, retrieval, and consolidation of object recognition memory. J. Neurosci. 25, 52-61.

Winters, B.D., Bussey, T.J., 2005b. Glutamate receptors in perirhinal cortex mediate encoding, retrieval, and consolidation of object recognition memory. J. Neurosci. 25, 4243-4251.

Winters, B.D., Forwood, S.E., Cowell, R.A., Saksida, L.M., Bussey, T.J., 2004. Double dissociation between the effects of peri-postrhinal cortex and hippocampal lesions on tests of object recognition and spatial memory: heterogeneity of function within the temporal lobe. J. Neurosci. 24, 5901-5908.

Winters, B.D., Reid, J.M., 2010. A distributed cortical representation underlies crossmodal object recognition in rats. J. Neurosci. 30, 6253-6261.

Winters, B.D., Saksida, L.M., Bussey, T.J., 2008. Object recognition memory: neurobiological mechanisms of encoding, consolidation and retrieval. Neurosci. Biobehav. Rev. 32, 1055-1070.

Witter, M.P., 2002. The parahippocampal region: past, present, and future. In: Witter, M., Wouterloud, F. (Eds.), The Parahippocampal Region. Oxford University Press, New York, pp. 3-19.

Witter, M.P., Naber, P.A., Lopes da Silva, F., 1999. Perirhinal cortex does not project to the dentate gyrus. Hippocampus 9, 605-606.

Witter, M.P., Naber, P.A., van Haeften, T., Machielsen, W.C., Rombouts, S.A., Barkhof F., Scheltens, P., Lopes da Silva, F.H., 2000a. Cortico-hippocampal communication by way of parallel parahippocampal-subicular pathways. Hippocampus 10 , 398-410.

Witter, M.P., Wouterlood, F.G., Naber, P.A., Van Haeften, T., 2000b. Anatomical organization of the parahippocampal-hippocampal network. Ann. N. Y. Acad. Sci. 911, 1-24.

Wixted, J.T., Mickes, L., Squire, L.R., 2010. Measuring recollection and familiarity in the medial temporal lobe. Hippocampus 20, 1195-1205.

Wixted, J.T., Squire, L.R., 2008. Constructing receiver operating characteristics (ROCs) with experimental animals: cautionary notes. Learn. Mem. 15, 687-690.

Wouterlood, F.G., Saldana, E., Witter, M.P., 1990. Projection from the nucleus reuniens thalami to the hippocampal region: light and electron microscopic tracing study in the rat with the anterograde tracer Phaseolus vulgaris-leucoagglutinin. J. Comp. Neurol. 296, 179-203.

Wyss, J.M., 1981. An autoradiographic study of the efferent connections of the entorhinal cortex in the rat. J. Comp. Neurol. 199, 495-512.

Wyss, J.M., Van Groen, T., 1992. Connections between the retrosplenial cortex and the hippocampal formation in the rat: a review. Hippocampus 2, 1-11.

Yaniv, D., Richter-Levin, G., 2000. LTP in the rat basal amygdala induced by perirhinal cortex stimulation in vivo. Neuroreport 11, 525-530.

Yaniv, D., Schafe, G.E., LeDoux, J.E., Richter-Levin, G., 2001. A gradient of plasticity in the amygdala revealed by cortical and subcortical stimulation, in vivo. Neuroscience 106, 613-620.

Yashiro, K., Philpot, B.D., 2008. Regulation of NMDA receptor subunit expression and its implications for LTD, LTP, and metaplasticity. Neuropharmacology 55, 1081-1094.

Young, B.J., Otto, T., Fox, G.D., Eichenbaum, H., 1997. Memory representation within the parahippocampal region. J. Neurosci. 17, 5183-5195.

Zhu, X.O., Brown, M.W., 1995. Changes in neuronal activity related to the repetition and relative familiarity of visual stimuli in rhinal and adjacent cortex of the anaesthetised rat. Brain Res. 689, 101-110.

Zhu, X.O., Brown, M.W., Aggleton, J.P., 1995a. Neuronal signalling of information important to visual recognition memory in rat rhinal and neighbouring cortices. Eur. J. Neurosci. 7, 753-765.

Zhu, X.O., Brown, M.W., McCabe, B.J., Aggleton, J.P., 1995b. Effects of the novelty or familiarity of visual stimuli on the expression of the immediate early gene c-fos in rat brain. Neuroscience 69, 821-829.

Zhu, X.O., McCabe, B.J., Aggleton, J.P., Brown, M.W., 1996. Mapping visual recognition memory through expression of the immediate early gene c-fos. Neuroreport 7, 1871-1875.

Zhu, X.O., McCabe, B.J., Aggleton, J.P., Brown, M.W., 1997. Differential activation of the rat hippocampus and perirhinal cortex by novel visual stimuli and a novel environment. Neurosci. Lett. 229, 141-143.

Ziakopoulos, Z., Tillett, C.W., Brown, M.W., Bashir, Z.I., 1999. Input- and layerdependent synaptic plasticity in the rat perirhinal cortex in vitro. Neuroscience $92,459-472$.

Ziakopoulos, Z., Brown, M.W., Bashir, Z.I., 2000. GABA $A_{B}$ receptors mediate frequency-dependent depression of excitatory potentials in rat perirhinal cortex in vitro. Eur. J. Neurosci. 12, 803-809. 